University of Rhode Island

DigitalCommons@URI

Open Access Master's Theses

1992

\title{
Some Applications of Electrochemical Impedance Spectroscopy
}

Mohd Norazmi Alias

University of Rhode Island

Follow this and additional works at: https://digitalcommons.uri.edu/theses

\section{Recommended Citation}

Alias, Mohd Norazmi, "Some Applications of Electrochemical Impedance Spectroscopy" (1992). Open Access Master's Theses. Paper 1032.

https://digitalcommons.uri.edu/theses/1032

This Thesis is brought to you for free and open access by DigitalCommons@URI. It has been accepted for inclusion in Open Access Master's Theses by an authorized administrator of DigitalCommons@URI. For more information, please contact digitalcommons-group@uri.edu. 
SOME APPLICATIONS OF ELECTROCHEMICAL IMPEDANCE SPECTROSCOPY

\author{
BY \\ MOHD NORAZMI ALIAS
}

A THESIS SUBMITTED IN PARTIAL FULFILLMENT OF THE REQUIREMENTS FOR THE DEGREE OF

MASTER OF SCIENCE

IN

CHEMICAL ENGINEERING

UNIVERSITY OF RHODE ISLAND 
MASTER OF SCIENCE

OF

MOHD NORAZMI ALIAS

APPROVED:

Thesis committee

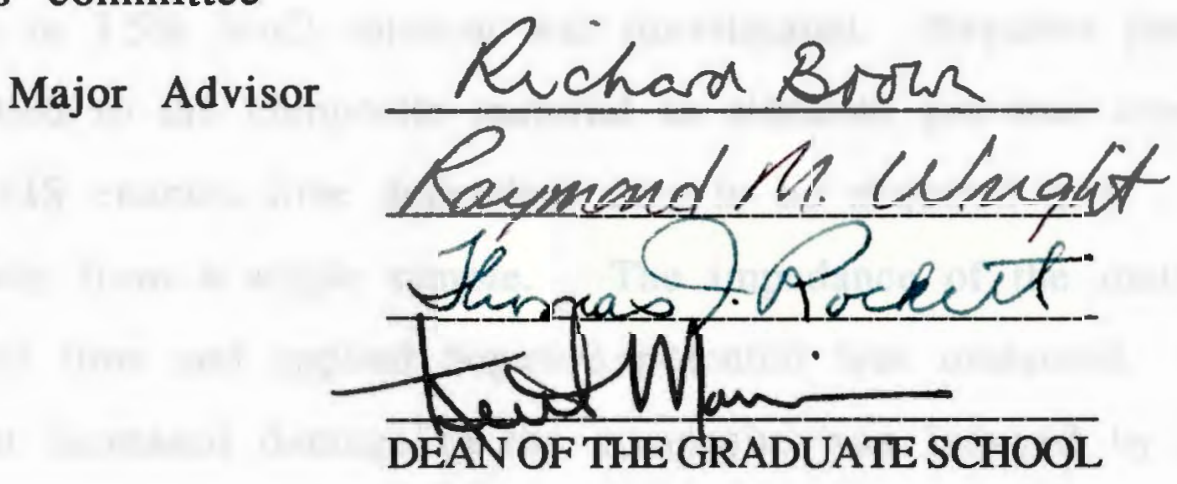

UNIVERSITY OF RHODE ISLAND

1992 


\section{ABSTRACT}

Electrochemical impedance spectroscopy (EIS) has been widely used to characterize rates and mechanisms during electrochemical processes. In this study, EIS was employed to probe the behavior for simulated galvanic coupling of a carbon fiber/polymer matrix composite in the marine environment. In a later study the effect of cathodic ion plating and ion implantation of 304 stainless steel on its corrosion behavior was examined.

The electrochemical behavior of a carbon fiber/vinyl ester composite in $3.5 \% \mathrm{NaCl}$ solution was investigated. Negative potentials were applied to the composite material to simulate galvanic coupling of metals. EIS enables time dependent data to be acquired non destructively from a single sample. The impedance of the material as a function of time and applied negative potential was measured. It was found that increased damage to the composite was induced by more applied negative potentials, as cathodic reactions were increased with decreasing potential. Experimental data from the measurement technique is also amenable to modelling by passive electrical circuit elements. The system was equivalently modelled by two interacting RCtype subcircuits representing the carbon fiber/moisture and vinyl ester/moisture interphases. The pore resistance $R_{p o}$ determined from the model was found to offer a damage monitoring criteria for the composite material.

In an examination of surface damage to composites, laboratory testings were found to simulate accurately long term surface damage from galvanic marine exposure in seawater. Surface examination after 
long term galvanic coupling in seawater indicated removal of the polymer matrix above carbon fibers in addition to previously found blisters. Therefore two types of damage, blistering and dissolution, occurred due to galvanic interactions seawater exposure. Blistering was found only 720 hours (30 days) at a potential of $-0.65 \mathrm{~V}_{\mathrm{SCE}}$, along with regions of polymer surface dissolution. Imposing a potential of $-1.2 \mathrm{~V}_{\mathrm{SCE}}$ resulted in exposing carbon fibers after the covering polymer layer was rapidly removed. Possible electrochemical mechanisms for the polymer dissolution process are discussed.

TiN and $\mathrm{ZrN}$ cathodic ion plated coatings were applied to a 304 stainless steel, and exposed to $0.5 \mathrm{~N} \mathrm{NaCl}$ solution. The TiN coatings were also ion implanted with $\mathrm{Ti}$ and $\mathrm{Au}$ to determine the effect of ion implantation on corrosion behavior. It was found that ion implantation did not enhance the corrosion resistance of the TiN on 304 stainless steel. However the $\mathrm{ZrN}$ did protect the stainless steel from corrosion. It is suggested that the $\mathrm{ZrN}$ is inherently more protective by formation of a passive layer. TiN even with excess $\mathrm{Ti}$ ions from implantation did not form a protective passive layer. Corrosion interfaces of coated and/or implanted stainless steel were modelled by a simple parallel RC-type circuit due to strong interfacial bonding between substrate and coatings. Modelled data indicated the charge transfer resistance of the $\mathrm{ZrN}$ was higher than TiN and was related to the enhanced protection of $\mathrm{ZrN}$. 


\section{ACKNOWLEDGEMENT}

I would like to thank my major professor Dr. Richard Brown for introducing this research area to me and guiding me throughout the duration of my master's program.

I also express appreciation to MARA of Malaysia for providing funding for most of the program which enabled me to pursue graduate education.

I am very greatful to Dr. Rockett and Dr. Wright for serving on my thesis committee.

To all my colleagues Mike, Iskandar, Bill, Larry van Leaven and others that are too many to be mentioned, I thank you all for moral and technical support. Valuable contributions from the secretary Lauren, technician Ray, and Charlie and Tom for making life smoother are also appreciated.

Support from my families give me the strength to continue my study away from home. Thank you for standing behind me all the time. Finally, I dedicated this thesis to my late mom and dad. Their love and advice really makes me who I am today. Thank you both. 


\section{PREFACE}

This Master's thesis is written in the Manuscript form according to guidelines for the URI graduate school. The first manuscript in the thesis was prepared for submission to the journal Corrosion. It was accepted and published in November 1991 issue. The work is an investigation into the application of impedance spectroscopy to simulate galvanic coupling of a carbon vinyl ester composite..

The second manuscript was also prepared for submission to the journal Corrosion. It was accepted for publication in 1992. The work in this manuscript reported observations of damage induced by galvanic interaction and discussed possible mechanisms for dissolution of the polymer surface of a carbon vinyl ester composite.

The third manuscript was prepared for submission to the Journal of Coating Science and Technology, and accepted for publication in 1992. The paper consists of a study of the corrosion behavior of TiN coated 52100 steel, and TiN and $\mathrm{ZrN}$ coated 304 stainless steel. The portion of the paper concerning corrosion behavior of $\mathrm{TiN}$ and $\mathrm{ZrN}$ coated 304 SS is submitted as original work in this thesis. 


\section{TABLE OF CONTENTS}

\section{CHAPTER}

I. Introduction

Nomenclatures

Introduction

Theoretical Background of Impedance Spectroscopy 4

Simple Basis of Circuit Models $\quad 6$

Impedance Data Representation $\quad 8$

$\begin{array}{ll}\text { Experimental Procedure } & 10\end{array}$

$\begin{array}{ll}\text { Circuit Analysis of Impedance Data } & 11\end{array}$

$\begin{array}{ll}\text { Procedure for EIS Modelling } & 14\end{array}$

$\begin{array}{ll}\text { Figure Captions } & 15\end{array}$

$\begin{array}{ll}\text { References } & 17\end{array}$

II. An Impedance Study of Carbon Fiber Vinyl Ester Composite 35 Abstract $\quad 36$

$\begin{array}{ll}\text { Introduction } & 37\end{array}$

Experimental Procedure 41

Results and Discussion $\quad 42$

$\begin{array}{ll}\text { Conclusion } & 51\end{array}$

$\begin{array}{ll}\text { Literature Cited } & 52\end{array}$

III. Damage to Composites from Electrochemical Processes 68 $\begin{array}{ll}\text { Abstract } & 69\end{array}$

$\begin{array}{ll}\text { Introduction } & 70\end{array}$ 
Experimental Procedure

Results

Discussion

76

Conclusions

81

References

82

Figure Captions

84

IV. Corrosion Behavior of Ion Plated and Implanted Films

Abstract

92

Introduction

93

Experimental Procedure

94

Experimental Results

97

Discussion

103

Conclusions

109

Figure Captions

113

V. Future Study

VI. Bibliography 


\section{NOMENCLATURES}

Symbols

\section{Alphabets}

C

$\mathrm{C}_{\mathrm{c}}$

$C_{\mathrm{dl}}$

f

F

i

$\mathbf{i}_{\text {corr }}$

$I_{m}$

j

L

n

$\mathbf{R}$

Rs

$\mathrm{Rt}$

t

T

v

V m

W

Ycpe

\section{Descriptions}

Capacitance

Coating capacitance

Double-layer capacitance

Frequency in $\mathbf{H z}$

Faraday's constant, 96500 Coulombs

current in Ampere

corrosion rate expressed in current density

$\mu \mathrm{A} / \mathrm{cm}^{2}$

Magnitude of sinusoidal current in Ampere

equals $\sqrt{-1}$, an imaginary number

Inductance in henry

Phenomenological constant or frequency power,

between 1 and -1

Resistance in ohm

Solution resistance

Charge transfer resistance

Time in seconds

Temperature in ${ }^{\circ} \mathrm{K}$

Voltage in volts

Amplitude of applied sinusoidal voltage

Warburg impedance, or impedance due to semiinfinite diffusion

Admittance of constant phase element in "mho" 
Adjustable parameters obtained from fitting procedure

Yw

Z

Z

Z"

$|Z|$

Greek Letters

$\beta_{\mathrm{a}}$

$\beta_{c}$

$\theta$ or Alpha

$\theta \max$

$\pi$

$\tau$

$\omega$

$\omega^{\theta \max }$
Admittance of Warburg impedance in "mho" Impedance in ohm

Imaginary impedance component

Real impedance component

Magnitude of impedance

Anodic Tafel's slope

Cathodic Tafel's slope

Phase shifts or phase angle

Maximum phase angle

equals 3.14

time constant in seconds

equals $2 \pi f$, radial frequency in radians

radial frequency at maximum phase angle 


\section{INTRODUCTION}

Electrochemical impedance spectroscopy (EIS) has been proven to be a powerful non destructive technique in electrochemical studies especially for highly resistive materials such as painted metals where other electrochemical methods are inadequate(1-5). Several reviews $(6,7)$ suggest two important areas of application, firstly rapid estimates of corrosion rates, and secondly identification of corrosion mechanisms, especially in the presence of an adsorbed film or an applied organic coating. Other investigators applied this technique to degradation of a porous electrode $(8,9)$, corrosion behavior of inhomogeneous surfaces $(10,11)$, characterization of passive films and localized corrosion (12-16). Electrochemical processes can also be examined by EIS in low conductivity media where meaningful dc measurements are impossible if the ohmic drop is not eliminated $(17,18)$.

Studies involving EIS to predict corrosion rates and behavior of coated and uncoated metals usually involve modelling of the experimental data to represent the electrochemical interface. The models consists of circuit design with passive elements such as resistors and capacitors. These passive circuits models are termed "equivalent circuit" models as they are analogs of the electrochemical nature of the corrosion process. Other circuit elements include for example the Warburg semi-infinite diffusion element. Various equivalent circuits for different electrode/electrolyte systems has been proposed as physical models from which corrosion rates are determined (8-16). However, 


\section{Theoretical Background of Impedance Spectroscopy}

When a purely sinusoidal voltage expressed as

$$
v(t)=v_{m} \sin (\omega t)
$$

where $\omega=2 \pi \mathrm{f}$, is applied to an electrochemical cell, the resulting steady state current will be

$$
\mathrm{i}(\mathrm{t})=\mathrm{I}_{\mathrm{m}} \sin (\omega \mathrm{t}+\theta)
$$

where $\theta$ is the phase difference between the voltage and the current, measured in degrees. The phase difference is zero for resistive behavior, and $90^{\circ}$ for capacitive behavior (see figure 1). Phase differences between $0^{\circ}$ and $90^{\circ}$ are found for systems with both resistive and capacitive nature due to different properties of localized sites at the interface.

The impedance of the cell is defined as

$$
Z(\omega)=v(t) / i(t)
$$

and the magnitude of the impedance, and phase angle are defined as

$$
|\mathrm{Z}(\omega)|=\mathrm{V}_{\mathrm{m}} / \mathrm{I}_{\mathrm{m}}(\omega), \quad \text { and } \theta(\omega)
$$

respectively. The impedance can also be represented in terms of its real $\left(Z^{\prime}\right)$ and imaginary $\left(Z^{\prime \prime}\right)$ values such that

$$
\mathrm{Z}=\mathrm{Z}^{\prime}+\mathrm{j} \mathrm{Z}^{\prime \prime}
$$

where

$$
\mathrm{Z}^{\prime}=\mathrm{Z} \cos \theta, \quad \mathrm{Z}^{\prime \prime}=\mathrm{Z} \sin \theta, \quad \text { and } \mathrm{j}=\sqrt{-1}
$$

Then, the magnitude of impedance is

$$
|Z|=\left[\left(Z^{\prime}\right)^{2}+\left(Z^{\prime \prime}\right)^{2}\right]^{1 / 2}
$$

and the phase angle is

$$
\theta=\tan ^{-1}\left(Z^{\prime \prime} / Z^{\prime}\right)
$$

The imaginary and real impedance can be plotted on a complex Argand diagram as shown in figure 2 . 
The most commonly employed technique of impedance spectroscopy is the measurement of system impedance directly in the frequency domain. A single-frequency voltage is applied to the cell and the phase shift and impedance magnitude are measured, or alternatively the real and imaginary parts of the resulting current at that frequency are measured. When applied over a wide frequency range or bandwidth (ie. $1 \mathrm{mHz}$ to $1 \mathrm{MHz}$ ), information on electrode processes involving a direct charge transfer processes and/or diffusion mechanisms is revealed through modelling of the experimental data.

\section{Simple Basis of Circuit Models}

The corrosion interface in solution adjacent to the electrode surface consists of double layers of an inner layer of electrons and an outer layer of ions. Their inherent capacitive reactances are characterized by their relaxation time, defined as the time needed for any system to reach equilibrium upon application of a small amplitude of perturbation (ie. voltage step), or more realistically the distribution of their relaxation times due to inhomogeneous properties of local sites in the system(19). The electrical responses of a cell of heterogeneous properties vary depending on the species of charge present, and the microstructure of the electrodes.

Electrochemical interfaces of electrode/electrolyte systems can be viewed as combinations of passive electrical circuits, ie. resistance, capacitance, and inductance (20). A corroding metal surface exposed to an electrolyte can be hypothetically represented by a simple Randlestype equivalent circuit as shown in figure 3 assuming only activation control. The corroding interface is represented by a parallel combination 
of resistance $R_{t}$ and double layer capacitance $C_{d 1}$. The parallel elements are introduced to account for a contribution to current from the faradaic ionic transfer process $\left(R_{t}\right)$, and double layer charging $\left(C_{d l}\right)$ to the total current through the interface (21). A simple model of the double layer is that of the Hemholtz model (22) where the two layers of opposite charges are due to electrons on the metal surface resulting from anodic reaction of metal to metal ions, and layers of positive ions in the solution at some distance from the metal surface. Further treatments of double layer structures for example the Gouy-Chapman diffuse layer and Stern compact region of the double layer are slight variations of the Helmholtz layer (23-24). The Helmholtz model is used in this discussion.

In an activation controlled system, $\mathbf{R}_{\mathbf{t}}$ is related to the corrosion current density, $\mathrm{i}_{\text {corr, }}$ by the Stern-Geary equation (25) which is only accurate for small overvoltages from the free corrosion potential $\left(E_{c o r r}\right)$, ie. +25 or $-25 \mathrm{mV}$ :

$$
\mathrm{i}_{\text {corr }}=\frac{\beta_{\mathrm{a}} \beta_{\mathrm{c}}}{2.303\left(\beta_{\mathrm{a}}+\beta_{\mathrm{c}}\right)} \frac{1}{\mathrm{R}_{\mathrm{t}}}
$$

Most electrochemical systems are nonlinear which gives rise to non-linear dependency of $R_{t}$ and $C_{d l}$ on the magnitude of the applied voltage $V_{m}$. However, at small enough magnitude the non-linearity of cell response becomes negligible. As long as the applied voltage amplitude is less than the thermal voltage $V_{m} \equiv R T / F$ which is about 25 $\mathrm{mV}$ at $25^{\circ} \mathrm{C}$, the response of the system becomes linear to a good approximation (19). 


\section{Impedance Data Representation}

Typical formats of graphical representation of the impedance data are the Nyquist plot (Imaginary $\mathrm{Z}$ vs. Real $\mathrm{Z}$ ), and the Bode plot $(\log |\mathrm{Z}|$ and $\theta$ vs. $\log$ frequency $(\mathrm{Hz})$ ). Typical Bode and Nyquist plots for system diagrammed in figure 3 are shown in figure 4 . Resistances $R_{S}$ and $R_{t}$ are obtained from the high and low frequency impedance arrests, respectively. The double layer capacitance is calculated by

$$
\omega^{\theta \max }=1 / \mathrm{C}_{\mathrm{dl}} \mathrm{R}_{\mathrm{t}}
$$

where $C_{d l} R_{t}$ is the time constant for the double layer charging process. Other types of graphical representations are discussed in literature, such as the idealized Randles plot of $Z^{\prime}$ vs. $\omega^{-1 / 2}$ usually used for system of diffusion-controlled behavior, and plots of $Z^{\prime}$ vs. $\omega Z^{\prime \prime}$ and $Z^{\prime}$ vs. $Z^{\prime \prime} / \omega$ (26).

In real systems, complications of impedance behavior at lower frequency $(0.1-0.001 \mathrm{~Hz})$ are often observed and explained as due to effect of concentration and diffusion of species across the interface (20). The equivalent circuit for metal/solution system with this behavior is shown in figure 5 where the diffusion related element is in series with the resistance Rt. On a Nyquist plot this is observed as a straight line at low frequency usually mentioned as a diffusion tail, see figure 6. A special case of diffusion is the semi-infinite Warburg diffusion (19), with diffusion tail is at $45^{\circ}$ to the real axis. Warburg diffusion on a Bode plot will give rise to a $\omega^{-1 / 2}$ behavior usually at low frequency limit, and is shown in the Bode plot in figure 6.

A very general equivalent circuit for an electrode/coating/electrolyte system is shown in figure 7. The coating layer is represented by a parallel pore resistance, $R_{\text {po }}$, and coating 
capacitance, $C_{c}$, and the metal/coating interface in general is represented by an interfacial impedance $Z_{i f}$ proposed by Mansfeld, Kendig and coworkers $(1,3)$. They proposed that the interfacial impedance $Z_{\text {if }}$ is equivalent to a parallel combination of $C_{d 1}$ and $R_{t}$ for an activation controlled process, or series combination of $\mathbf{R}_{\mathbf{t}}$ and Warburg diffusion element $\mathrm{W}$ for a diffusion controlled processes at the metal/coating interface. These are represented by circuits (a) and (b), respectively in figure 7. Walter $(2,27,28)$ however proposed that this interface can be modelled by a parallel $C_{d 1}$ and impedance $Z$ which consists of series $R_{t}$ and $\mathrm{W}$ combination, shown as circuit (c) in figure 7. The Warburg impedance (W) is to account for diffusion processes within the paint film. The impedance behavior for systems described by circuits (a), (b), and (c) in general are shown as two maxima of time constants at high and low frequency on the Bode plot, see figure 8. One problem encountered for systems showing multiple maxima of time constants is overlapping of time constants which make it difficult to obtain parameter values. These problems are overcome by a nonlinear least squares analysis to be discussed later. In previous studies the performance of a coating has been correlated to changes in the values of $R_{p o}$ and $C_{c}$ with time. Increase in $C_{c}$ and decrease in $R_{p o}$ are suggested to indicate increase in water uptake by the coating and development of ionic conducting paths through the coating to the metal/coating interface. An equivalent circuit similar to that for a bare metal exposed to electrolyte (see figure 3 ) has been proposed for a perfect dielectric coating with no defects, and is referred to as a quasi-homogeneous 3-D model of metal/coating system (29). 
A more complex equivalent circuit was proposed to described a coating with defects which is referred as inhomogeneous 3-D layer model (29). This was used to describe corrosion behavior in the presence of corrosion products and of pitting corrosion on aluminum alloys $(9-11,14)$. The inhomogeneous $3-D$ model is shown in figure 9.

In this study, the two most important models which provided the basis of analysis are those shown in figures 3 and 7. More specific models were developed from these two to further explain mechanisms corresponding to the impedance behavior and corresponding physical changes observed.

\section{Experimental Procedure}

The general experimental arrangement for EIS testing is as shown in Figure 10. A glass spherical joint with a rubber ' $o$ ' ring seal are clamped onto surface of the sample to be examined. A platinum sheet and calomel electrode suspended in the electrolyte served as counter and reference electrodes, respectively, with the material to be tested as the working electrode. The electrolyte solution employed was $\mathrm{NaCl}$ solution at concentration of $0.50 \mathrm{~N}$. Impedance measurement was performed by a PAR 273 potentiostat in conjunction with an IBM personal computer and a Solartron 1255 high frequency response analyzer (FRA), with PARC 388 control software. The measurements were carried out for a frequency range of $0.001 \mathrm{~Hz}$ to $100 \mathrm{kHz}$. A repetition of seven frequency readings per decade was employed.

The impedance of the sample is measured using the FRA which generates a sine wave voltage of low amplitude (normally $5 \mathrm{mV}$ ) through the potentiostat to the electrochemical cell. The cell response in 
sine wave current is analyzed by the FRA which then converts it to imaginary and real impedance, and phase angle. These are stored by the computer on disks for further analysis.

Samples used in this study were

a. Stainless steel

b. Stainless steels coated with $\mathrm{TiN}, \mathrm{ZrN}$, and $\mathrm{TiN}$ further implanted with $\mathrm{Ti}$ and $\mathrm{Au}$, and

c. Carbon vinyl ester composite

The area exposed to solution is in the range of 1.737 to $3.25 \mathrm{~cm}^{2}$. Impedance measurement involving stainless steel and those with different coatings including ion implantation were carried out at open circuit potential. Cathodic potentials in the range of -650 to $-1200 \mathrm{mV}$ vs. SCE were applied to the composite materials to simulate galvanic coupling and cathodic protection on metal/composite couple. Changes of current in the cell was registered. Scanning electron microscopy was employed to observe changes on the sample after exposure to sodium chloride. All impedance data are represented in either Bode or Nyquist plots. The simulated data from analysis are plotted with the actual data for comparison.

\section{Circuit Analysis of Experimental Data}

Interpretation of impedance data can be carried out using various methods of data analysis (30-32). These are available as commercial software such as EQUIVCRT (33), and LEVM (34). In the analysis, equivalent circuit models of the system are proposed which usually consists of combinations of passive elements such as R, C, L, and diffusion related element such as W. Complex nonlinear least squares 
methods are the common technique of fitting a curve to the experimental data. All the experimental data are simultaneously compared to the equivalent circuit model often chosen by the experimenter for a particular system. Values of parameters of the model are determined such that errors between fitted and experimental data are minimized (35). Macdonald and coworkers applied a complex nonlinear least squares method (CNLS) to determine parameters of models specifically for impedance and/or admittance data of an electrode/material system (31). A good capability of this technique is to produce a good estimation of parameter values in an equivalent circuit and analyzing convoluted data such as overlapping of two semicircles at high and low frequency or of a Warburg diffusion tail and a semicircle (32).

Kendig and coworker (30) developed a program called CIRFIT later modified to ACFIT to determine corrosion rates. These apply iterative routine techniques, Newton-Raphson and Marquadt routines, based on initial guesses of parameter values for a particular physical model. The ability of this technique to converge to some minimum values depend on the selection of an appropriate model and good initial guesses of parameter values. The former is most important and is highly dependent on the system under investigation.

The commercial software EQUIVCRT writtten by Boukamp allows the operator to arbritarily build the equivalent circuit that physically explained the cell response. In this study, all analysis of impedance data were carried out employing this software. Passive electrical elements and diffusion related elements available for modeling purposes are resistor, capacitor, inductor, Warburg impedance, and a constant 
phase element. The most important feature in this software is the constant phase element (CPE) which is widely used to fit impedance data that shows deviation from an ideal capacitive behavior. On a Nyquist plot this often results in a depression of the semicircle with the center of the semicircle located under the real impedance axis, for example in figure 11 the center of the semicircle could be below the $\mathrm{Z}^{\prime}$ axis. This behavior is suggested as due to inhomogeneities in the electrode surfaces (36), both laterally and within the oxide film (12).

The constant phase element can be represented in its admittance form as

$$
Y_{\mathrm{cpe}}(\omega)=Y_{\mathrm{o}}(\mathrm{j} \omega)^{\mathrm{n}}=\mathrm{Y}_{\mathrm{o}} \omega^{\mathrm{n}} \cos (\mathrm{n} \pi / 2)+j Y_{\mathrm{o}} \omega^{\mathrm{n}} \sin (\mathrm{n} \pi / 2)
$$

where $Y_{O}$ is the adjustable parameter obtained from the least squares analysis, containing the diffusion coefficient (33). This is a very general dispersion formula, and reduced to a Warburg semi-infinite diffusion at $\mathrm{n}=0.5$, given as

$$
Y_{W}(\omega)=Y_{O}(j \omega)^{0.5}=Y_{O}\left[(\omega / 2)^{0.5}+j(\omega / 2)^{0.5}\right]
$$

For $n=0$ it represents a resistance with $R=Y_{0}{ }^{-1}$, for $n=1$ it represents a capacitance with $\mathrm{C}=\mathrm{Y}_{0}$, and for $\mathrm{n}=-1$ it represents an inductance with $\mathrm{L}=\mathrm{Y}_{\mathrm{O}}{ }^{-1}$.

A parallel combination of CPE and resistance $R$ yields an arc in the Nyquist plot and the depression of the arc depends on the parameter $n$. The total impedance of this parallel circuit is

$$
\mathrm{Z}_{\text {total }}=\mathrm{R} /\left(1+\mathrm{Y}_{\mathrm{o}} \mathrm{R}(\mathrm{j} \omega)^{\mathrm{n}}\right)
$$

and the time constant $\tau=\left(Y_{0} R\right)^{1 / n}$. For a circuit which consists of parallel $\mathrm{R}$ and $\mathrm{C}$, the time constant is given as $\tau=\mathrm{RC}$. Equating the time constants gives

$$
\mathrm{RC}=\left(\mathrm{Y}_{0} \mathrm{R}\right)^{1 / \mathrm{n}}
$$


then, the capacitance of interface modelled by parallel $R-Y_{c p e}$ circuit is

$$
C=\left(Y_{0} R\right)^{1 / n} / R
$$

The constant phase element is found to best fit for an interface with deviation from ideal capacitive behavior, as shown in chapters 2 through 4 .

\section{Procedure for EIS Modelling}

The modelling starts with an analysis of the experimental data where the dispersion of the impedance data will be decomposed into subcircuits which will lead to an indication of many possible subcircuits. The tentative identification of these subcircuits will provide the starting values for the adjustable circuits. The selected sub-circuits will be optimized using partial NLLSF. The optimized sub-circuits will be subtracted from the total dispersion. This will cause distortion to the rest of the dispersion. Usually the distorted part is removed to ease further analysis. Subtraction will be carried out until no reasonable circuit elements are represented in the distorted dispersion file. Final optimization of the subtracted sub-circuits will be performed by total NLLSF. An example of experimental data the circuit modelled to the data and the prediction from the model is shown in figure 11. An example of what is called a good fit and a poor fit using different models is shown in figure 12 . 


\section{FIGURE CAPTIONS}

Figure 1. The relationship between alternating current and voltage signals for a resistive or capacitive behavior.

Figure 2. Complex plane plot of imaginary vs. real impedance at any particular frequency indicating the magnitude of impedance and phase angle determination.

Figure 3. Schematic diagram of a double layer at the metal/solution interface and a Randles-type equivalent circuit of system with purely activation controlled process at the interface.

Figure 4. Typical Nyquist and Bode plots of a purely activation controlled system as shown in figure 3 .

Figure 5. Equivalent circuit of a metal/solution system with diffusion controlled behavior. $R_{S}, R_{t}$ and $C_{d l}$ are as defined, and $Z_{d}$ is the diffusion related impedance.

Figure 6. Typical Nyquist and Bode plots of system of a diffusion controlled reaction with an equivalent circuit shown in figure 5 .

Figure 7. General equivalent circuit for a coated electrode/electrolyte system with various models for different processes at the metal/coating interface. 
Figure 8. Typical Bode plot for a metal/paint/electrolyte system for circuits (a), (b), and (c) in figure 7 at the metal/coating interface.

Figure 9. Inhomogeneous 3-D model for a coating with defects and in presence of corrosion products.

Figure 10. Apparatus for measuring the impedance of an electrochemical cell.

Figure 11. Typical plot of simulated data from EIS modeling procedure along with the experimental data.

Figure 12. Typical plot of simulated data from EIS modeling procedure shows difference quality of fitting from two different equivalent circuit models. 


\section{REFERENCES}

1. F. Mansfeld, M.W. Kendig, and S.Tsai, "Evaluation of Corrosion Behavior of Coated Metals with AC Impedance Measurements", Corrosion, v38 (1982), p478-485

2. G. W. Walter, "Application of Impedance Measurements to Study Performance of Painted Metals in Aggressive Solutions", Journal of Electroanalytical Chemistry, v118 (1981), p259-273

3. M. W. Kendig, F. Mansfeld, and S. Tsai, "Determination of the Long Term Corrosion Behavior of Coated Steel with A.C. Impedance Measurements", Corrosion Science, v23 (1983), p317-329

4. J. R. Scully, "Electrochemical Impedance of Organic-Coated Steel: Correlation of Impedance Parameters with Long-Term Coating Deterioration", Journal of the Electrochemical Society, v136 (1989), p979-990

5. C-T. Chen, and B. S. Skerry, "Assessing the Corrosion Resistance of Painted Steel by AC Impedance and Electrochemical Noise Techniques", Corrosion, v47 (1991), p598-611

6. C. Gabrielli, "Identification of Electrochemical Proceses by Frequency Response Analysis", Solartron Instrumentation Group, 1980 
7. D. D. Macdonald, and M. C. McKubre, "Impedance Measurements in Electrochemical Systems", Modern Aspects of Electrochemistry, J. O'M. Bockris, B. E. Conway, and R. E. White, Eds., v14, Plenum Press, New York, p61, 1982

8. S. J. Lenhart, D. D. Macdonald, and B. G. Pound, "An AC Impedance Study of the Degradation of Porous Nickel Battery Electrodes", Journal of the Electrochemical Society, v135 (1988), p1063-1071

9. J. Hitzig, K. Juttner, W. J. Lorenz, and W. Paatsch, "AC-Impedance Measurements on Corroded Porous Aluminum Oxide Films", Journal of the Electrochemical Society, v133 (1986), p887-892

10. K. Juttner, W. J. Lorenz, M. W. Kendig, and F. Mansfeld, "Electrochemical Impedance Spectroscopy on 3-D Inhomogeneous Surfaces", Journal of the Electrochemical Society, v135 (1988), p332-339

11. K. Juttner, W. J. Lorenz, and W. Paatsch, "The Role of Surface Inhomogeneities in Corrosion Processes-Electrochemical Impedance Spectroscopy (EIS) on Different Aluminum Oxide Films", Corrosion Science, v29 (1989), p279-288

12. J. A. Bardwell, and M. C. H. McKubre, "AC Impedance Spectroscopy of the Anodic Film on Zirconium in Neutral Solution", Electrochimica Acta, v36 (1991), p647-653 
13. A. E. Bohe, J. R. Vilche, K. Juttner, W. J. Lorenz, W. Kautek, and W. Pattsch, "An Electrochemical Impedance Spectroscopy Study of Passive Zinc and Low Alloyed Zinc Electrodes in Alkaline and Neutral Aqueous Solutions", Corrosion Science, v32 (1991), p621633

14. H. Shih, and F. Mansfeld, "A Fitting Procedure for Impedance Spectra Obtained for Cases of Localized Corrosion", Corrosion, v45 (1989), p610-614

15. R. Oltra, and M. Keddam, "Application of Impedance Technique to Localized Corrosion", Corrosion Science, v28 (1988), p1-18

16. C. C. Streinz, "Electrochemical Impedance Spectroscopy of SurfaceModified Metals", Journal of the Electrochemical Society, v136 (1989), p293C-294C

17. D. D. Macdonald, "Some Advantages and Pitfalls of Electrochemical Impedance Spectroscopy", Corrosion, v46 (1990), p229-243

18. S. Chechirlian, P. Eincher, M. Keddam, H. Takenouti, and H. Mazille, "A Specific Aspect of Impedance Measurements in Low Conductivity Media. Artefacts and Their Interpretations", Electrochimica Acta, v35 (1990), p1125-1131

19. J. R. Macdonald, Impedance Spectroscopy: Emphasizing Solid Materials and Systems, Wiley, New York, 1987 
20. K. Hladky, L. M. Calloway, and J. L. Dawson, "Corrosion Rates from Impedance Measurements: An Introduction", British Corrosion Journal, v15 (1980), p20-25

21. A. J. Bard, and L. R. Faulkner, Electrochemical Methods: Fundamentals and Applications, Wiley, New York, 1980

22. E. C. Potter, Electrochemistry: Principles and Applications, Macmillan, New York, 1961

23. J. S. Newman, Electrochemical Systems, Prentice Hall, New Jersey, 1973

24. Comprehensive Treatise of Electrochemistry, Volume 1: The Double Layer, J. O'M. Bockris, E. Conway, and E. Yeager, eds., Plenum Press, New York, 1980

25. M. Stern, and A. L. Geary, "Electrochemical Polarization. I. Shape of Polarization Curves", Journal of the Electrochemical Society, v104 (1957), p56

26. EG\&G Princeton Applied Research, "Basics of Electrochemical Impedance Spectroscopy (EIS)", Application Note AC-1, 1989 
27. G. W. Walter, "A Review of Impedance Plot Methods Used for Corrosion Performance Analysis of Painted Metals", Corrosion Science, v26 (1986), p681-703

28. G. W. Walter, "The Application of Impedance Spectroscopy to Study the Uptake of Sodium Chloride Solution in Painted Metals", Corrosion Science, v32 (1991), p1041-1058

29. J. Titz, G. H. Wagner, H. Spahn, M. Elbert, K. Juttner, and W. J. Lorenz, "Characterization of Organic Coatings on Metal Substrates by Electrochemical Impedance Spectroscopy", Corrosion, v46 (1990), p221-229

30. M. W. Kendig, E. M. Meyer, G. Linberg, and F. Mansfeld, "A Computer Analysis of Electrochemical Impedance Data", Corrosion Science, v23 (1983), p.

31. J. R. Macdonald, and J. A. Garber, "Analysis of Impedance and Admittance for Solids and Liquids", Journal of the Electrochemical Society, v124 (1977), p.1022

32. M. Kleitz, and J. H. Kennedy, "Resolution of Multicomponent Impedance Diagrams" in Fast Ion Transport in Solids, P. Vashista, J. N. Mundy, and G. K. Shenoy eds., p185-188, Elsevier-North Holland, New York, 1979 
33. B. A. Boukamp, Equivalent Circuit (EQUIVCRT.PAS) Users Manual, 2nd ed., University of Twente, Netherlands, 1989

34. J. R. Macdonald, CNLS Complex Non-Linear Least Squares Immittance Fitting Program (LEVM) Manual, 1990

35. G. W. Walter, D. N. Nguyen, and M. A. D. Madurasinghe, "Impedance Analysis Method for Painted and Unpainted Metals", Electrochimica Acta, v37 (1992), p.245

36. I. Epelboin, and M. Keddam, "Faradaic Impedances: Diffusion Impedance and Reaction Impedance", Journal of the Electrochemical Society, v117 (1970), p.1052 


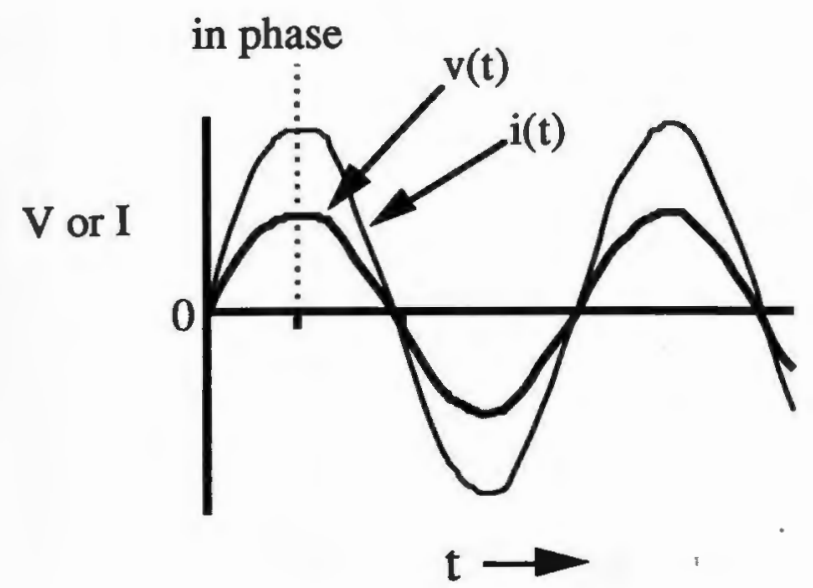

(a). $i(t)$ in-phase with $v(t)$ to give a resistance

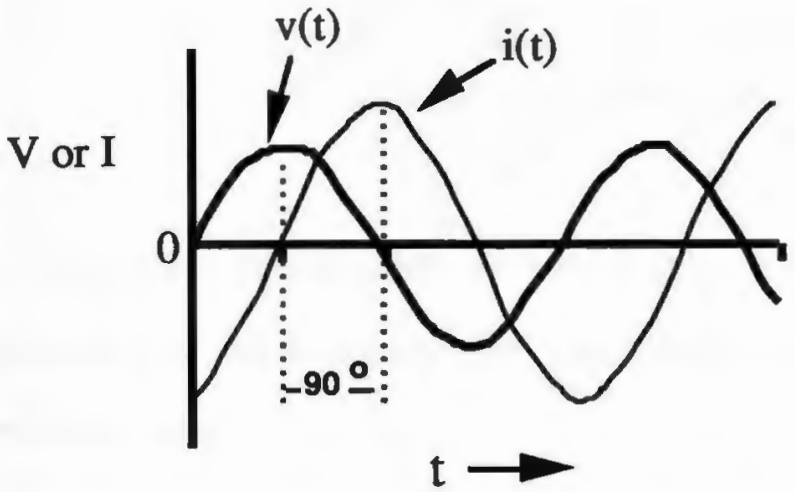

(b). $i(t) 90^{\circ}$ out of phase from $v(t)$ to give a capacitance

Figure 1. The relationship between alternating current and voltage signals for resistive or capacitive behavior. 


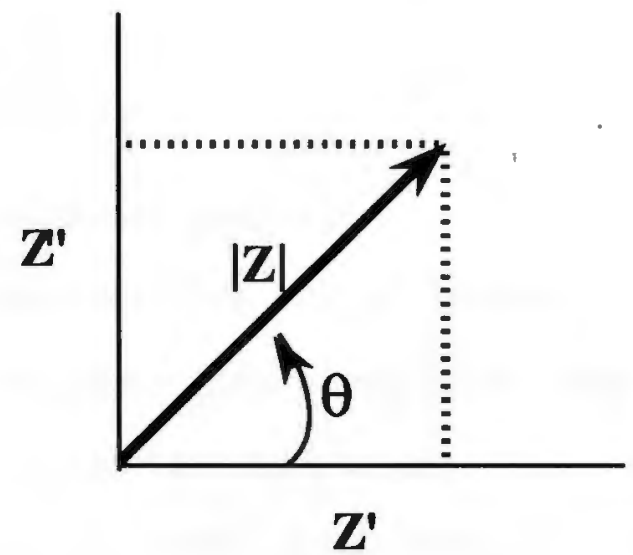

Figure 2. Complex plane plot of imaginary vs. real impedance at any particular frequency indicating the magnitude of impedance and phase angle determination. 


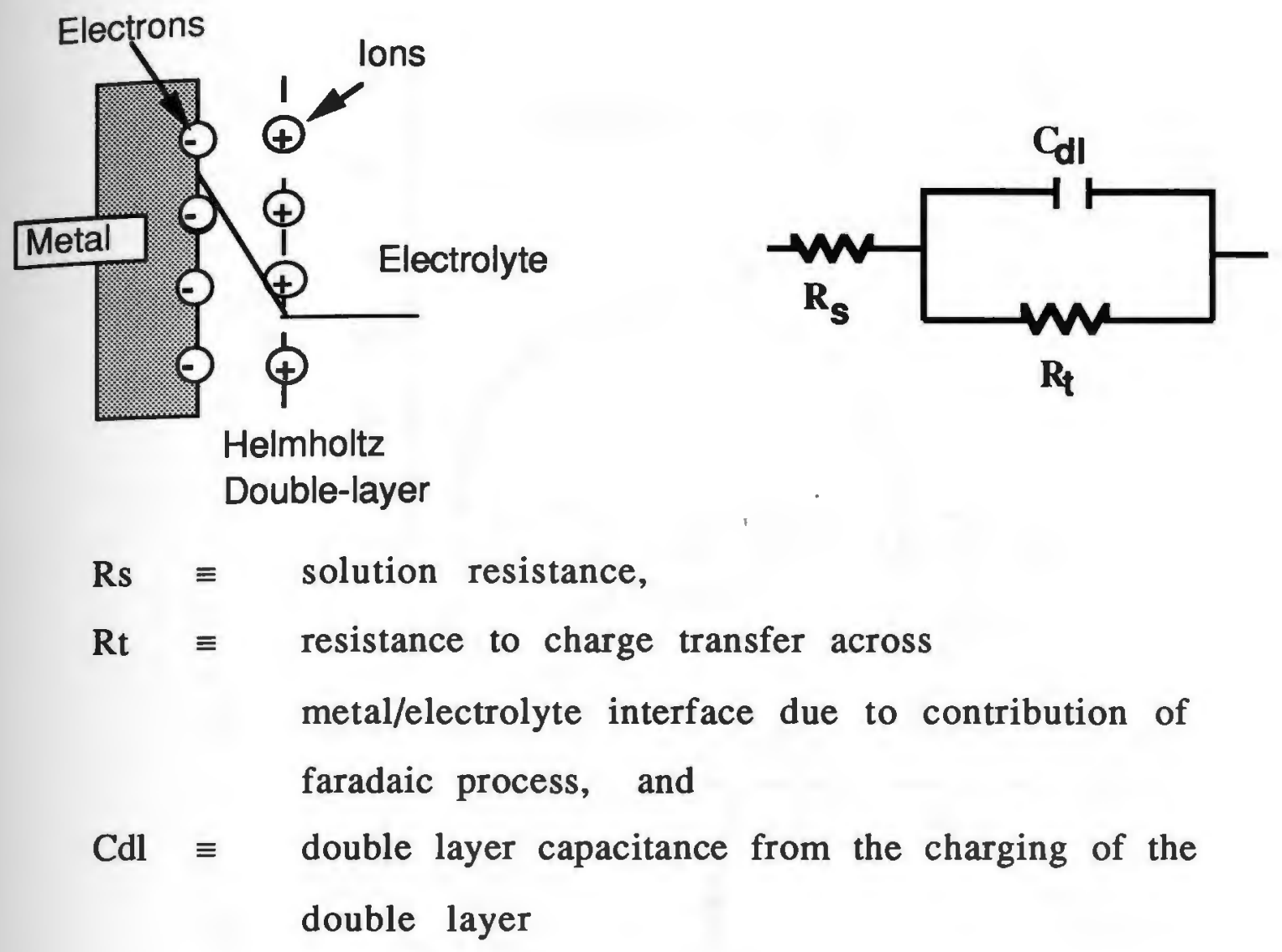

Figure 3. Schematic diagram of a double layer at the metal/solution interface and Randles-type equivalent circuit of system with purely activation controlled process at the interface. 


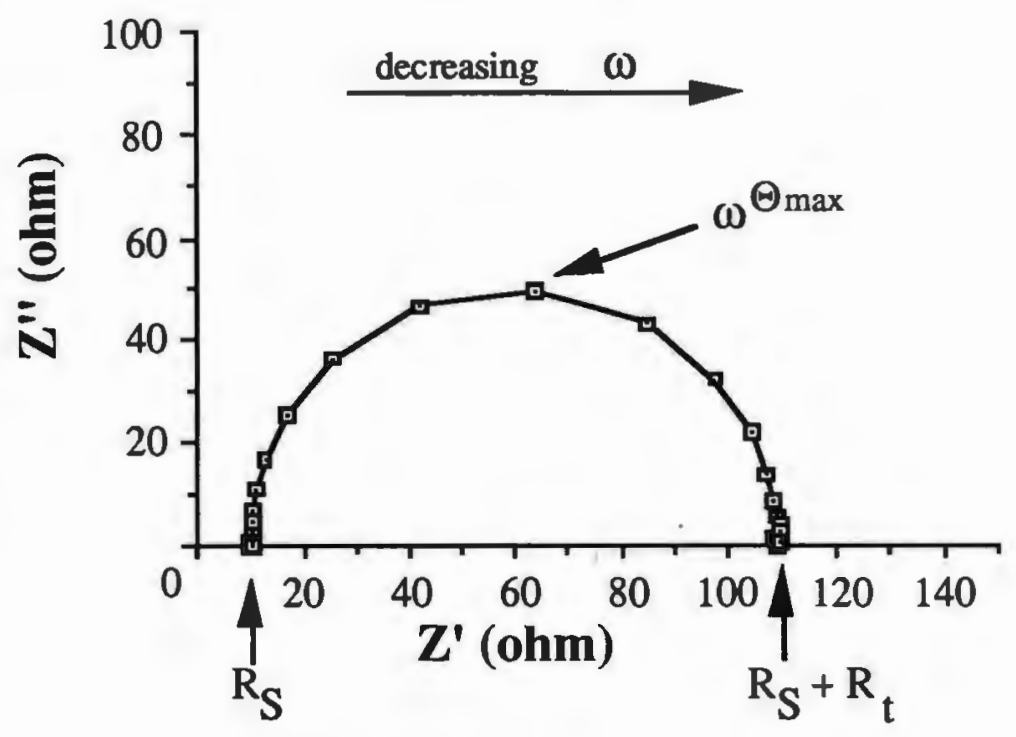

(a). Nyquist plot

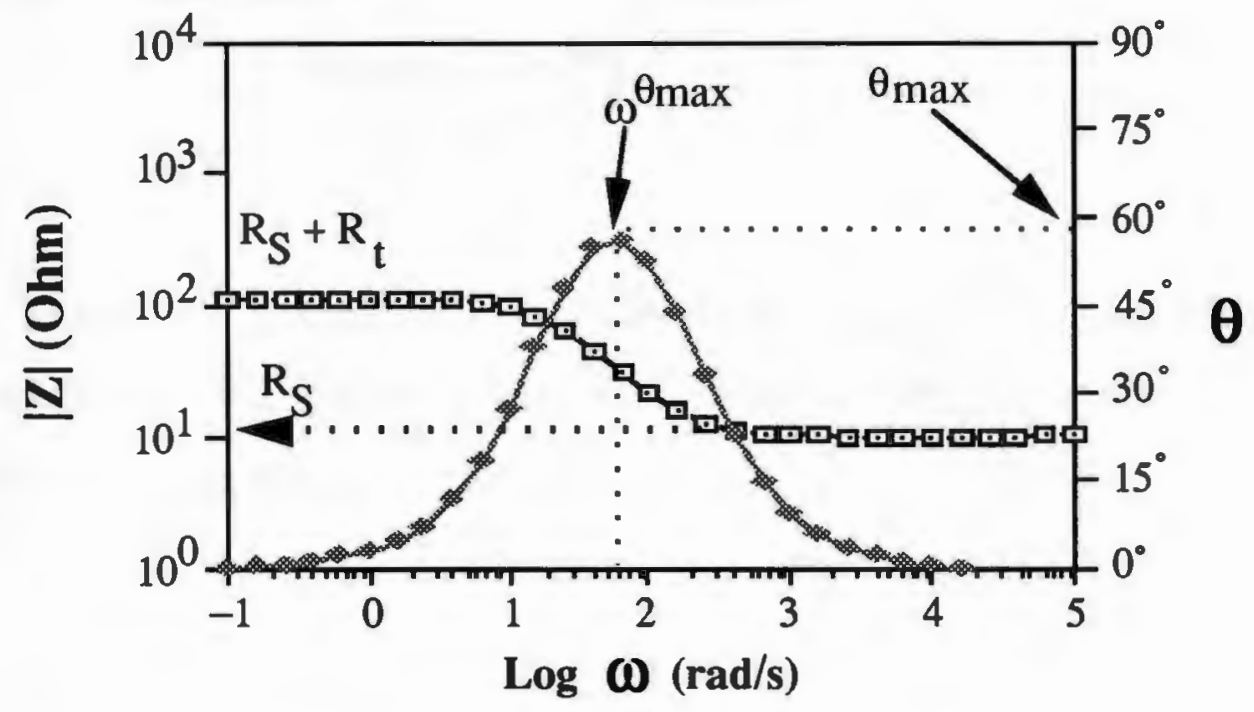

(b). Bode plot

Figure 4. Typical Nyquist and Bode plots of a purely activation controlled system as shown in figure 3 . 


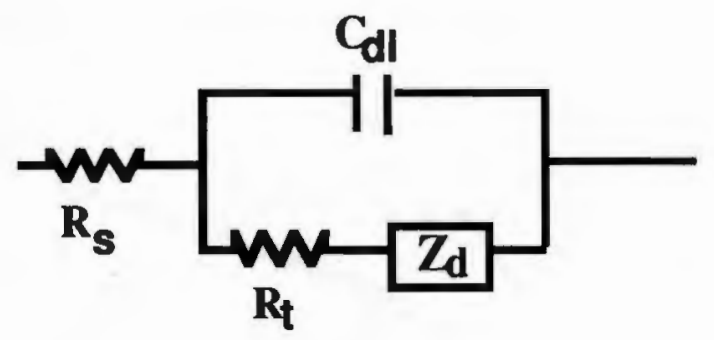

Figure 5. Equivalent circuit of a metal/solution system with diffusion controlled behavior. $\mathbf{R}_{\mathrm{S}}, \mathrm{R}_{\mathrm{t}}$ and $\mathrm{C}_{\mathrm{dl}}$ are as defined, and $\mathrm{Z}_{\mathrm{d}}$ is the diffusion related impedance. 

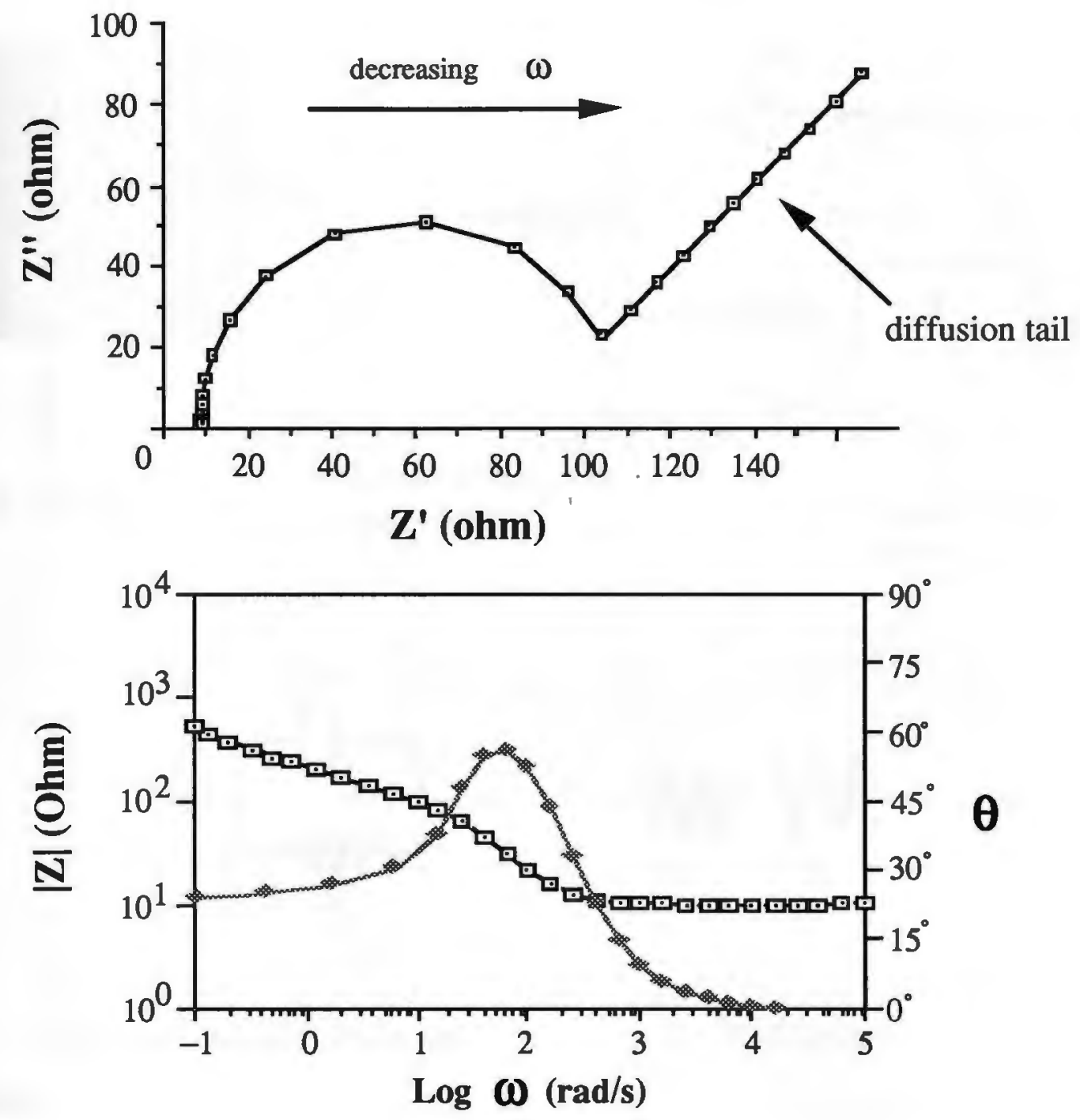

Figure 6. Typical Nyquist and Bode plots of system of a difusion controlled reaction with an equivalent circuit shown in figure 5 . 


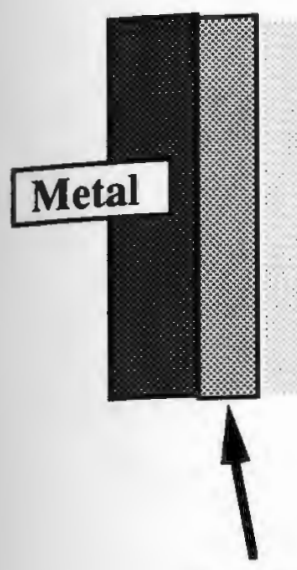

Coating
Electrolyte

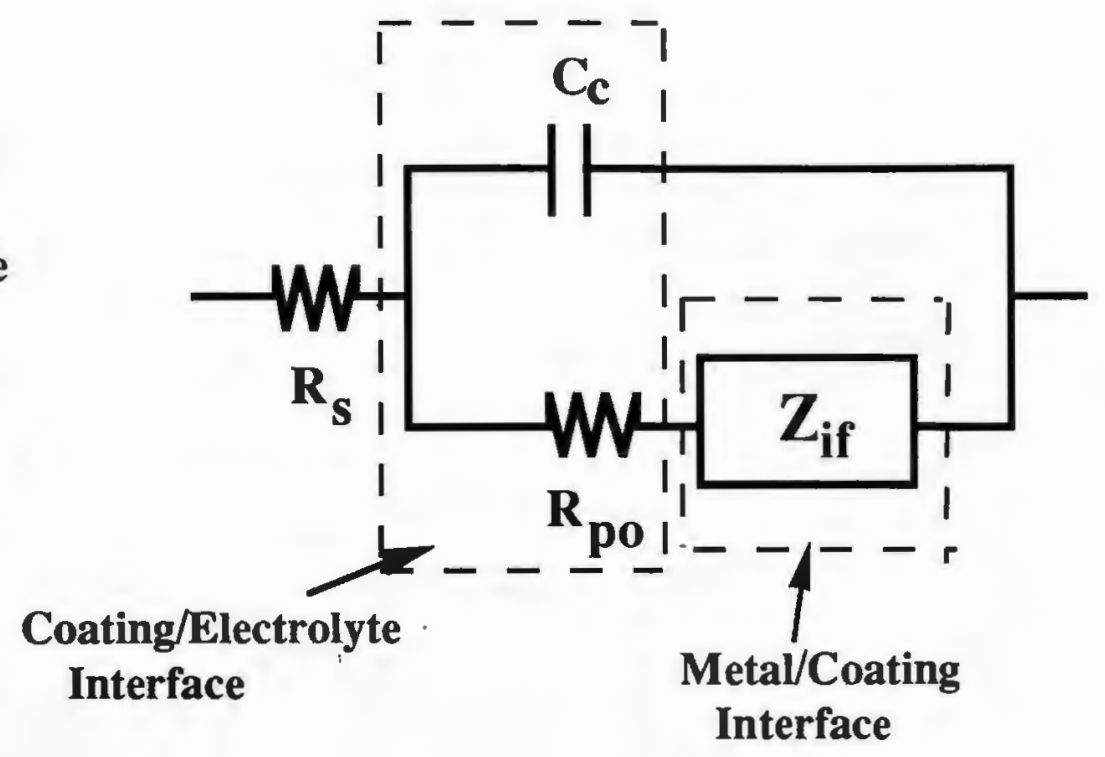

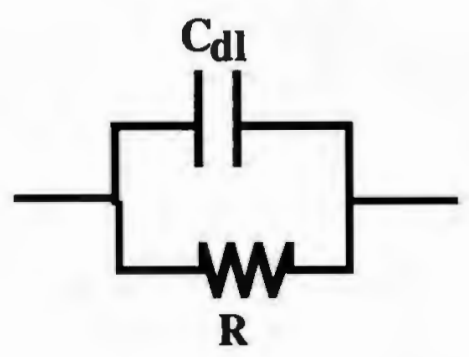

(a) Activation controlled

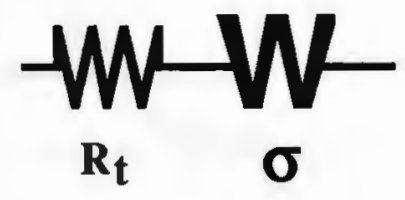

(b) Diffusion

controlled

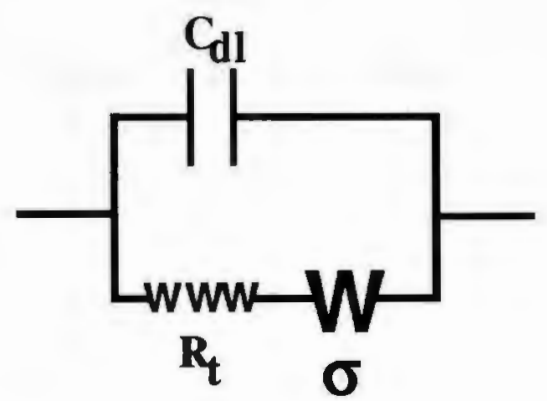

(c) Activation and diffusion controlled

Figure 7. General equivalent circuit for a coated electrode/electrolyte system with various models for different processes at the metal/coating interface. 


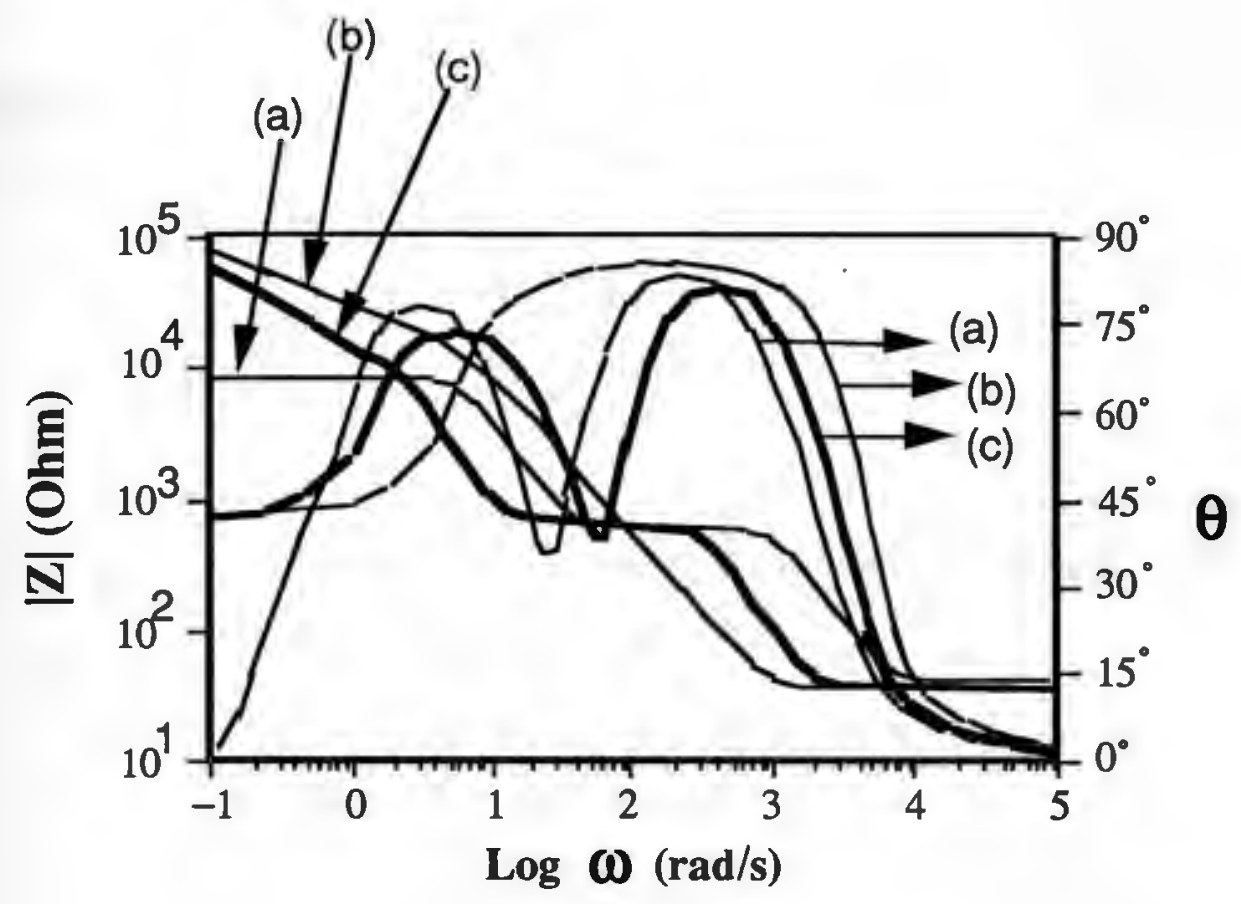

Figure 8. Typical Bode plot for a metal/paint/electrolyte system for circuits (a), (b), and (c) in figure 7 at the metal/coating interface. 


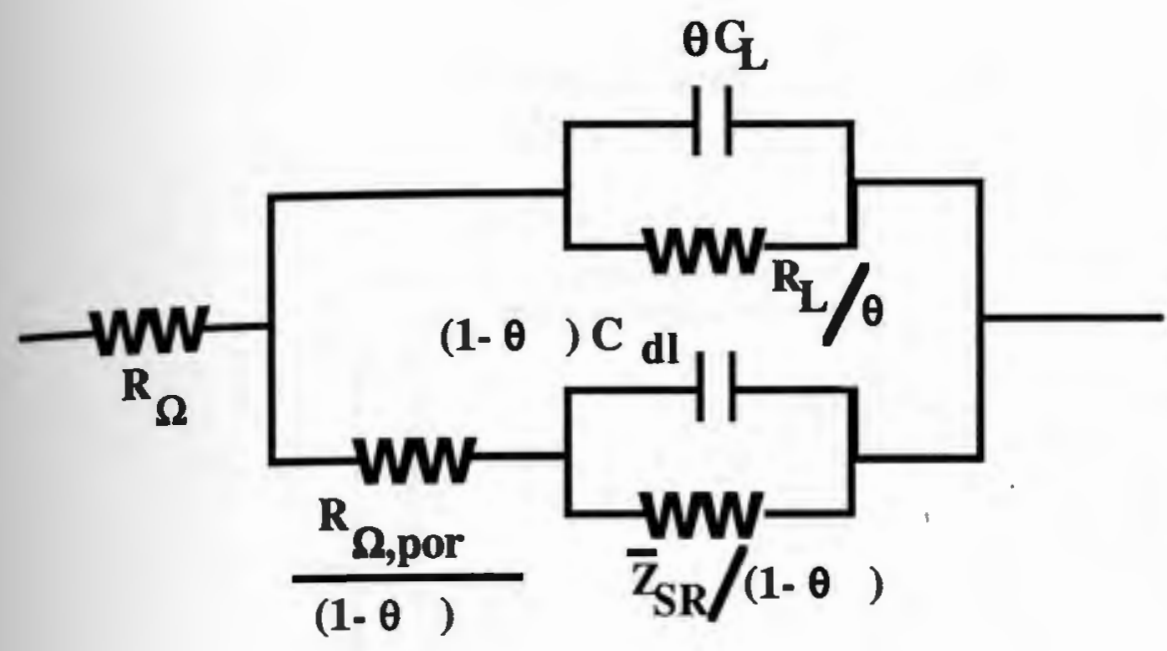

Porous

Layer

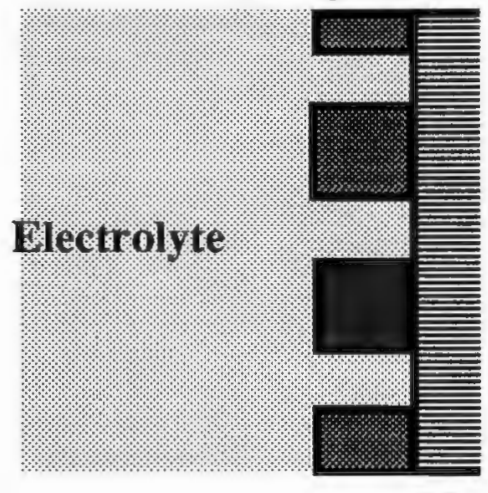

$\mathrm{Me}$

where $\theta=$ inactive surface area or degree of surface coverage,

$$
\begin{aligned}
(1-\theta) & =\text { active surface area, } \\
C_{L} & =\text { capacitance of coating or of the inactive surface area, } \\
R_{L} & =\text { resistance of the coating layer, } \\
C_{d l} & =\text { double layer capacitance of the metal/coating interface, } \\
Z_{S R} & =\text { impedance of the metal/coating interface, } \\
R_{\Omega} & =\text { solution resistance, and } \\
R_{\Omega, p o r} & =\text { pore resistance due to the electrolyte penetration. }
\end{aligned}
$$

Figure 9. Inhomogeneous 3-D model for a coating with defects and in presence of corrosion products. 


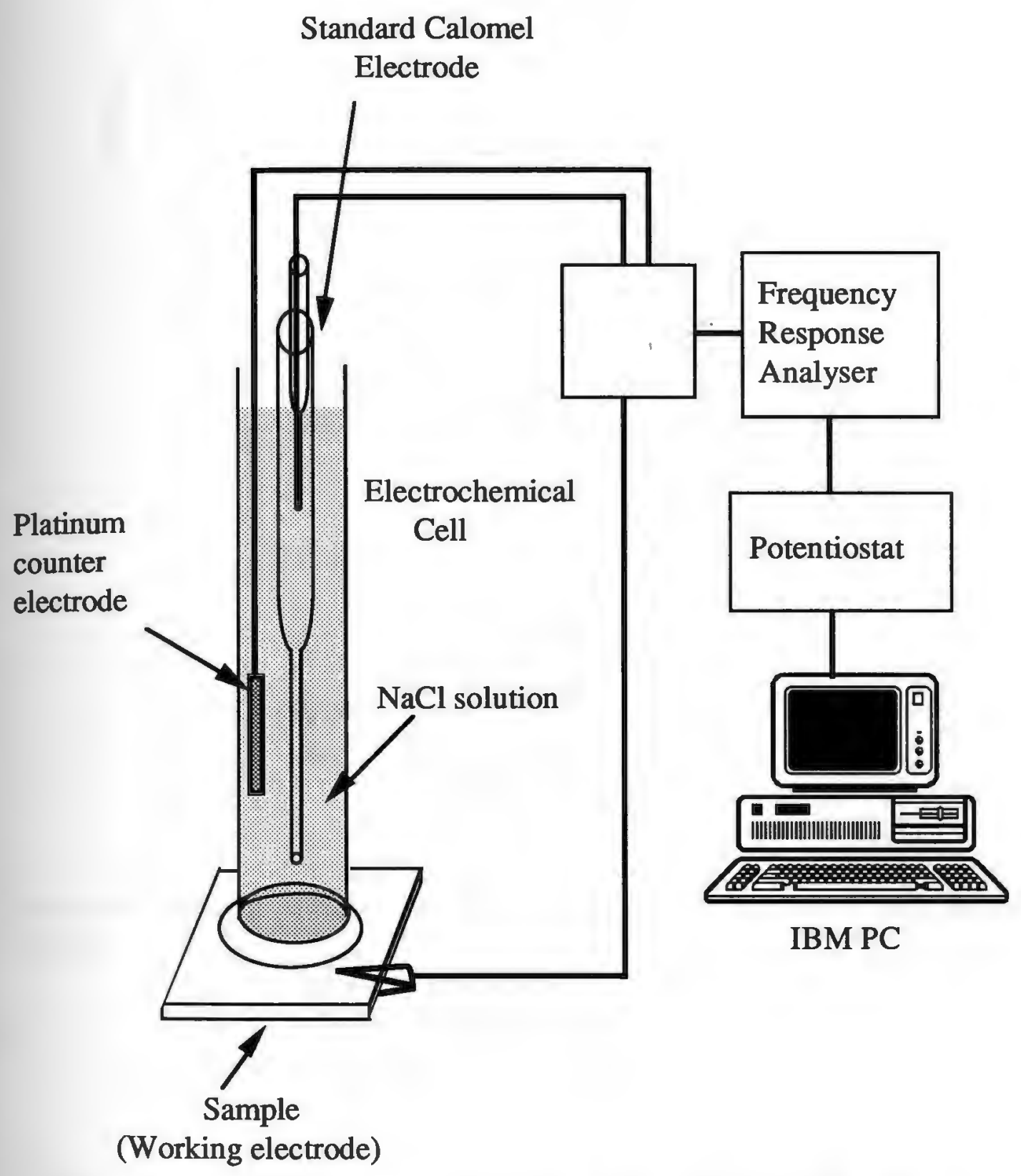

Figure 10. Apparatus for measuring the impedance of an electrochemical cell. 


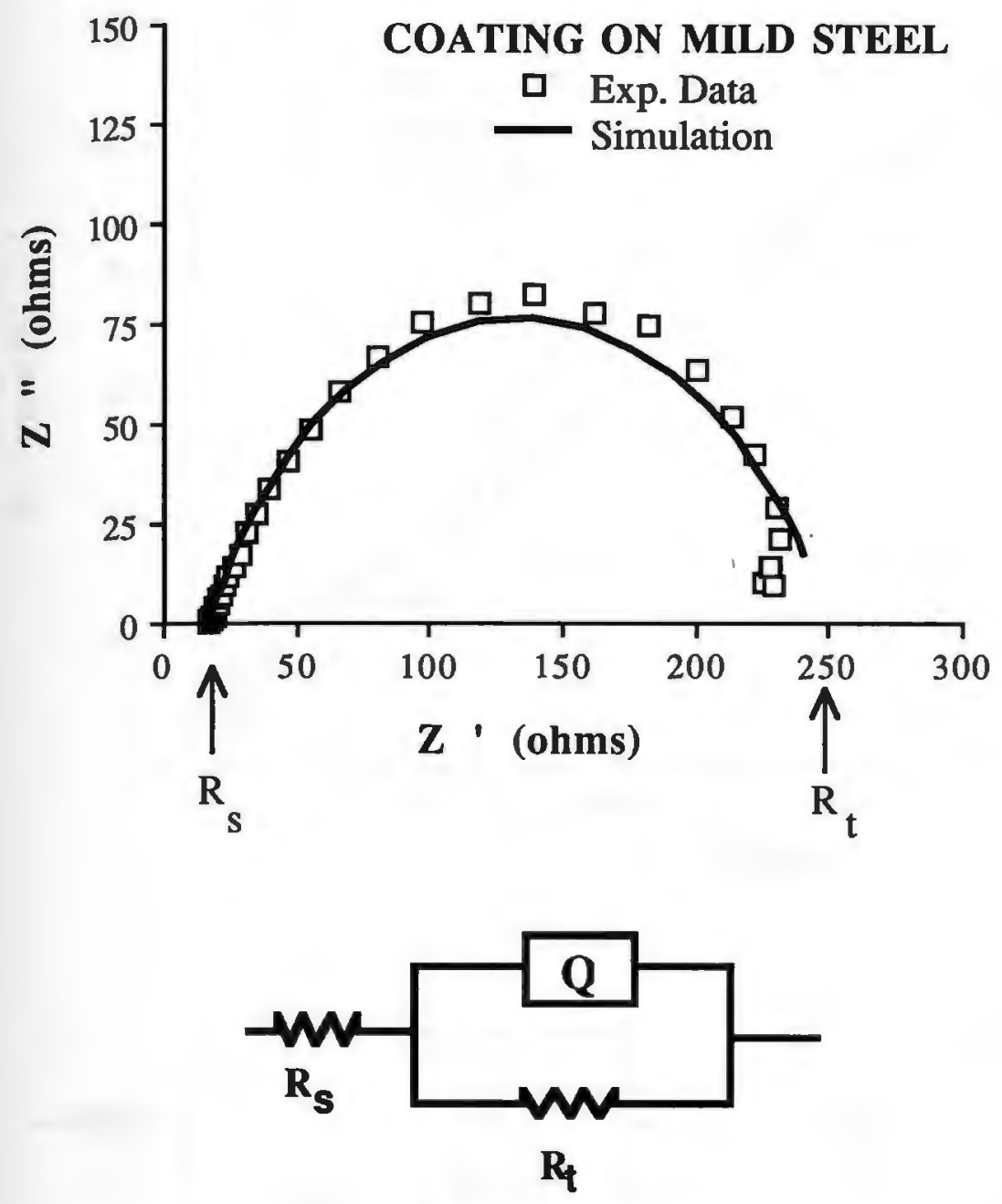

Equivalent circuit model for impedance behavior shown on Nyquist plot where;

$$
\begin{aligned}
\mathrm{R}_{\mathbf{S}} & =\text { solution resistance } \\
\mathrm{R}_{\mathrm{t}} & =\text { charge transfer resistance, and } \\
\mathrm{Q} & =\text { constant phase element }
\end{aligned}
$$

Figure 11. Typical Nyquist plot of simulated data from modeling procedure and the experimental data. 

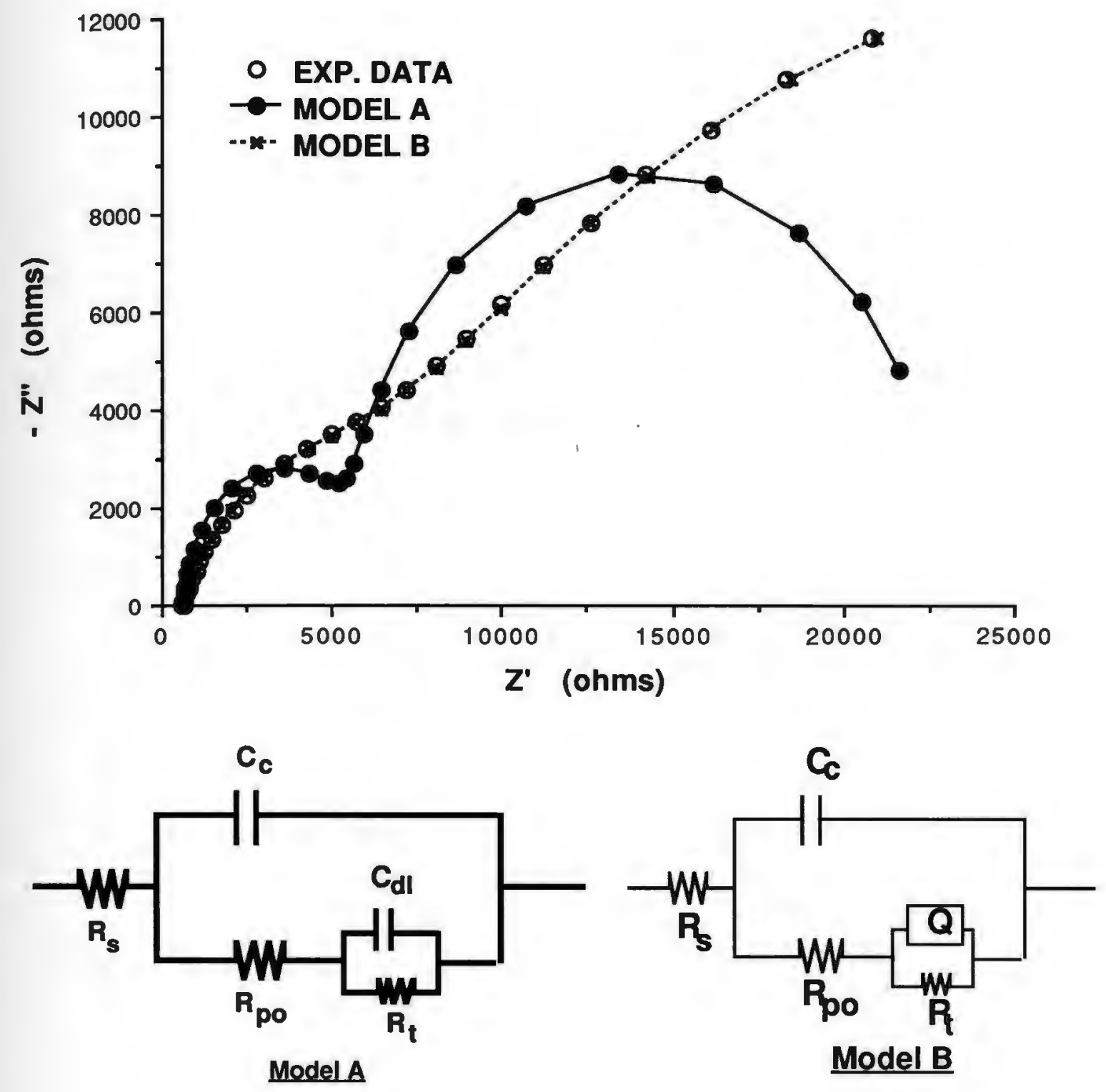

Figure 12. Typical plot of simulated data from EIS modeling procedure shows quality of fitting from two different equivalent circuit models. 
AN IMPEDANCE STUDY OF CARBON FIBER VINYL ESTER COMPOSITE 


\section{ABSTRACT}

The electrochemical behavior of a carbon fiber/vinyl ester composite in $0.5 \mathrm{~N} \mathrm{NaCl}$ solution was investigated. The technique chosen for the study was electrochemical impedance spectroscopy (EIS) which enables time dependent data to be acquired non destructively on single samples. The data from the measurement technique is also amenable to modelling by passive electrical circuit elements. Negative potentials were applied to the composite material to simulate galvanic coupling of metals to it. The impedance of the material as a function of time and applied negative potential was measured. The data was adequately modelled by passive circuit elements. It was found that increased damage to the composite was induced by more applied negative potentials, as cathodic reactions were increased with decreasing potential. At a potential of $-1.2 \mathrm{~V}$ (SCE) holes were found in the composite surface after 90 hours of exposure. The pore resistance determined from the model used to fit the impedance data was found to offer a damage monitoring criteria for the composite material. 


\section{INTRODUCTION}

Non-corrosion related blistering of glass fiber/polymer matrix composites in the marine environment is well known, and is thought due to an osmotic process which is diffusion controlled[1]. Water molecules from the environment diffuse into the polymer matrix under the influence of a concentration gradient existing between the initial moisture content in the composite and its saturation value. Combination of diffusing water molecules with water soluble material in the polymer forms a new concentrated solution which resides in pores and in turn creates an osmotic pressure with moisture in the composite. This pressure draws more water into the pores, creating further increase in localized pressure. As the osmotic pressure exceeds the yield stress of the resin, blisters form. No electrochemical process is thought to be involved in blisters formation for glass fiber based/ polymer composites.

Previous studies on the corrosion behavior between a graphite/polymer composite and metals, observed that galvanic corrosion can also induce blisters [2]. The galvanic interaction between a carbon fiber vinyl ester composite and anodically active metals such as steel and aluminum 2014 rapidly initiated blisters[2,3]. Over the same time period of exposure, up to three months, no blistering was observed in the composite in the absence of a galvanic coupling with metal. The site of the blisters was over the location where a glass cross weave in the uni directional carbon fiber weave was closest to the exposed composite surface. A schematic diagram of the cross section of the composite indicating the fiber locations is shown in figure 1. The larger the separation on 
the galvanic series between the cathodic carbon composite and the active coupled metal, the more rapidly blisters form and more metallic corrosion observed.

One major difference between diffusion controlled blisters in glass fiber composites and the electrochemically induced blistering in carbon fibre hand-prepared composite was the $\mathrm{pH}$ of blister fluid. It was 4 for blisters induces by osmotic pressure in fiber glass based composites and 11 for electrochemically induced blisters in the carbon fiber based composite.

The objective of this study was to observe the role of applying potentials ( $\mathrm{E}_{\mathrm{app}}$ ) on the electrochemical behavior of a carbon fiber based composite. Several scenarios are possible. The first would involve diffusion limited reactions as the polymer film separating the carbon from the environment retards diffusion of cathodic reaction species to the reaction site within the composite. A fully saturated composite would control the cathodic reaction and a limiting current would result. The composite would in this case not be damaged in the sense that the electrochemical reaction has not initiated a physical separation of the polymer material, as is in the case when blisters are formed and physical damage is then present. In a second case, it is suspected that at potentials more negative than the composite rest potential (Ecorr) cathodic reaction at the carbon fibers initiates damage in the polymer matrix in the form of blisters or other defects, enabling the carbon fibers to increasingly become Alectrochemically active as a cathode reaction site.

The potentials chosen for this study simulated galvanic coupling of different anodically active metals, e.g. low alloy steels 
and aluminum alloys, to the composite and also when cathodic protection is applied to a system containing coupled metals and composites.

The variation in electrochemical behavior of the composite with time at fixed values of $E_{a p p}$ will be determined by measurements utilizing impedance spectroscopy. Many studies have been conducted to evaluate the corrosion behavior of organic coatings placed on aluminum and steel. Using the sophisticated technique of electrochemical impedance spectroscopy (EIS), models of corrosion behavior for coated aluminum and steel had been proposed by various authors [4,5]. Generally, coated steel and some aluminum alloys can be represented by Model 1 shown in Figure 2, and most coated aluminum by Model 2, also shown in Figure 2 .

As an initial basis of modeling the equivalent circuit of a composite coupled with metal, the general model was used ( see Figure 2 ). A schematic diagram of the composite is shown in figure 1 for reference of the circuit elements to physical entities.The equivalent circuit consists of $R_{S}$, the solution resistance; $C_{c}$, the capacitance of the matrix polymer separating the conductive carbon fibers from the environment; $R_{p o}$, the pore resistance of the matrix polymer due to the penetration of electrolyte from the surface through to the conductive fibers ; and $Z_{\mathrm{if}}$, the general impedance behavior of the metal/coating interface. In this study, $Z_{i f}$ represents the impedance behavior of the interphase region between the carbon fiber and moisture. Of particular interest was to determine whether a specific model can be used to generalize the composite coupled with metals. From a previously proposed blistering mechanism (2), 
particular passive elements for the model were predicted. It was expected that the impedance spectrum will show diffusion behavior at low frequency. Therefore, model 1 is not expected to represent the experimental data in this case.

Finally, a measurable damage criteria characteristic representing composite damage was sought. Initial $\mathbf{R}_{\text {po }}$ values for coatings was previously found not to show any correlation with their long-term behavior [5]. However, this parameter , $\mathbf{R}_{\mathbf{p o}}$, varies with the immersion time of the coating in the solution. In this case, pore resistance could possibly be a measure of the physical damage to the polymer matrix material. When the value of $R_{\text {po }}$ decreases the assumption could be made that the matrix is either being removed or becoming so porous as to be non effective as a barrier to moisture permeation. In effect the carbon fibers are gradually uncovered and eventually freely acting as a cathode. The value of $R_{p o}$ as a function of time determined from application of the passive circuit models was therefore investigated as a damage monitoring characteristic of physical damage in the composite initiated by electrochemical reactions. The relationship of Rpo with time was obtained using nonlinear regression which could be used to predict the time for physical damage initiation of the polymer matrix. Other data monitored includes current as a function of time. A correlation of $\mathrm{R}_{\text {po }}$ with current would indicate the polymer film over the carbon fibers is controlling the cathode reaction rate. These results will be discussed. 


\section{EXPERIMENTAL PROCEDURE}

Sample Preparation

Samples of a carbon fiber vinyl ester composite described previously (2) with dimensions $2.54 \mathrm{~cm}$ by $2.54 \mathrm{~cm}$ by $0.635 \mathrm{~cm}$ thick were used. A schematic diagram of a cross section of the composite is shown in figure 1. A unidirectional carbon fiber mat was held together by a glass fiber cross weave. Both the carbon fibers and the glass fibers regularly approached the surface in a sinusoidal wave, but at $90^{\circ}$ to each other. The total fiber volume fraction, both carbon and glass fibers, in the vinyl ester polymer matrix is $26 \%$. The volume ratio of glass fibers to carbon fibers in the composite was 1:4. Prior to each experiment, the surface of specimens were degreased with acetone and rinsed with deionized water. This treatment was not detrimental to the composite.

Experimental Setup

The electrochemical cell is schematically shown in Figure 3 and consisted of a test specimen and spherical glass joint clamped together. The area of the working electrode exposed to the electrolyte ( $3.5 \% \mathrm{NaCl}$ ) was $1.767 \mathrm{~cm}^{2}$. A platinum sheet and a standard calomel electrode (SCE) served as counter and reference electrodes, respectively. Impedance measurements were performed with a Solartron 1250 frequency response analyzer coupled to a Princeton Applied Research 273 potentiostat interfaced to an IBM PS2 computer. Electrochemical impedance spectroscopy ( EIS ) measurements in the frequency range $100 \mathrm{KHz}$ to $0.1 \mathrm{~Hz}$ were conducted at open-circuit potential, measured at $0.256 \mathrm{~V}$ (SCE), and under potentiostatic control potentials of $-0.65 \mathrm{~V}$ and $-1.20 \mathrm{~V}$ (SCE) 
for exposure periods up to 90 hours. A logarithmic repetition of 7 frequency points per decade was chosen. The amplitude of the sinusoidal system perturbation was $5 \mathrm{mV}$. The current at the end of each EIS test was measured. Transfer function analysis by standard software was performed applying non-linear fit routines. Analysis of Impedance Data

Each impedance spectrum was displayed as both a Bode plot ( $\log |\mathrm{Z}|$ vs $\log \mathrm{f}$, and phase angle vs $\log \mathrm{f}$ ) and as a Nyquist plot ( $\mathrm{Z}$ vs $\left.Z^{\prime}\right)$. In a Bode plot the capacitive and resistive regions are clearly distinguishable, and the frequency dependence of the phase angle can be easily noticed. Visual inspection of the Nyquist plot was employed to predict the equivalent circuits for the composite . Values of the parameters in the equivalent circuit were determined using the Non-Linear Least Square Fit ( NLLSF ) analysis readily available in the commercial software. This technique is very useful in analyzing convoluted dispersions especially those having two overlapping semi-circles or a straight line overlapping a semi-circle [6].

\section{RESULTS AND DISCUSSION}

\section{Circuit Analysis / Equivalent Circuit}

Two different models were proposed initially to simulate the impedance behavior of carbon fiber vinyl ester composite at applied potential, see Figure 4. Model A, similar to other models proposed previously and shown as model 1 , figure 2 , was found not to fit the experimental data. This was predicted initially due to the diffusion based degradation mechanism operating for the polymer matrix. Model A is limited to an ideal capacitive behavior at both the vinyl 
ester/solution interface and at the carbon fiber/moisture interface. In this case the model is not accurate because of the composite physical properties such as cracks and pores, and the diffusion of water and migration of ions through the defects inside the composite. Better simulations of the experimental data were achieved using Model B. A Constant Phase Element (CPE) was used in model B replacing $\mathrm{Cdl}$ in model $\mathrm{A}$. The use of a constant phase element allows diffusion to contribute to the equivalent circuit model for the carbon fiber/moisture interphase region. The vinyl ester/solution interphase region can be represented by the Rpo-Cc sub-circuit. The simulated plots for different Eapp values using this circuit are plotted along with the experimental data in Figures 5 through 7 which are impedance spectrum of the carbon fiber/vinyl ester composite at Eapp values of $0,-0.65 \mathrm{~V}$, and $-1.20 \mathrm{~V}$, after periods of exposure from 0 to 90 hours. A good correlation with model B was found when comparing the experimental and model predictions. Model B was used for all subsequent determination of values of circuit elements such as pore resistance, Rpo.

\section{General Observations}

Initial data for three different values of Eapp shows a general decrease in impedance with negative applied potential increases. In the Nyquist plots, figures $5 \mathrm{a}, 6 \mathrm{a}, 7 \mathrm{a}$, the semi-circle at high frequency becomes increasingly apparent when a negative potential is applied to the composite. Initial values of Rpo determined through NLLSF as a function of time for the three values of Eapp are shown in Figure 8. The pore resistance as determined by application of model B decreased rapidly with decreasing initial applied negative potential. 


\section{Impedance Behavior of the Composite at Open Circuit}

Over the duration of 90 hours at open circuit, the composite exhibited a very high resistance to degradation indicated by little change in both the Nyquist and Bode plots with time. The resistance to charge transfer across the vinyl ester/solution region remains at the order of $10^{6}$ ohms during the 90 hours period. The pore resistance remains constant at the order of 14000 ohms over the same period of time, figure 8 .

Initially the complex impedance diagram ( Nyquist plot ) shows a Warburg-like straight line, figure 4a. This can be interpreted as either part of a large radius semi-circle, or alternatively overlapping between a straight line at low frequency and a semi-circle at high frequency. Only a small deviation from the straight line behavior was found. Bode plots also indicated little variation with time.

The phase angle versus frequency data did not indicate a clear maxima of time constant, figure 4. A small increase in phase angle up to $70^{\circ}$ with frequency was found indicating very non-conducting behavior at frequencies up to $500 \mathrm{~Hz}$. At higher frequency, some electrolytic conductivity is shown as the phase angle varies from $65^{\circ}$ at $1 \mathrm{kHz}$ to $20^{\circ}$ at $100 \mathrm{kHz}$. The conductivity decreases as the frequency decreases. From the impedance data at the start of exposure, little conductivity in the composite is indicated.

However, some ionic conductivity was observed in the Bode plots with increased exposure. A slow decrease from initial values at frequencies below $30 \mathrm{~Hz}$ was noted as exposure progressed, indicating ionic conductivity. This was believed due to the slow 
penetration of water through the polymer matrix. Some microscopic porosity is typically present in the polymer matrix in composites. The diffusion of water is sluggish because the driving force to induce this action is solely due to the concentration difference between the initial moisture content in the composite matrix and its moisture saturation value. This is shown on the Bode plots as the deviation of the phase angle from $w^{-1}$ behavior. Through visual and scanning electron microscopy observation, no damage was observed on the exposed surface of the composite (7).

Impedance Behavior of the Composite at Eapp values of $0.65 \mathrm{~V}$ and $-1.20 \mathrm{~V}$

The initial impedance spectra for both applied potentials in figure 5 and 6 show a less resistive behavior in comparison to that of the open circuit potential described above. By fitting the experimental data using the circuit of model $\mathrm{B}$ in figure 4, the values for the pore resistance at the initiation of exposure were 10900 and $7700 \mathrm{ohms}$ for the -0.65 and -1.2 Eapp respectively, while at open circuit the pore resistance was $14050 \mathrm{ohms}$. As time of exposure increases RPO remained constant for the open circuit conditions but decreased when negative potentials were applied as shown in fig7. With more negative or cathodic applied potentials Rpo decreased more rapidly. It was noted that the Rpo value obtained from modelling procedures for the $-1.2 \mathrm{~V}$ Eapp reached a minimum value of $20 \mathrm{ohms}$ between thirty and forty hours of 
exposure. The pore resistance minimum was accompanied by a steep rise in the direct current measured, figure 9.

In addition black particles were found in the electrolyte solution after 50 hours of exposure. At the end of the 90 hours of exposure visual inspection of the $-1.2 \mathrm{~V}$ samples indicated areas located above the closest approach of the carbon fiber weave to the electrolyte were removed leaving small holes $1.5 \mathrm{~mm}$ in diameter in a regular pattern over the surface. Scanning electron microscopy of the regions indicated exposed fibers with no vinyl ester covering them (7). Some fibers were broken and it is suspected that the black particles in the solution were in fact carbon fibers released from the surface as the vinyl ester was removed. The nature of the surface near an attacked region is of small voids interconnecting with the surface. No blisters on the surface of the composite similar to the ones previously reported for galvanic coupling of the composite material with active metals (2) were found in this study at the applied potential of $-1.2 \mathrm{~V}$ for 90 hours.

The high $\mathrm{pH}$ of the blisters found previously (2) suggests that the hydroxyl ion remaining after cathodic reaction involving decomposition of water to form hydrogen at carbon fiber sites reacted at the glass fibers location. Only metals with corrosion potentials below the water decomposition potential initiated blisters when coupled to the composite, indicating that the oxygen reduction cathodic reaction was not effective in blister formation. The hydroxyl ions may have permitted rapid blistering of the composite by osmotic processes near the glass fibers while at the same time an dectrochemical cathodic process occured above the carbon fibers 
located closest to the surface. The increased rate of moisture uptake when the composite was galvanically coupled in comparison to uncoupled data would support the blistering mechanism. In addition, examination of samples from galvanic coupling over exposure periods much longer up to six months did indeed show damage similar to that found in this study over the carbon fiber locations (7). The data suggest that the electrochemical damage of the polymer matrix is independent of sample geometry.

It is suspected that the degradation process of the vinyl ester matrix responsible for holes initiates in the interior of the sample at the carbon fiber/ vinyl ester interphase region and moves slowly outwards towards the electrolyte until the carbon fibers are exposed to the solution. The decreasing Rpo values followed by a constant low pore resistance in the $-1.2 \mathrm{~V}$ sample monitor the condition of the vinyl ester above the carbon fibers as it is slowly removed until fibers are exposed to solution. The pore resistance can provide very important information as it non-destructively monitors in-situ chemical damage from the electrochemical process in the polymer matrix as evidenced by both the physical damage and current measurements, fig 9.

The Bode plots for the applied potentials were generally at lower impedance values than the open circuit data at the start of testing. This behavior suggests that the cathodic reaction was initiated immediately upon the potential being applied. In addition, two maxima of time constants were observed on the Bode plots for Eapp of -0.65 and $-1.2 \mathrm{~V}$, fig 6 and 7. As noted previously, a clear maxima was not found under open circuit conditions. It is suggested 
the two maxima were representative of interphase regions due to the vinyl ester moisture and the carbon fibers moisture regions both affecting the electrochemical reactions.

Applying a negative applied potential to the composite promoted cathodic reaction at the carbon fiber sites. At the potentials and bulk pH of 6 employed in this study, the preferred reaction is reduction of oxygen in solution which is not deaerated. However as noted earlier, at potentials above $-0.65 \mathrm{~V}$ no damage to the composite was found after extended exposure. A reaction possible at potentials of $-0.65 \mathrm{~V}$ is decomposition of water to form hydrogen. An increase in hydroxyl ion content would accompany this reaction. The decreased impedance and pore resistance values at the initial application of negative potentials indicated the moisture required for reaction and consumption to form hydrogen was that originally retained in the composite from manufacturing techniques. An incubation period would be present if moisture diffusing from the surface down to the fibers was the controlling process for the cathodic reaction. The presence of an incubation period would be indicated by impedance values identical to open circuit values for the applied cathodic potentials. However no incubation period was found. It is proposed the initial moisture content contained in the vinyl ester matrix which surrounded carbon fibers formed a carbon fiber/moisture electrochemical interphase region at which a cathodic reaction was supported. At an open circuit potential, the cathodic reaction of hydrogen formation from water is not favoured and moisture content is stable in the vinyl ester resin. The vinyl ester/ 
moisture interphase region then dominates resulting in the Bode plots in figure 5 .

The requirement for water to sustain the cathodic reaction at the carbon fiber location in the composite is met by transport of moisture through the matrix polymer. At open circuit, the difference between saturation level and instantaneous level of moisture in the vinyl ester is the only driving force. When a cathodic reaction in the composite continuously consumes moisture from the area surrounding carbon fibers, namely in the vinyl ester, an electrochemical driving force for moisture transport in the vinyl ester is added to the moisture differential driving force. In addition, the moisture differential driving force due to concentration gradients will remain large due to the constant removal of moisture in the cathodic reaction. As proposed, the decomposition of water in the vinyl ester to form hydrogen at the carbon fibers will not allow an increase in moisture content to saturation levels. An increase in moisture transport rate is expected as a function of more negative potentials increasing the cathodic reaction rate in the composite. Evidence was previously found in support of electrochemical interaction increasing transport rate when galvanically coupled composite gained more weight than the uncoupled composite (8).

With increasing time of exposure at the different Eapp, the phase angle maxima at high frequency shifted to the lower frequencies. Previous studies indicated that polymer swelling due to water uptake was associated with maxima shifts to higher frequencies as capacitance increased (9). In a separate study of the cathodic delamination of polybutadiene coated steel (10) shifts of the 
high frequency maximum to lower frequencies were suggested to result from an increase in the area of metal exposed to the electrolyte. For an epoxy coated steel under cathodic current control (11), phase angle maxima shifts to higher frequencies were associated with increased delamination of the coating - However, it was proposed that the effect of decreasing coating thickness was to produce a phase angle maxima shift to lower frequencies. The stability of the polymer coating separating the cathode from the environment appears to control the phase angle maxima shift. A stable coating will maintain its thickness but diffusion through it will decrease film and charge transfer resistance as the substrate becomes active. Phase angle maxima shifts to higher frequencies will result in this case as found in other studies (11). When the coating is electrochemically degraded and slowly removed, its thickness is effectively decreased. The phase angle maxima then shifts to lower frequencies which supports the calculated thickness effects reported previously (11). The phase angle maxima shift in this study appears to be associated with degradation of the matrix material. The same degradation i.e. polymer dissolution, was also responsible for the low pore resistance values found after 50 hours of exposure.

For the $-0.65 \mathrm{~V}$ Eapp, the values of pore resistance dropped at a decreasing rate during the period of the experiment. Surface damage was found on the sample when examined by scanning electron microscopy in the form of surface separations in the vinyl ester matrix over the carbon fibers (7). No blisters were found for the 90 hours of exposure but were found after 30 days of exposure. As pore resistance appears to characterize polymer degradation, the 
combination of decreasing pore resistance and surface damage would indicate that the decomposition reaction for the vinyl ester initiates at the carbon fiber interface and propagates to the external surface. As the cathodic reaction favoured is decomposition of water to form hydrogen production either intermediate hydrogen ions or hydrogen atoms or alternatively hydroxyl ion byproduct of the reaction would appear responsible for the decomposition of the composite. Further work is currently being conducted on these degradation mechanisms.

\section{CONCLUSIONS}

1. Impedance spectroscopy is applicable to studies of the degradation of carbon fiber composites by electrochemical processes. The degradation can be modelled very well by passive circuit elements.

2. Applying negative potentials typical of metallic coupling to a carbon fiber/ vinyl ester composite produced damage in the composite material which could be non destructively monitored by the pore resistance of the material.

3. Damage prediction can be made for the vinyl ester matrix of the carbon composite from non linear least squares fitting of pore resistance data obtained from modelling of the impedance behavior as a function of time. 
4. The damage to the composite was a result of a cathodic reaction at the carbon fiber/moisture interface. Vinyl ester was dissolved initially at the interface with the carbon fibers and propagated to the external surface. The moisture for the reaction was that originally contained in the composite but was later supplied by diffusion.

\section{LITERATURE CITED}

1. T. J. Rockett, " The Causes of Boat Hull Blisters ", University of Rhode Island Report for U.S. Coast Guard Grant \#1502,1987

2. W. C. Tucker, L. Russell, and R. Brown, " Corrosion Between a Graphite/Polymer Composite and Metals ", J. of Composites, 24, 1990, p92

3. W. C. Tucker, and R. Brown, "Blister Formation on Graphite/Polymer Composites Galvanically Coupled with Steel in Seawater ", J. of Composites, v23, 1989, p389

4. F. Mansfeld, M. W. Kendig, and S. Tsai, "Evaluation of Corrosion Behavior of Coated Metals with AC Impedance Measurements", $\quad$ Corrosion, v38, 1982, p498

5. M. W. Kendig, F. Mansfeld, and S. Tsai, "Determination of the Long Term Corrosion Behavior of Coated Steel with A.C. Impedance Measurements", Corrosion Science, v23, 1983, p317 
6. B. A. Boukamp, Equivalent Circuit - Users Manual, 2nd ed., revised, University of Twente, Netherlands ,1989

7. M. N. Alias, and R. Brown, "Damage to a Vinyl Ester Based Composite from Electrochemical Processes", submitted to Corrosion

8. W. C. Tucker, "Graphite Composites in the Marine Environment", Ph. D. Thesis, University of Rhode Island, 1987.

9. J. F. McIntyre, and H. Leidheiser,Jr., "Resistance Measurements on Thin Film Substrates as a Technique Studying the Deterioration of Coated Metals", Ind. Eng. Chem Prop. Res. Dev, v24, Sept 1985, p348

10. EG\&G Princeton Applied Research Technical Notes AC-2, "Evaluation of Organic Coatings by Electrochemical Impedance Measurements", 1989

11. S. Haruyama, M. Asari, and T. Tsuru, "Impedance Characteristics During Degradation of Coated Steel", in Corrosion Protection by Organic Coatings, ed. M.W. Kendig and H. Leidheiser, The Electrochemical Society, Proceedings vol 872, p197 


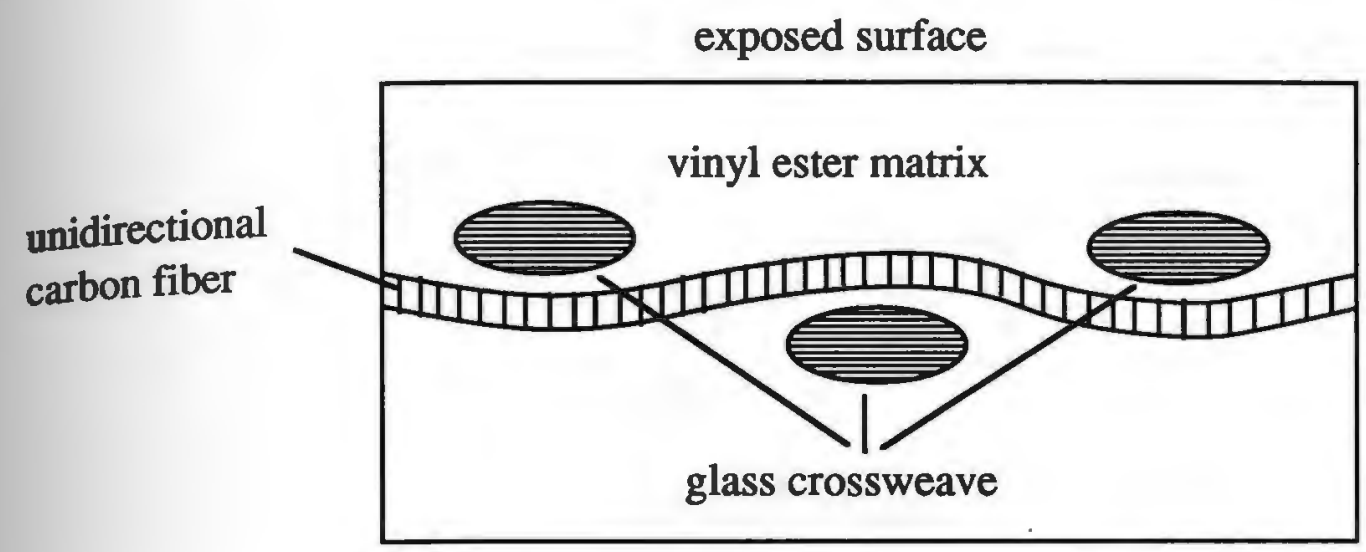

Figure 1. Schematic diagram of carbon vinyl ester composite 


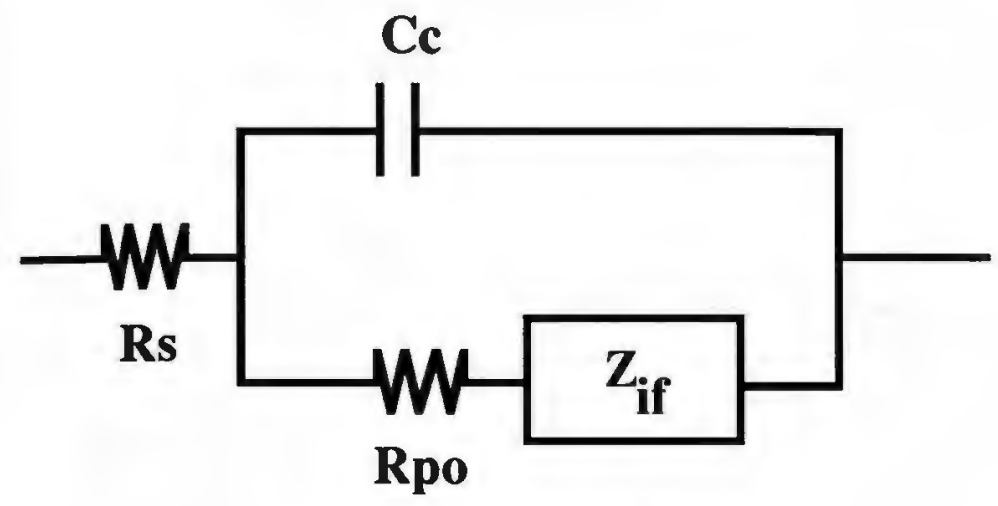

General model

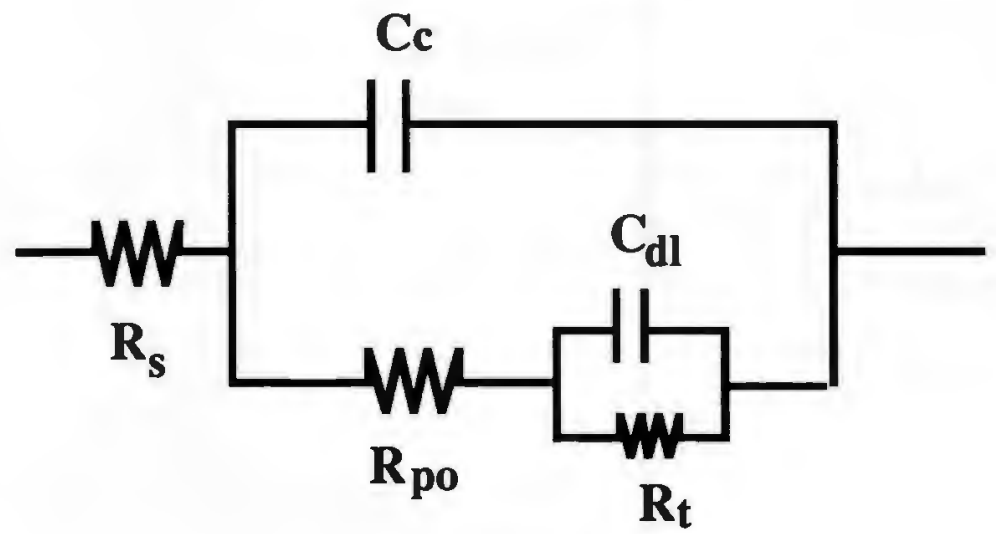

Model 1

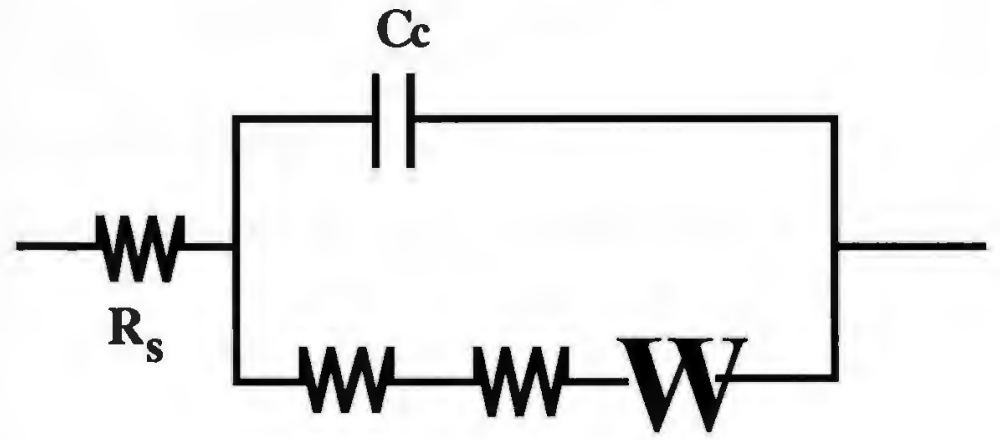

$\begin{array}{lll}R_{\text {po }} & \mathbf{R}_{\mathrm{t}} & \boldsymbol{\sigma}\end{array}$

Model 2

Figure 2. Equivalent circuits as proposed by Mansfeld and Kendig for most polymer-coated metals. 


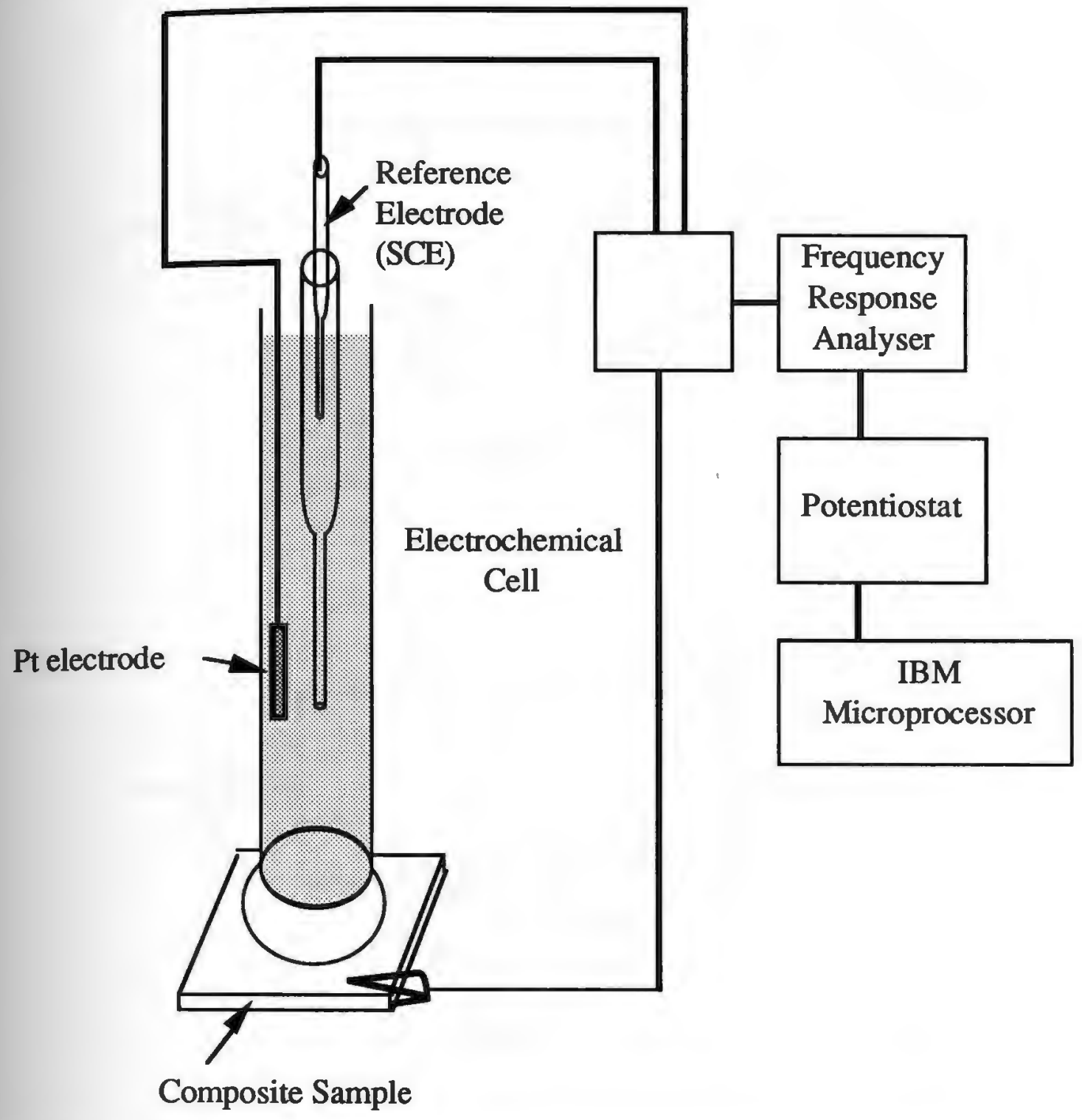

Figure 3. Experimental setup for impedance spectroscopy 


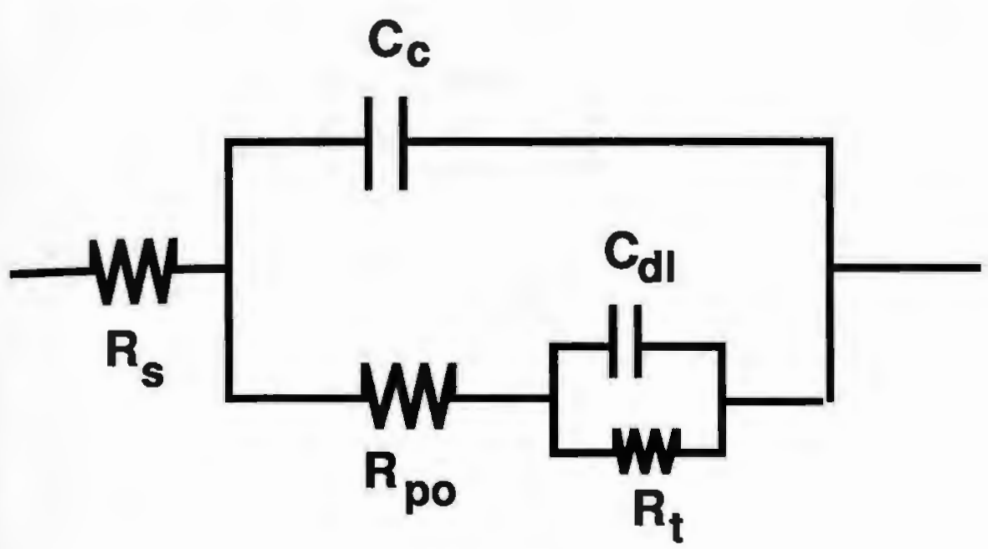

Model A

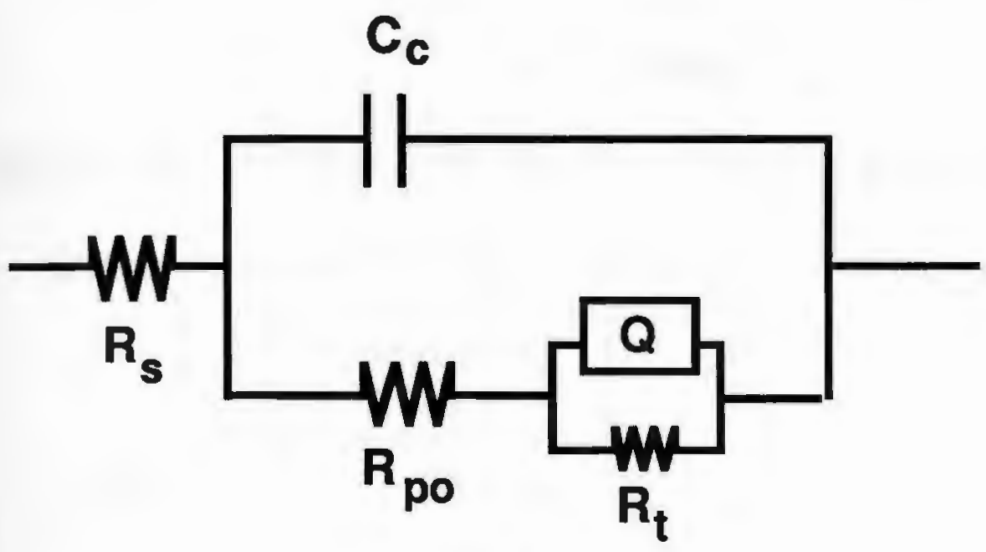

Model B

Figure 4. Equivalent circuit models for simulation of carbon fiber vinyl ester composite in $3.5 \% \mathrm{NaCl}$ solution 


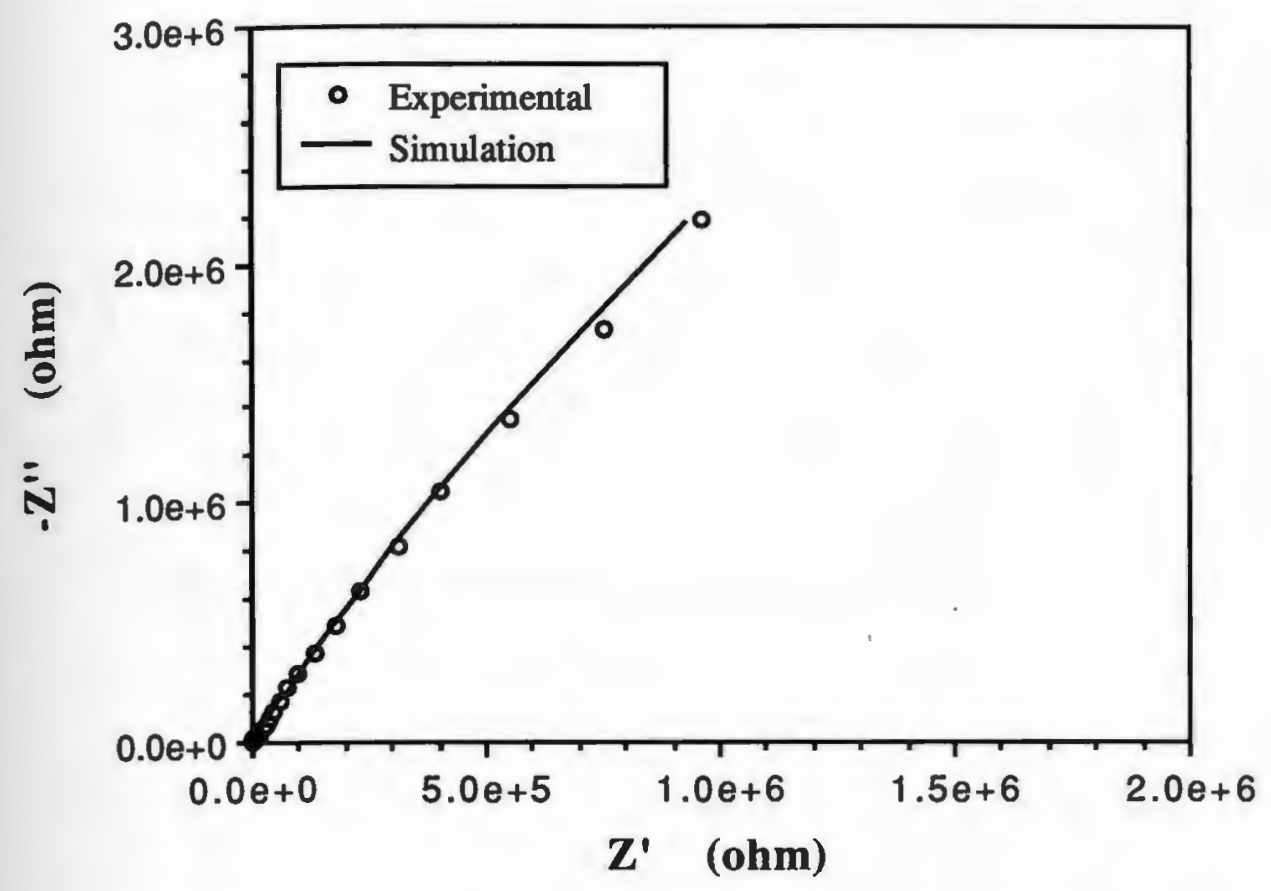

Figure 5a. Nyquist plot for open circuit potential at 0 hour

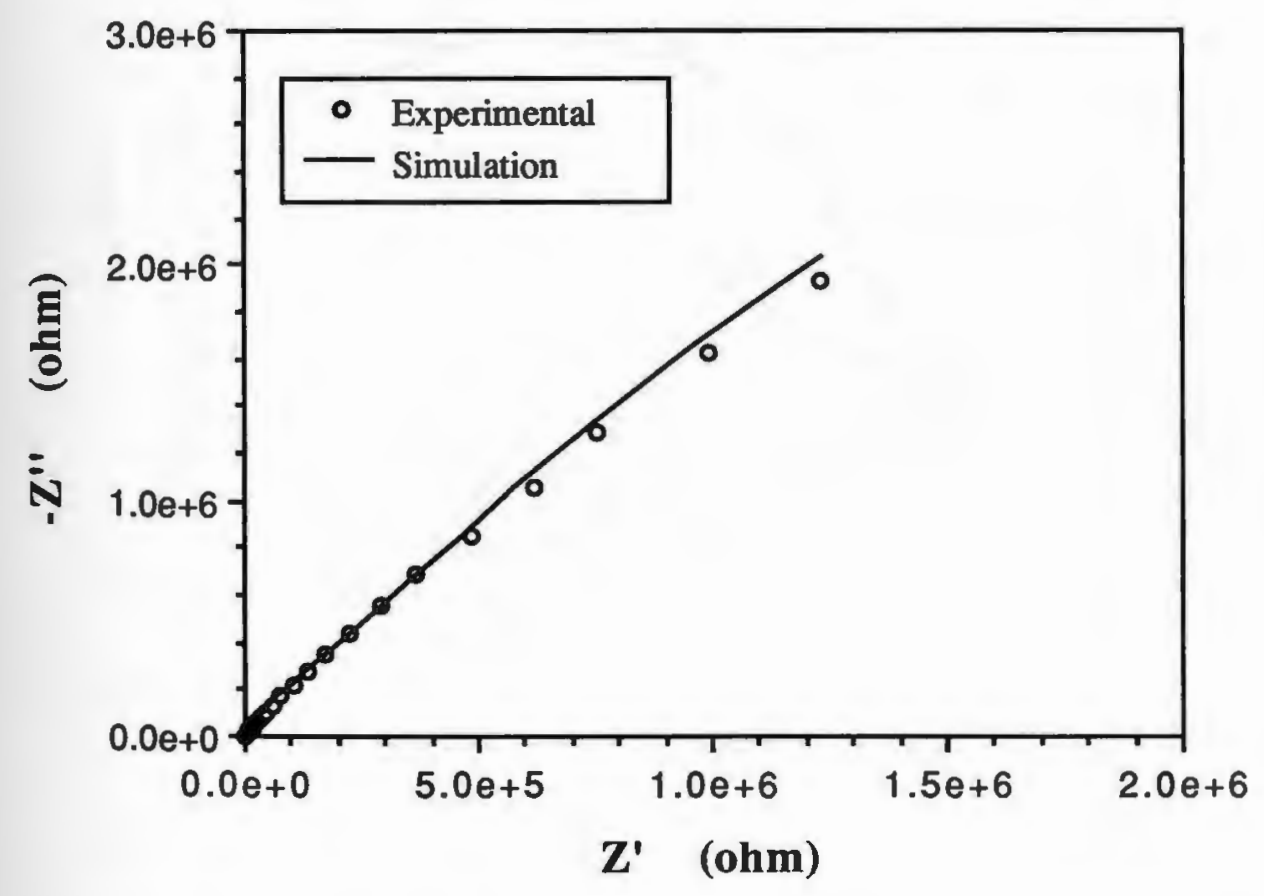

Figure 5b. Nyquist plot for open circuit potential at 90 hours 
5c.

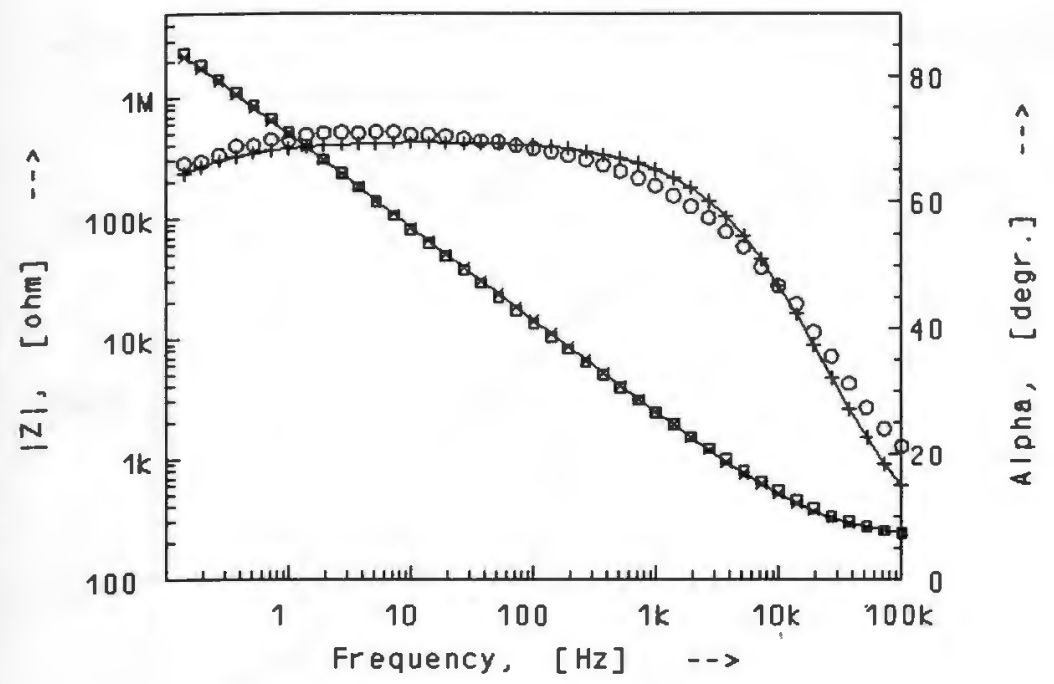

$5 d$.

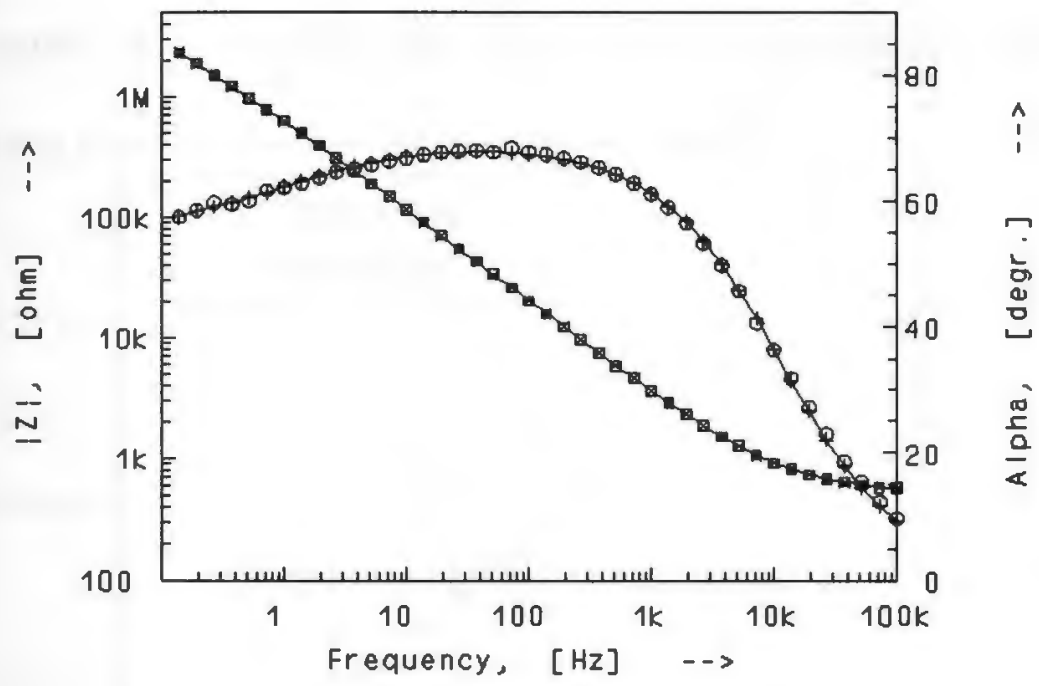

Figure 5c-d. Bode plots for open circuit potentials at $0 \mathrm{~h}$ and $90 \mathrm{~h}$, respectively, Squares and circles are the experimental $|Z|$ and phase angle respectively, and $x$ and + are the corresponding simulated values. 


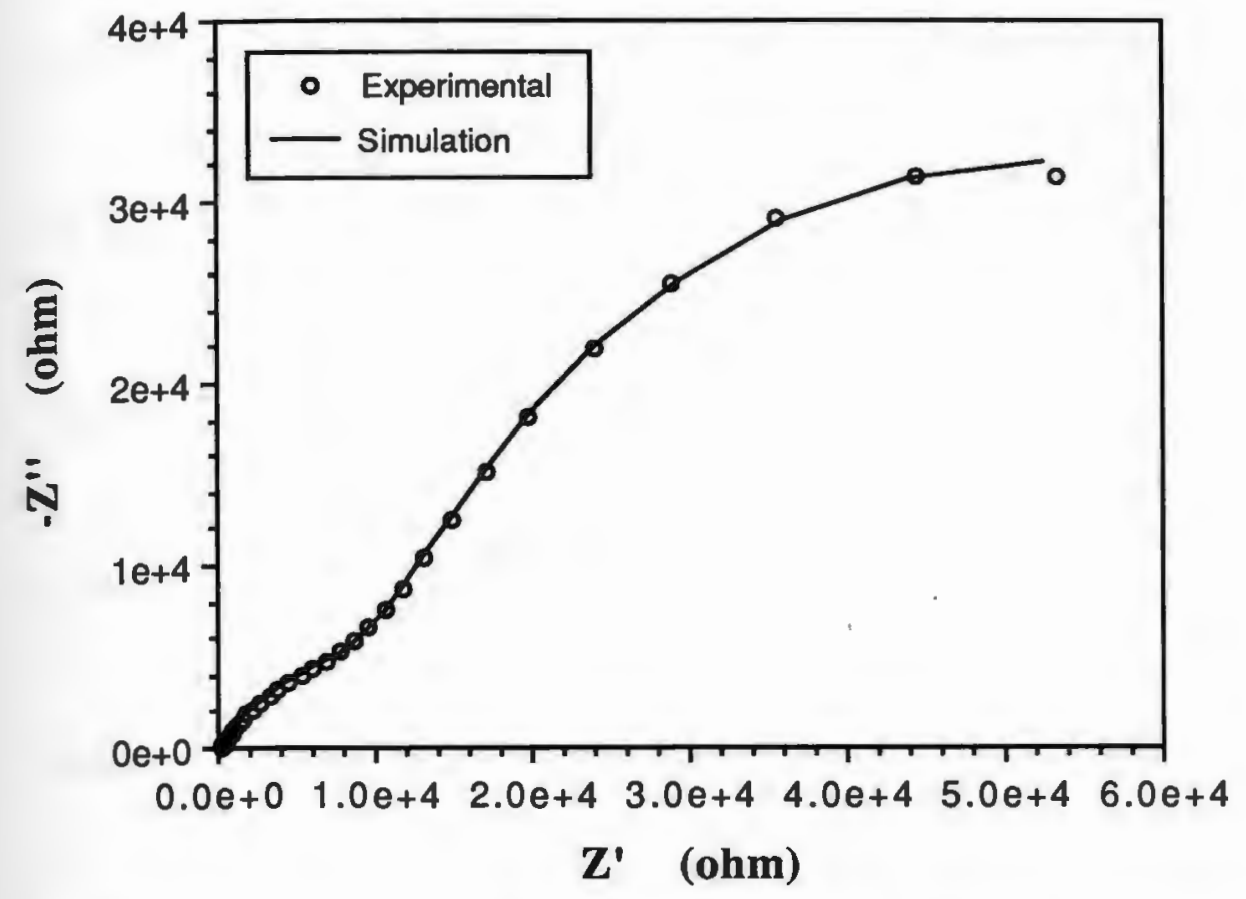

Figure 6a. Nyquist plot for -0.65 volts applied potential at 0 hour

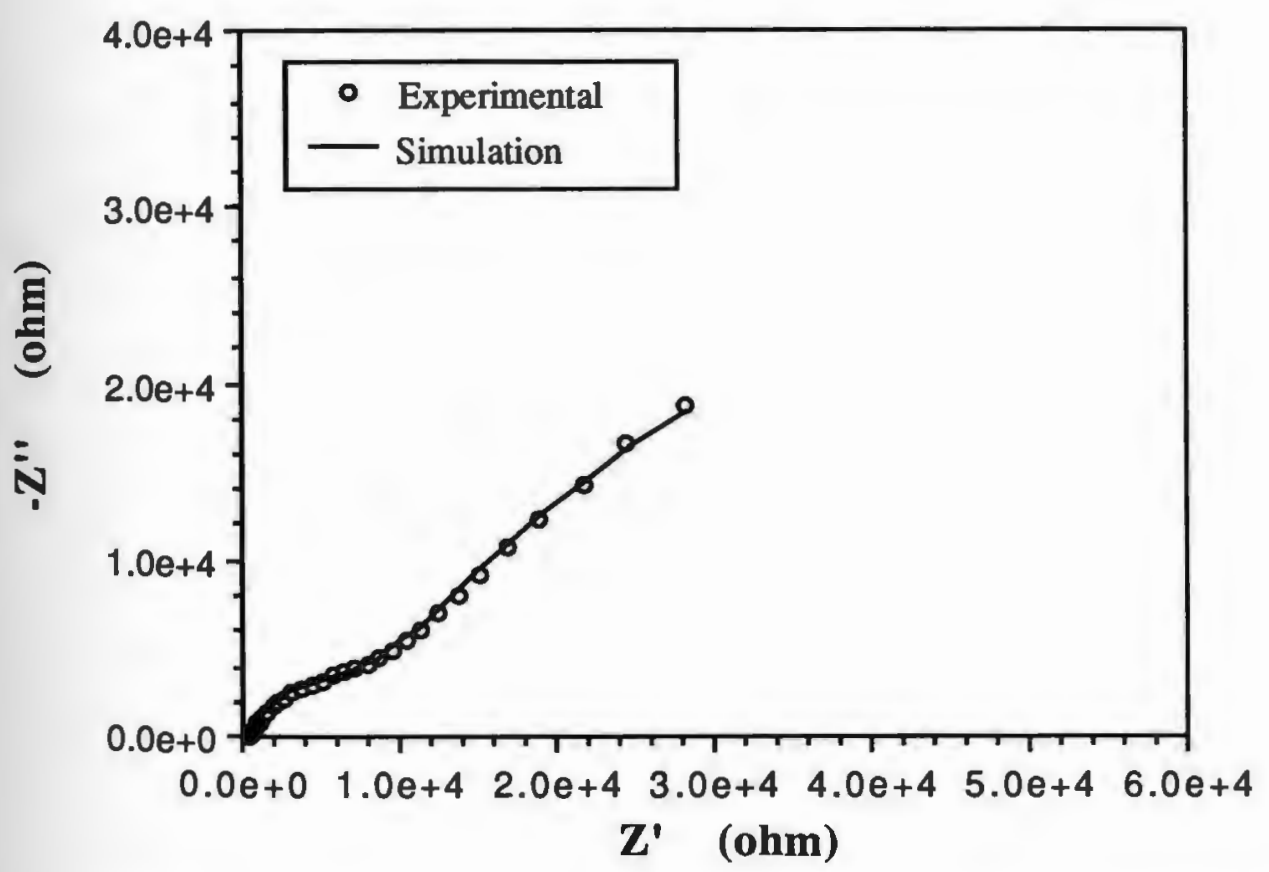

Figure $6 \mathrm{~b}$. Nyquist plot for -0.65 volts applied potential at 30 hours 


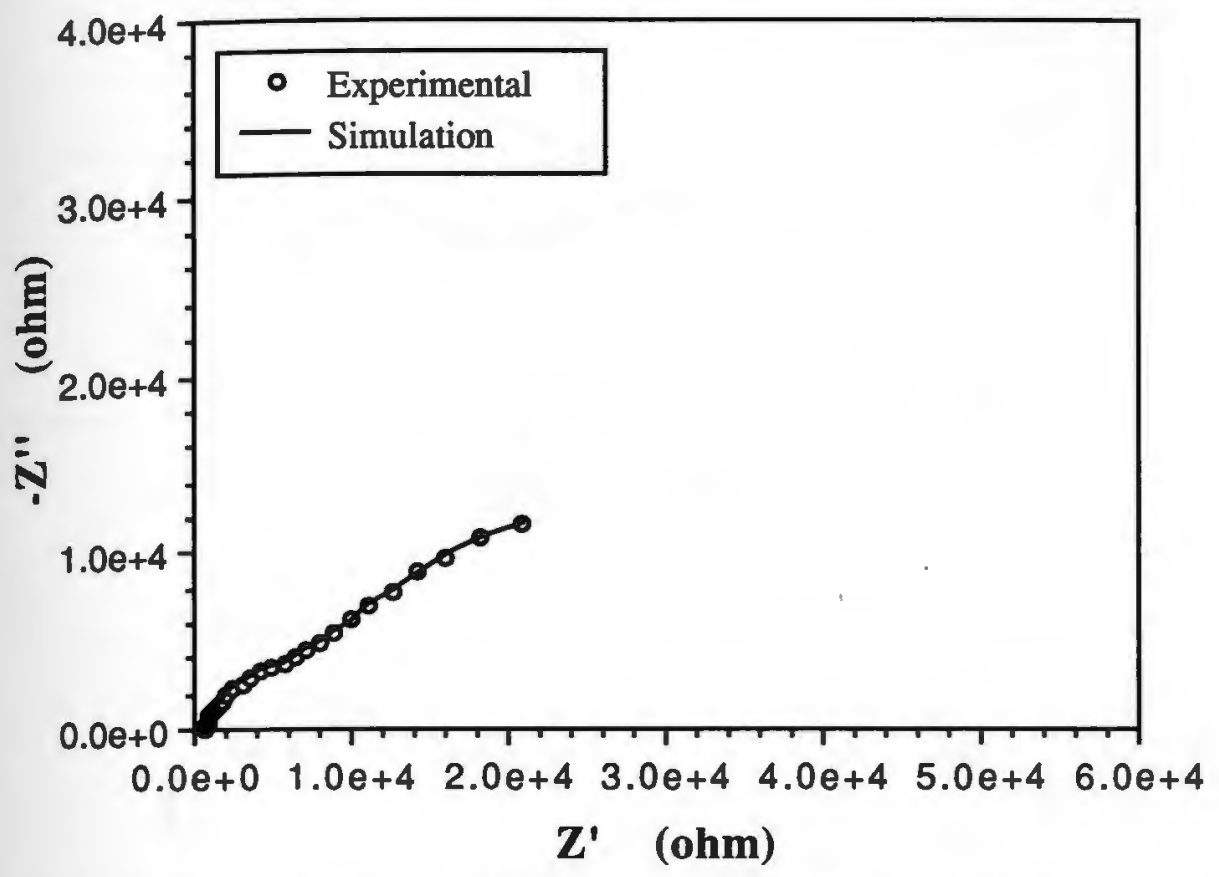

Figure 6c. Nyquist plot for -0.65 volts applied potential at 90 hours 
$6 d$.

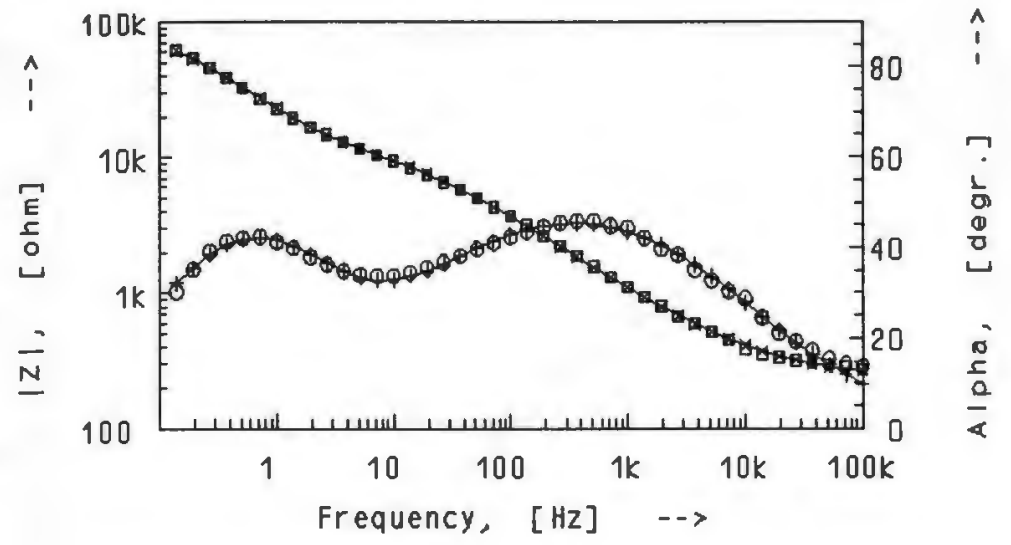

$6 e$.

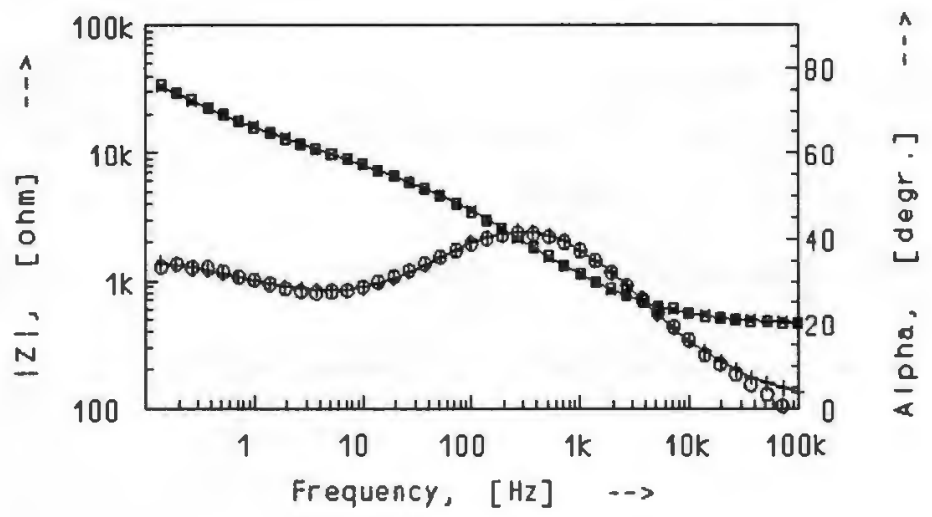

$6 f$.

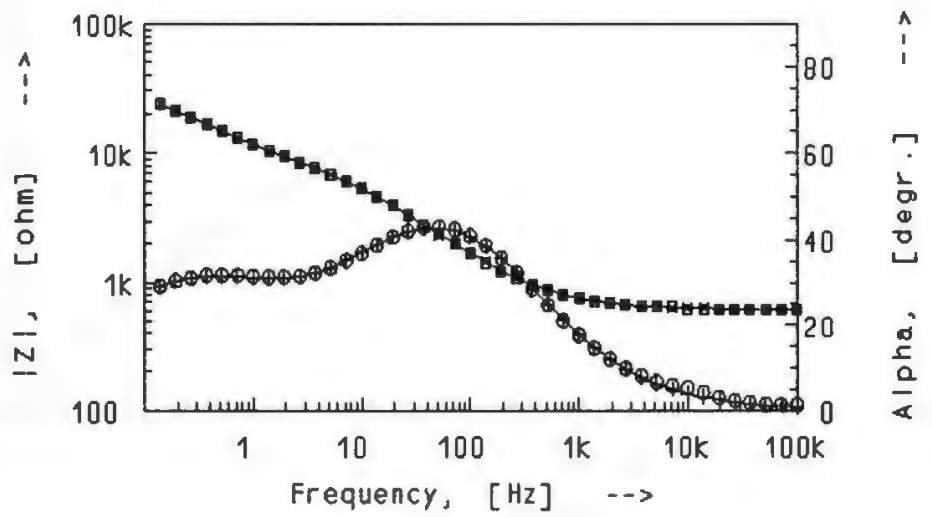

Figure 6d-f. Bode plots for $-0.65 \mathrm{~V}$ applied potential at 0,30 , and 90 hours, respectively. Symbols meaning as described previously. 


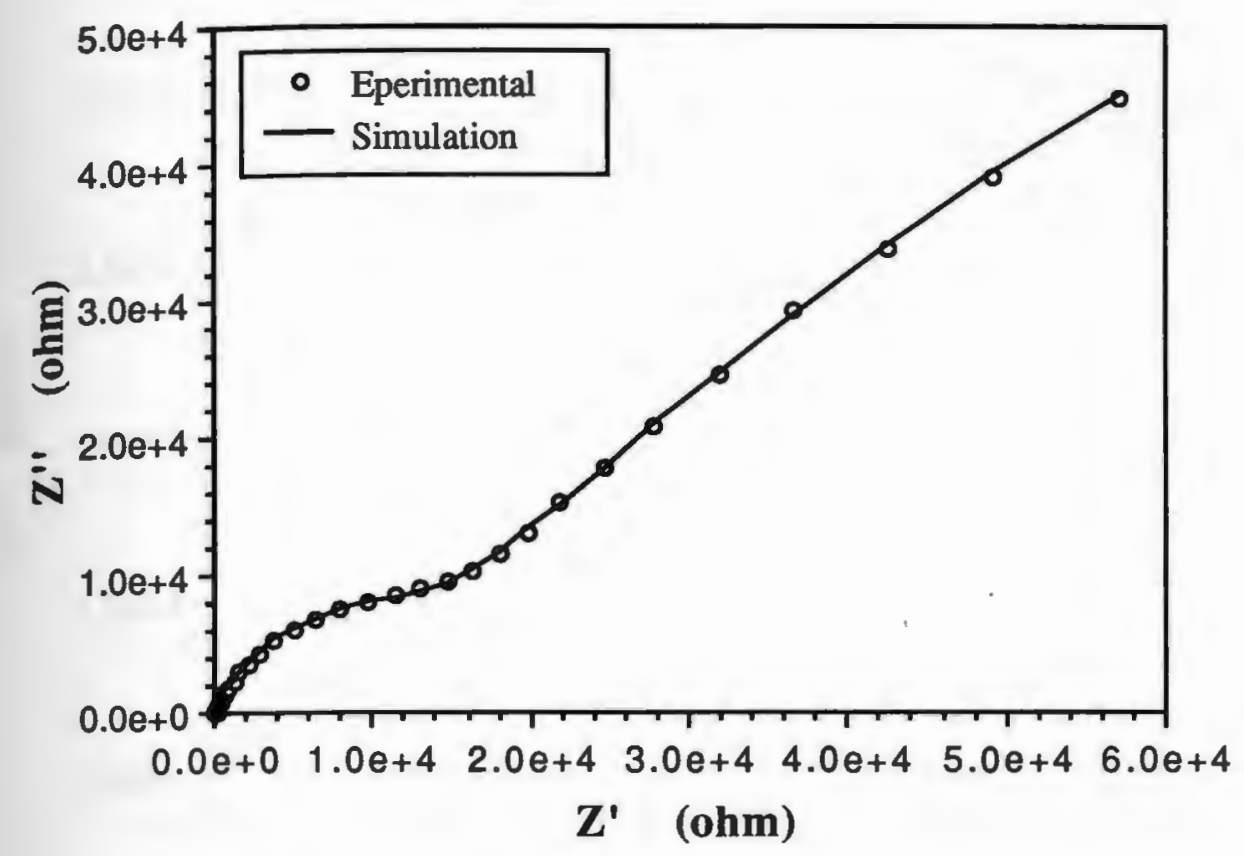

Figure 7a. Nyquist plot for -1.20 volts applied potential at 0 hour

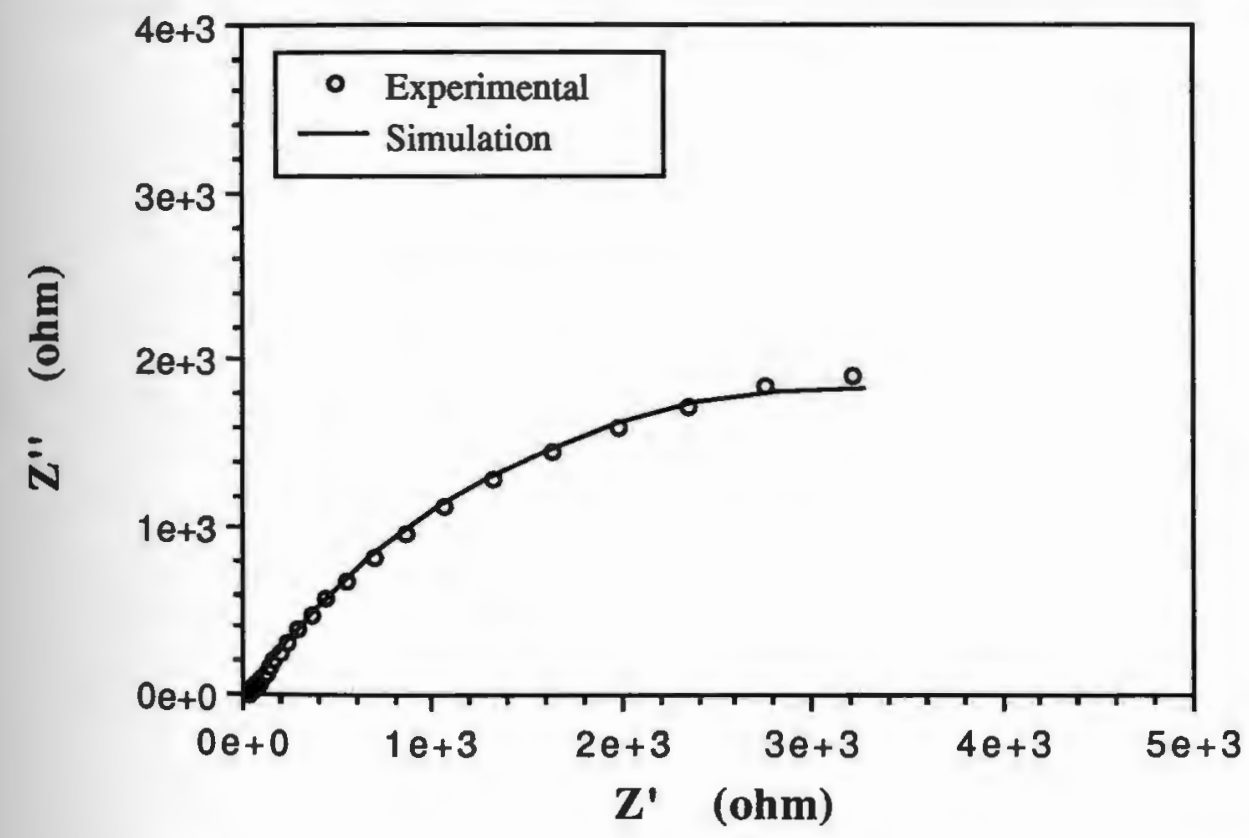

Figure $7 \mathrm{~b}$. Nyquist plot for -1.20 volts applied potential at 30 hours 


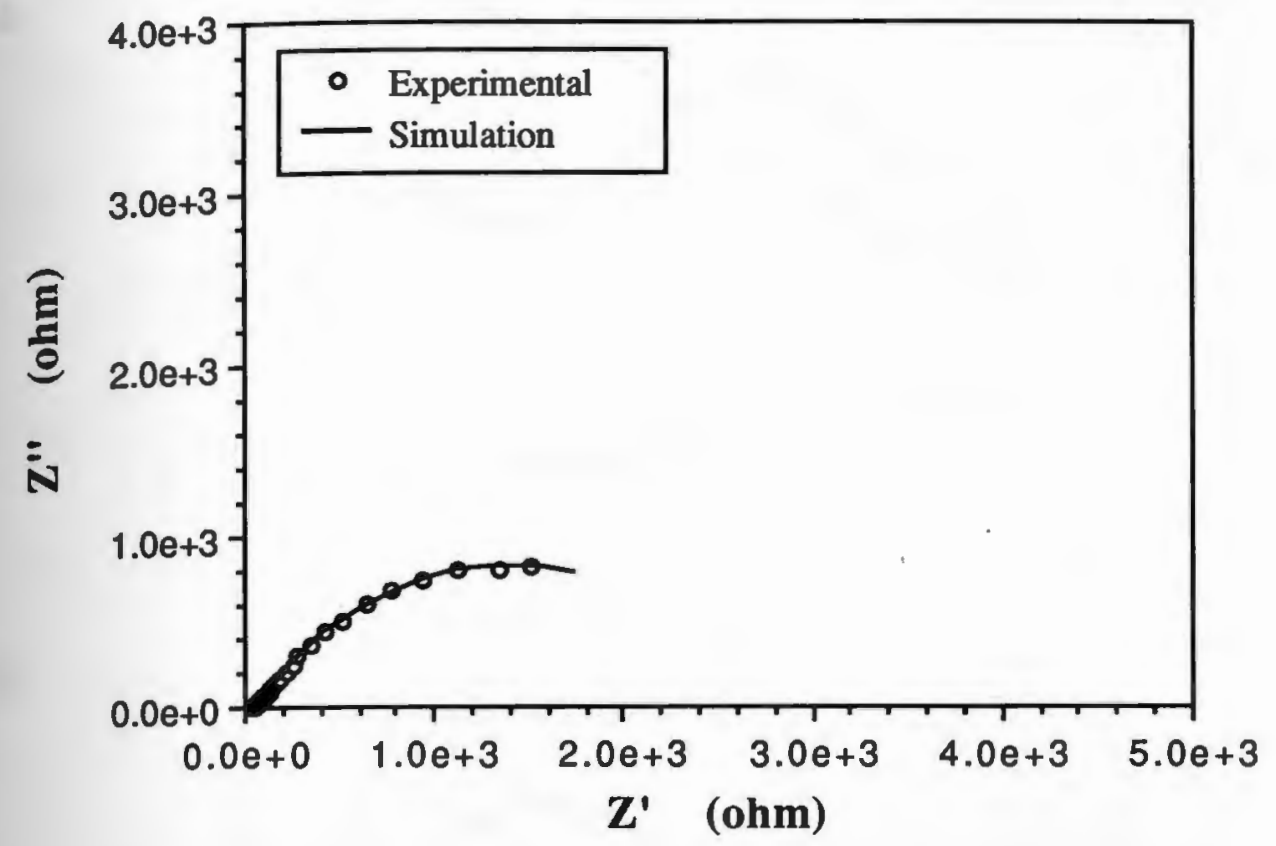

Figure 7c. Nyquist plot for -1.20 volts applied potential at 90 hours 
$7 d$.

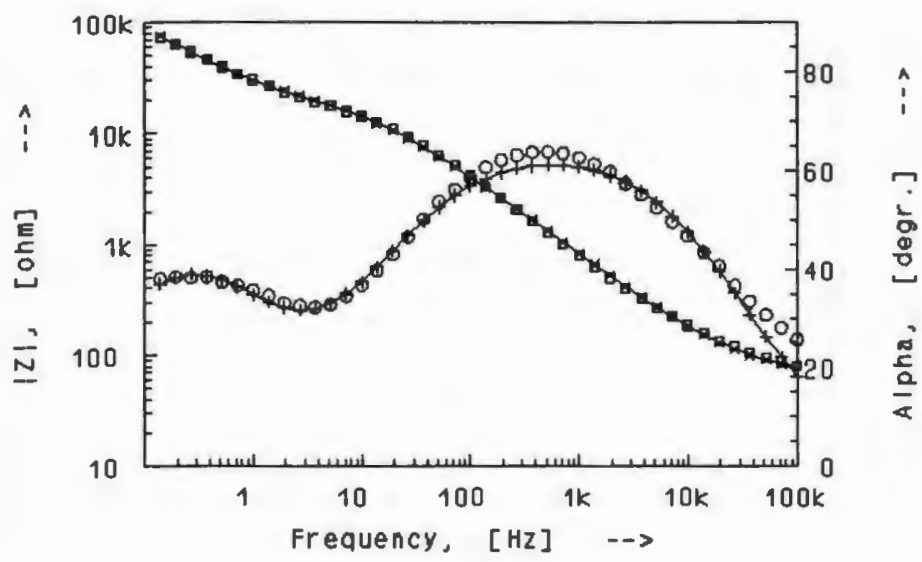

7 e.

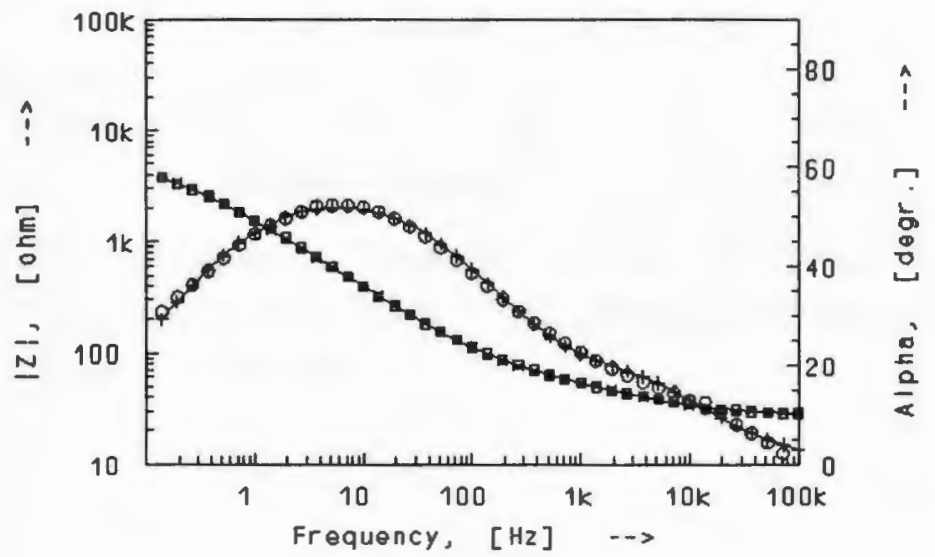

$7 f$.

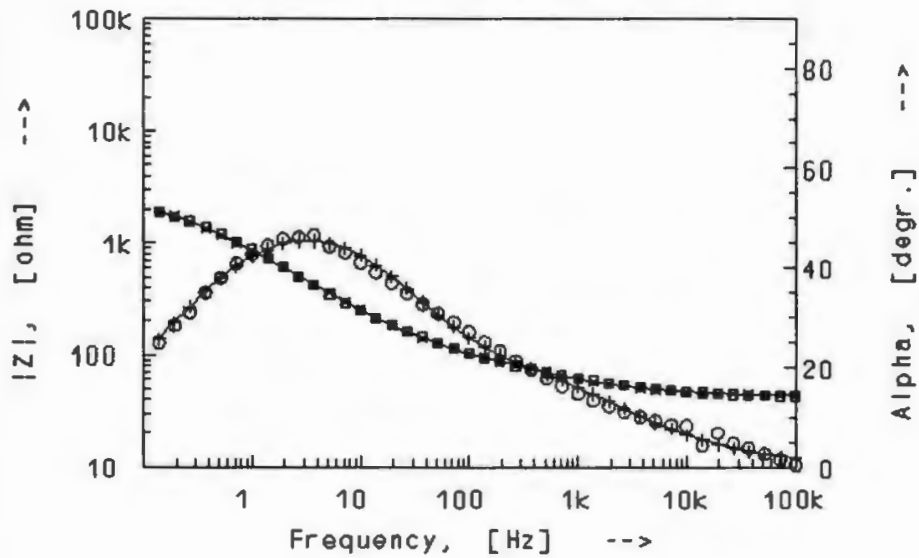

Figures 7d-f. Bode plots for $-1.20 \mathrm{~V}$ applied potential at 0,30 and 90 hours, respectively. Symbols meaning as described previously. 


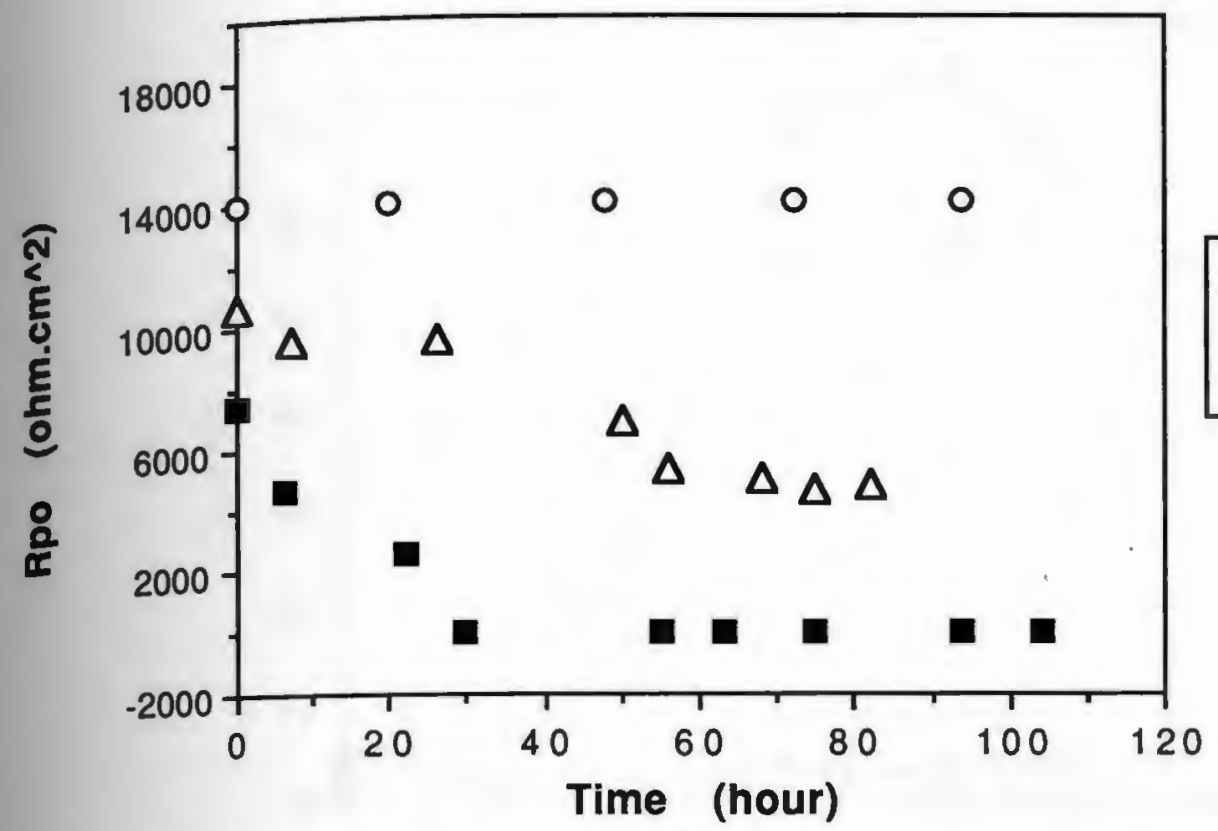

Figure 8. Plot of Rpo vs time for carbon vinyl ester composite in contact with $3.5 \% \mathrm{NaCl}$ solution at three different applied potentials 


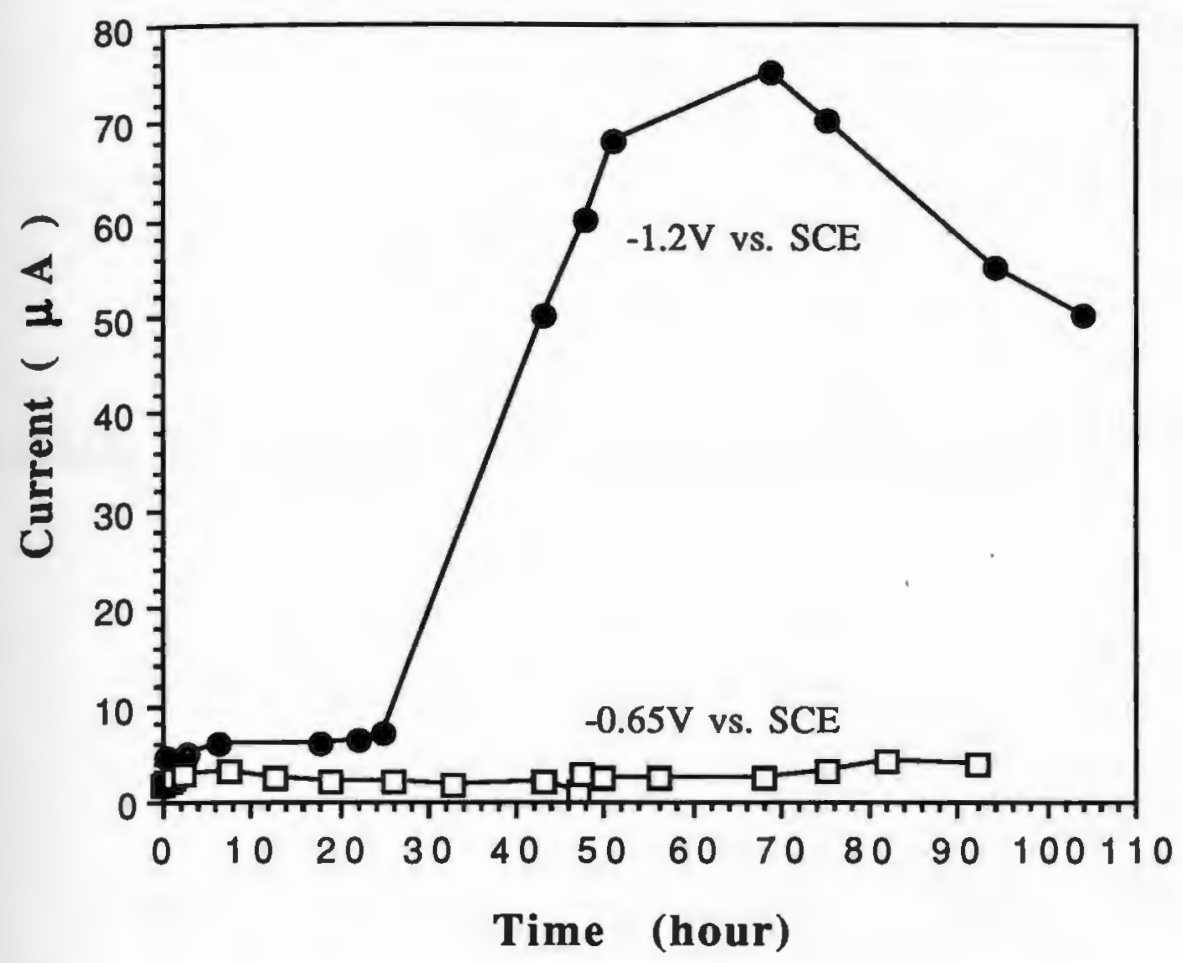

Figure 9. Plot of current vs. time for carbon vinyl ester composite at different potentials. 
DAMAGE TO COMPOSITES FROM ELECTROCHEMICAL PROCESSES

68 


\section{ABSTRACT}

Damage to a carbon fiber vinyl ester matrix composite material has been evaluated with different test techniques. Surface examination after long term galvanic coupling in seawater indicated removal of the polymer matrix above carbon fibers in addition to previously found blisters. Therefore two types of damage, blistering and dissolution, occurred due to galvanic interactions seawater exposure.

In a laboratory simulation of the process, after 90 hours exposure in $3.5 \% \mathrm{NaCl}$ with the composite at a potential of $-0.65 \mathrm{~V}_{\mathrm{SCE}}$ regions of polymer surface dissolution were found. After 720 hours blistering was found accompanying dissolution. Imposing a potential of $-1.2 \mathrm{~V}_{\mathrm{SCE}}$ resulted in exposing carbon fibers after the covering polymer layer was rapidly removed.

Laboratory testing techniques were found to simulate accurately long term surface damage from galvanic marine exposure in seawater. Electrochemical mechanisms for the polymer dissolution process are discussed. 


\section{INTRODUCTION}

Carbon fiber reinforced polymer matrix materials are light weight, high specific modulus materials aimed at replacement of heavier metallic materials. One possible application is in the marine environment as replacements for aluminum alloys and steels. The composite will likely not exist in isolation, but be combined with metals. In these situations, galvanic couples form between the metal and conductive carbon fibers in the composite.

For a galvanically coupled vinyl ester carbon fiber composite blisters formed in the polymer where an undulating glass fiber cross weave in the carbon fiber repeatedly approached the exposed surface (1). The $\mathrm{pH}$ of the blisters was measured at 10 to 11 . The proposed mechanism for blistering involved the cathodic reduction of dissolved oxygen to form hydroxyl ions on carbon fibers. These ions then reacted with either the glass or components in the polymer to form an osmotic cell.

In a later study investigating a method to measure composite degradation due to electrochemical reactions (2), after 90 hours exposure at $-0.65 \mathrm{~V}_{\mathrm{SCE}}$ no blistering was found. The non destructive electrochemical impedance spectroscopy (EIS) technique was employed to study damage to the composite. Nonlinear least squares fitting of the experimental data was conducted using the equivalent circuit software EQUIVCRT by Boukamp (3). Several possible equivalent circuit models were used to simulate these data including those proposed by Mansfeld and Kendig (4) for most polymer coated metals. Best fitting of the 
xperimental data was found employing the equivalent circuit shown below

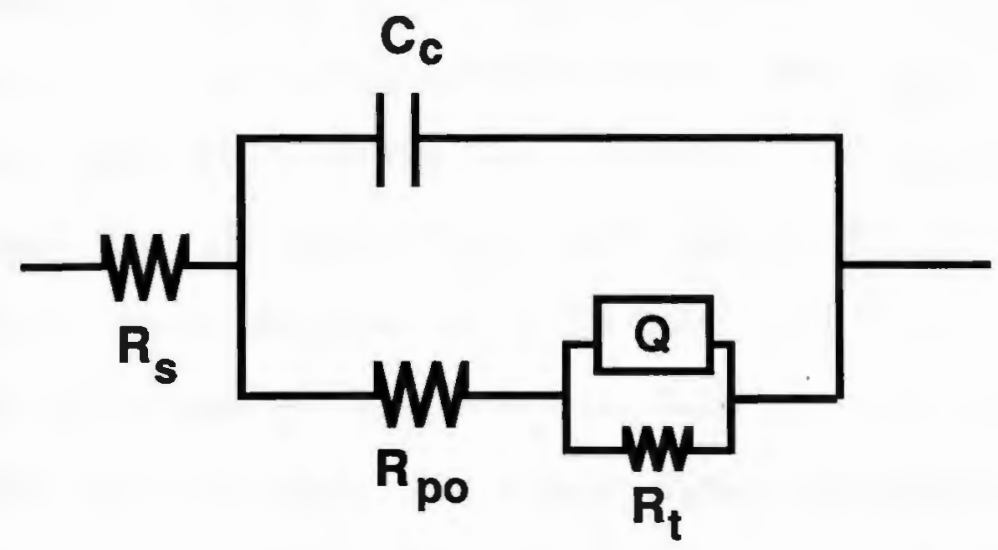

where $R_{S}$ is the solution resistance, $C_{c}$ is the capacitance of the vinyl ester matrix, $R_{p o}$ is the pore resistance of the matrix due to the penetration of electrolyte through defects and pores in the matrix, $Q$ is a constant phase element which allows contribution of diffusion at the carbon fiber/moisture interphase region and $R_{t}$ is the charge transfer resistance at the carbon fiber/moisture interphase. An example of the experimental data and the fit provided by the application of the model is shown in figure 1 when a potential of $-0.65 \mathrm{~V}(\mathrm{sce})$ was imposed on the composite. The polymer pore resistance $\left(R_{p o}\right)$ in this model of the electrochemical behavior decreased with exposure time, fig 2 . The data is provided in this paper for comparison with the results from surface examination of the composite after exposure.

In this paper surface damage from both long term galvanic tests and laboratory simulation are compared. The mechanisms of composite damage are also discussed. 


\section{EXPERIMENTAL PROCEDURE}

The composite material employed in the study was described in detail elsewhere (1). The unidirectional carbon fiber weave pre-pregs contained a fiber glass cross weave. As a result of the mixed weave, carbon fibers and then the glass fibers were alternately closest to the external surface of the composite. A vinyl ester rich layer separated the fibers from the environment. $2.5 \mathrm{~cm}$ square samples were sectioned from a $0.64 \mathrm{~cm}$ thick plate of vinyl ester matrix carbon reinforced composite material originally hand layed and room temperature cured.

For electrochemical studies the experimental setup is shown elsewhere (2). The only method of moisture uptake in the composite is permeation through the surface layer. $3.5 \mathrm{wt} \% \mathrm{NaCl}$ in distilled water was the electrolyte. Open circuit and applied potentials of -0.65 and -1.2 $\mathrm{V}_{\text {SCE }}$ were employed.

Samples from a previous study into galvanic interactions involving carbon composites (1) were also examined. Small pieces of metal were placed in notched sections of composite material and held by an interference fit. The samples of metal and composite were fully immersed in bowls of natural seawater for periods up to three months.

The surfaces of all samples were examined visually for signs of blisters, indicated by increases in height from the original composite surface. If blisters were present their location was usually easily correlated with fiber type as the white appearance of glass fibers could be easily discerned from the black carbon fibers through the translucent vinyl ester surface layer. Other surface variations were noted at this time. 
After visual examination, samples were examined in a scanning electron microscope for better definition of surface features.

\section{RESULTS}

\section{a. Open Circuit Conditions.}

After 90 hours at open circuit conditions no surface damage was observed. In previous studies (1), after three months immersion in seawater no damage was detected. Electrochemical studies employing impedance spectroscopy as a non destructive damage monitoring tool also indicated no damage at open circuit conditions and little tendency to initiate any damage (2). The pore resistance value determined from passive electrical circuit models of the electrochemical interface measured in EIS was used as a parameter to measure the susceptibility of the polymer matrix to electrochemical attack. The data for open circuit conditions indicating limited change in impedance values as a function of time, is shown in figure 2 .

Overall the surface characterization and electrochemical data over a three month period and also for short term exposure were identical with no damage accumulation evident.

\section{b. Applied Potential of $\mathbf{- 0 . 6 5} \mathrm{V}_{\mathrm{SCE}}$.}

At a potential of $-0.65 \mathrm{VSCE}_{\mathrm{SC}}$ for 90 hours, surface damage was found by scanning electron microscopy examination. The microstructural location of the damage was over the carbon fibers where they regularly 
approached closest to the surface. Removal and separation of surface material occurred parallel to the carbon fiber orientation, figure 3 . Considerable effort was taken in examination of the surface in the scanning electron microscope, however no damage was found on the surface over the glass fiber location. Indication of damage was found by impedance spectroscopy for the 90 hours of exposure (2). The pore resistance decreased markedly during the exposure period. The values for pore resistance over the 90 hours at $-0.65 \mathrm{~V}_{\mathrm{SCE}}$ is shown in figure 2 . The examination by scanning electron microscopy confirmed that the dectrochemical measurement of damage was accurate.

A different situation was found for the same applied potential at a longer exposure time of 720 hours. Under visual examination blisters were apparent over the closest approach of the glass fiber cross weave to the vinyl ester surface. Damage to the surface of the vinyl ester above the carbon fibers was also found by scanning electron microscopy and was similar to the damage found for 90 hours of exposure at the same potential. After 525 hours of exposure the pore resistance determined from passive circuit modelling was $4890 \mathrm{ohms.cm} 2$, similar to the data for 90 hours exposure. 
c. Carbon Fiber Coupled to Aluminum and Mild Steel.

Composite samples from a previous study (1) were examined. The samples in this case were immersed in seawater and coupled to aluminum 2014 or a mild steel for three months. Surface blistering was found in the usual location above glass fibers. Scanning electron microscopy indicated some additional damage in the region over carbon fibers. A typical damage region is shown in figure 4. Vinyl ester material was removed in thin channels parallel to the carbon fiber direction underlying the surface layer. In this galvanically coupled sample as for the 720 hours at an imposed potential of $-0.65 \mathrm{~V}_{\mathrm{SCE}}$, both blistering and polymer removal were apparent.

\section{d. Applied potential of $-1.2 \mathrm{~V}_{\mathrm{SCE}}$.}

Severe degradation of the composite was found after 90 hours when a potential of $-1.2 \mathrm{~V}_{\mathrm{SCE}}$ was applied to the composite material. The polymer matrix was locally removed in the region directly above carbon fibers which left them exposed to electrolyte, figures 5 and 6. After 30 hours, black debris was floating in the solution, accompanied by a rapid increase in the current flowing in the sample. The debris was carbon fibers released from the surface after the vinyl ester resin was completely removed. In the region surrounding exposed carbon fibers, figure 5 , the damage appears as thin channels running parallel to the carbon fiber direction and is similar to the damage previously found on galvanically tested samples. 


\section{DISCUSSION}

\section{Polymer Dissolution}

The polymer matrix on the surface over carbon fibers was damaged after 90 hours at $-0.65 \mathrm{~V}_{\mathrm{SCE}}$ and totally removed after the same time at $-1.2 \mathrm{~V}_{\mathrm{SCE}}$, indicating that the process was potential dependent. After 3 months of galvanic contact with an aluminum alloy or steel the amount of matrix damage was similar to the laboratory sample of 90 hours exposure at $-0.65 \mathrm{~V}_{\mathrm{SCE}}$. The damage accumulation rate decreased to very low levels after 90 hours of exposure. Blisters were present at the same time as polymer removal for exposures from 720 hours to three months. It therefore appears that both blister damage and matrix dissolution occur at the same time.

Rotating disc electrode studies in electrolytes similar to the one employed in this study (11) indicated that at potentials -0.2 to $-0.5 \mathrm{~V}_{\mathrm{SCE}}$ formation of hydroxyl ions and hydrogen peroxide is favoured as shown in reaction 1.

$$
\mathrm{O}_{2}+2 \mathrm{H}_{2} \mathrm{O}+2 \mathrm{e}^{-} \rightarrow 2 \mathrm{OH}^{-}+\mathrm{H}_{2} \mathrm{O}_{2}
$$

At more negative potentials in the range of -0.7 to $-1.2 \mathrm{~V}_{\mathrm{SCE}}$ a second reaction involving reduction of hydrogen peroxide to hydroxyl ions occurs, shown in reaction 2.

$$
\mathrm{H}_{2} \mathrm{O}_{2}+2 \mathrm{e}^{-} \rightarrow 2 \mathrm{OH}^{-}
$$


For both these cathodic reactions the rate limiting step is mass transport of oxygen to the cathodic surface.

Other possible reactions include reduction of protons, but at an extremely low rate for the $\mathrm{pH}$ ranges of 6 to 7 for this study. Oxygen reduction is occurring at a much faster rate than proton reduction. A second reaction to form hydrogen is available at potentials more negative than $-1.2 \mathrm{~V}_{\mathrm{SCE}}$ and is shown as reaction 3.

$$
\mathrm{H}_{2} \mathrm{O}_{\mathrm{ad}}+\mathrm{e}^{-} \rightarrow \mathrm{H}_{\mathrm{ad}}+\mathrm{OH}^{-}
$$

This reaction is not mass transport limited and only depends on the supply of water and electrons. Hydroxyl ions are also produced by this reaction.

The reduction of oxygen reaction is mass transport limited and at slow rotational velocity, constant current density was observed over the potential range from -0.65 to $-1.2 V_{S C E}(11)$.

Under the static solution conditions in this study, increased polymer dissolution rates accompanied increasingly negative imposed potentials. Production of hydrogen is a reaction that varies considerably with potential in static solution. At $-0.650 \mathrm{~V}_{\mathrm{SCE}}$, a negligible reaction rate from proton reduction reaction is available and would normally be overshadowed by the oxygen reduction reaction. The reaction rate is also mass transport limited. At $-1.2 \mathrm{~V}_{\mathrm{SCE}}$, the production of hydrogen increases rapidly by reaction 3 and is not mass transport limited.

The reactivity of the polymer as a function of potential and to the species available should indicate the cathodic reaction for dissolution. Hydroxyl ions do not dissolve the polymer, indicated by the stability of 
the polymer surrounding blisters containing fluid of $\mathrm{pH} 10$ (2). Hydrogen peroxide was shown to dissolve epoxy matrix for an epoxy graphite composite (5) and as such may have contributed to the limited amount of damage at potentials of $-0.65 \mathrm{~V}_{\mathrm{SCE}}$ imposed potential. At the $-1.2 \mathrm{~V}_{\mathrm{SCE}}$ potential hydroxyl ion production is favoured by reaction 2 . However the polymer dissolution rate, initially low and decreasing with time at $0.65 V_{S C E}$ was rapid at $-1.2 V_{S C E}$. This rate follows closely the hydrogen production over the potential range used in this study. At $-1.2 \mathrm{~V}_{\mathrm{SCE}}$, hydrogen is favoured at the potential by reaction 3 and may be present in low amounts by proton reduction at the $-0.65 \mathrm{~V}_{\mathrm{SCE}}$ potential.

A useful analogy may be that for hydrogen embrittlement of high strength steels. The fracture toughness under cathodically controlled conditions is a function of imposed potential in sodium chloride solutions, with lower fracture toughness values at more negative potentials over the range -0.65 to $-1.2 \mathrm{~V}_{\text {SCE }}(6)$. The accepted reason is that hydrogen is produced by cathodic reactions and the high strength steels are very sensitive to small amounts of hydrogen. The combination results in markedly decreased fracture toughness values with increasingly negative potentials. One possibility to explain the dissolution of the polymer is that they too are very susceptible to attack by atomic hydrogen as well as hydrogen peroxide.

\section{Blister Formation}

Although hydrogen is proposed as contributing to polymer dissolution, the reduction of oxygen reaction will also be proceeding, but at a constant rate over the potential range of this study. The hydroxyl ion 
from the reaction is free within the composite after cathodic reaction on the carbon fibers. The $\mathrm{pH}$ of blisters was reported to be 10 to 11 . The elevated $\mathrm{pH}$ results from hydroxyl ion diffusion in the vinyl ester to a location near the glass fiber where it can initiate a blister by initiating attack on the glass or combining with glass wetting agents. It should be noted that blisters can form by moisture diffusion and combination with water soluble components from the polymer (7). Blisters formed by this mechanism are usually acidic with $\mathrm{pH}$ of 3-4. However long term exposure of the vinyl ester composite without coupling indicated that it was highly resistant to this mechanism of blister formation (1).

Blister formation from osmotic pressure is dependent on the chemical , diffusional and mechanical properties $(7,8,9,10)$ of the matrix material. The stress within a blister from osmotic pressure will continuously increase while the necessary chemical components are available. The osmotic pressure overcomes the elastic stiffness of the material to move the matrix and increase the surface height which then indicates a blister. One upper limit of the process is when the pressure increases to a point where the blister bursts and the osmotic pressure is relieved. The second is when hydroxyl ion production ceases when oxygen in solution is depleted.

It is suggested that the blistering reaction initiates simultaneously with hydrogen production in the composite. An incubation period is required for the pressure to increase sufficiently to raise the surface of the vinyl ester. For open circuit or uncoupled conditions, the electrochemical reaction is not possible. At long exposure times an inelastic creep deformation mechanism in the vinyl ester may be invoked. A simple test conducted on the 30 day sample indicated the 
blisters could be forced back down to produce a flat surface by simple finger pressure. As blisters in this material are fluid filled (1), the pressure from finger contact is sufficient to redistribute fluid and remove evidence of blistering. A flat surface was easily produced indicating no permanent deformation of the samples. However flattening of blisters was not possible for long term exposure samples. A low continuous stress would lead to a creep process with the appearance of the blister being somewhat delayed in comparison to the start of the reaction. In addition, if a mechanism for release of the pressure was available then no blisters would be found. This may be the situation above the carbon fibers where the production of hydrogen ions reacts with the polymer to provide a free surface for escape of further reactants. A pressure build up necessary for the formation of blisters is therefore avoided and blisters cannot form. 


\section{CONCLUSIONS}

1. Two different degradation mechanisms operate in a carbon and glass fiber reinforced vinyl ester resin composite. One mechanism operates over the carbon fibers closest approach to the surface and causes loss of matrix material. The second operates over the closest approach of the glass fibers to the surface and produced blisters.

2. The first reaction over carbon fibers was highly potential dependent, while the second reaction of blistering was dependent on additional factors. These additional factors include the strength of the polymer, the diffusion rate and location of the species forming an osmotic pressure.

\section{ACKNOWLEDGEMENTS}

The authors would like to acknowledge the Malaysian Government for student support (M.N.A.), the department of Chemical Engineering at the University of Rhode Island for provision of laboratory facilities and Drs T. J Rockett and W. C. Tucker for stimulating discussion. 


\section{REFERENCES}

1. W. C. Tucker, and R. Brown, "Blister Formation on Graphite/Polymer Composites Galvanically Coupled With Metals", J. of Composites, 23, 1989, p.389

2. D. Kaushik, M. N. Alias, and R. Brown, "An Impedance Study of Carbon Fiber Vinyl Ester Composite", submitted to Corrosion, Dec. 1990.

3. B. A. Boukamp, Equivalent Circuit-Users Manual, 2nd ed., revised, University of Twente, Netherlands, 1989.

4. F. Mansfeld, M. W. Kendig, and S. Tsai, "Evaluation of Corrosion Behavior of Coated Metals with AC Impedance Measurements", Corrosion, 38, 1982, p.478

5. F. E. Sloan, "The Effects of Long Term Seawater Exposure on Graphite Epoxy Composite Materials", Ph. D. Thesis, University of California, San Diego, 1991.

6. P. S. Tyler, M. Levy, and L. Raymond, "Investigation of the Conditions for Crack Propagation and Arrest Under Cathodic Polarization by Rising Step Load Bend Testing", Corrosion, 47, 1991, p.82 
7. T. J. Rockett, and V. Rose, "The Causes of Boat Hull Blisters", Report for US Coast Guard, Project 1502, 1987

8. W.H. Bruggeman, "Blistering of Gel Coat Laminates", 33rd Annual Conference, Reinforced Plastics Composites Institute, The Society of Plastics Industries, 1978.

9. R. Davis, J. S. Ghota, T. R. Mahli, and G. Pritchard, "Blister Formation in R.P. The Origin of the Osmotic Pressure", 38th Annual Conference, Reinforced Plastics Composites Institute, The Society of Plastics Industries, 1983.

10. Chen-Chi Ma, and J. Y. Tsai, "Corrosion Behavior of Sheet Molding Compound in Water (1) Crosslinked Unsaturated Polyester Resins", 43rd Annual Conference, Reinforced Plastics Composites Institute, The Society of Plastics Industries, 1988.

11. M. B. Ives, Y. C. Lu, and J. L. Luo, "Cathodic Reactions Involved in Metallic Corrosion in Chlorinated Saline Environments", Corrosion Science, 32, 1991, p.91 


\section{FIGURE CAPTIONS}

Figure 1. Typical Bode plots of a carbon fiber/vinyl ester composite in $3.5 \% \mathrm{NaCl}$ solution at cathodic applied potential.

Figure 2. Pore Resistance values modelled from EIS data at open circuit, 0.65 and $-1.2 V_{S C E}$ applied potentials, from ref 2 .

Figure 3. Scanning electron micrograph of surface damage to the vinyl ester matrix after exposure to $0.5 \mathrm{~N} \mathrm{NaCl}$ at a potential of $-0.65 \mathrm{~V}_{\mathrm{SCE}}$ for 90 hours. Some dissolution and separation was found.

Figure 4. Surface damage to the vinyl ester matrix after galvanic coupling to steel for three months and immersion in natural seawater.

Figure 5. Scanning electron micrograph of polymer removal from regions directly over carbon fibers. The sample was maintained at a potential of $1.2 \mathrm{~V}_{\mathrm{SCE}}$ for 90 hours.

Figure 6. Carbon fibers exposed by electrochemical action. Little of the original vinyl ester matrix separating fibers from the external surface remained. 

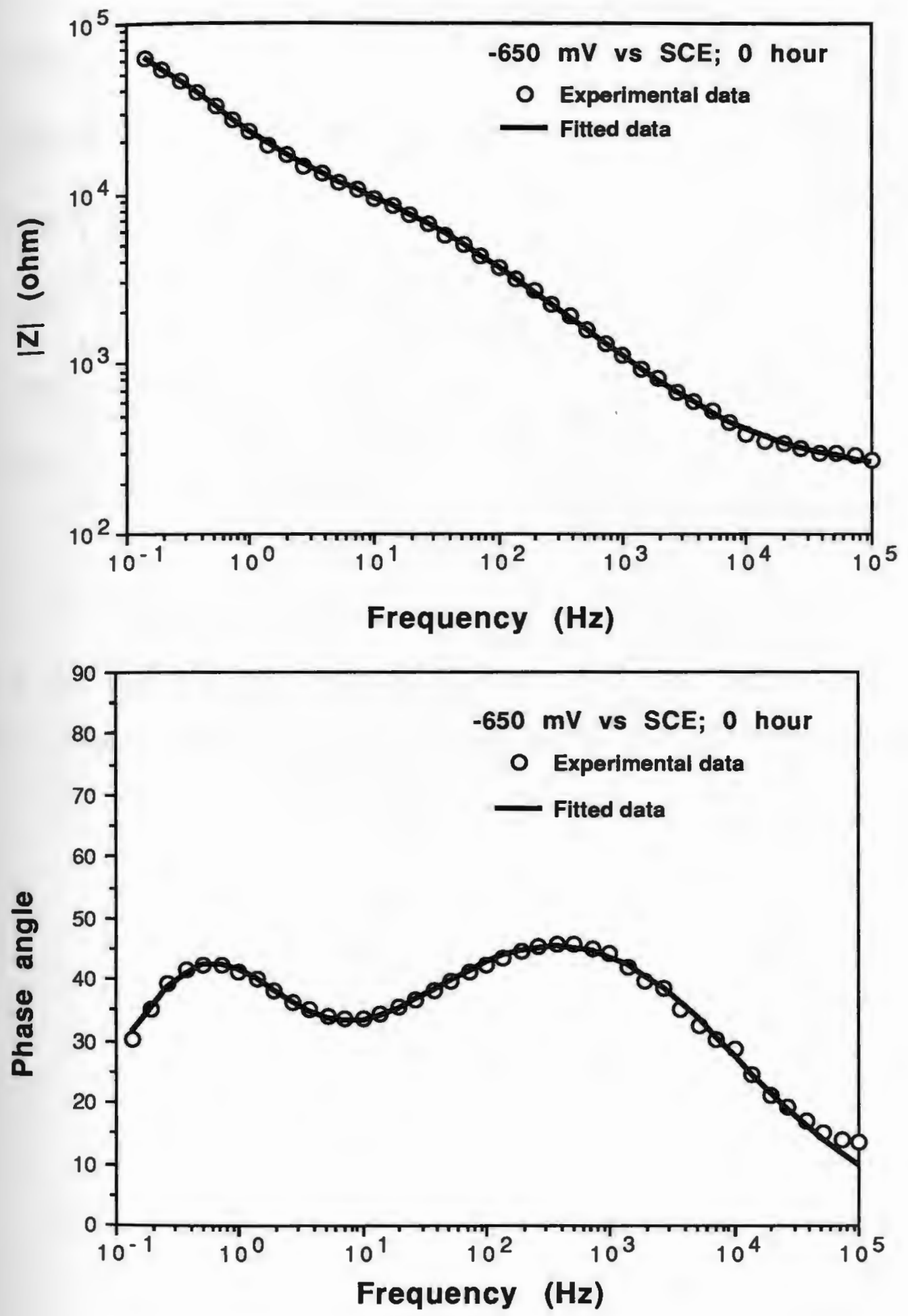

Figure 1. Typical Bode plots of a carbon fiber/vinyl ester composite in $3.5 \% \quad \mathrm{NaCl}$ solution at cathodic applied potential. 


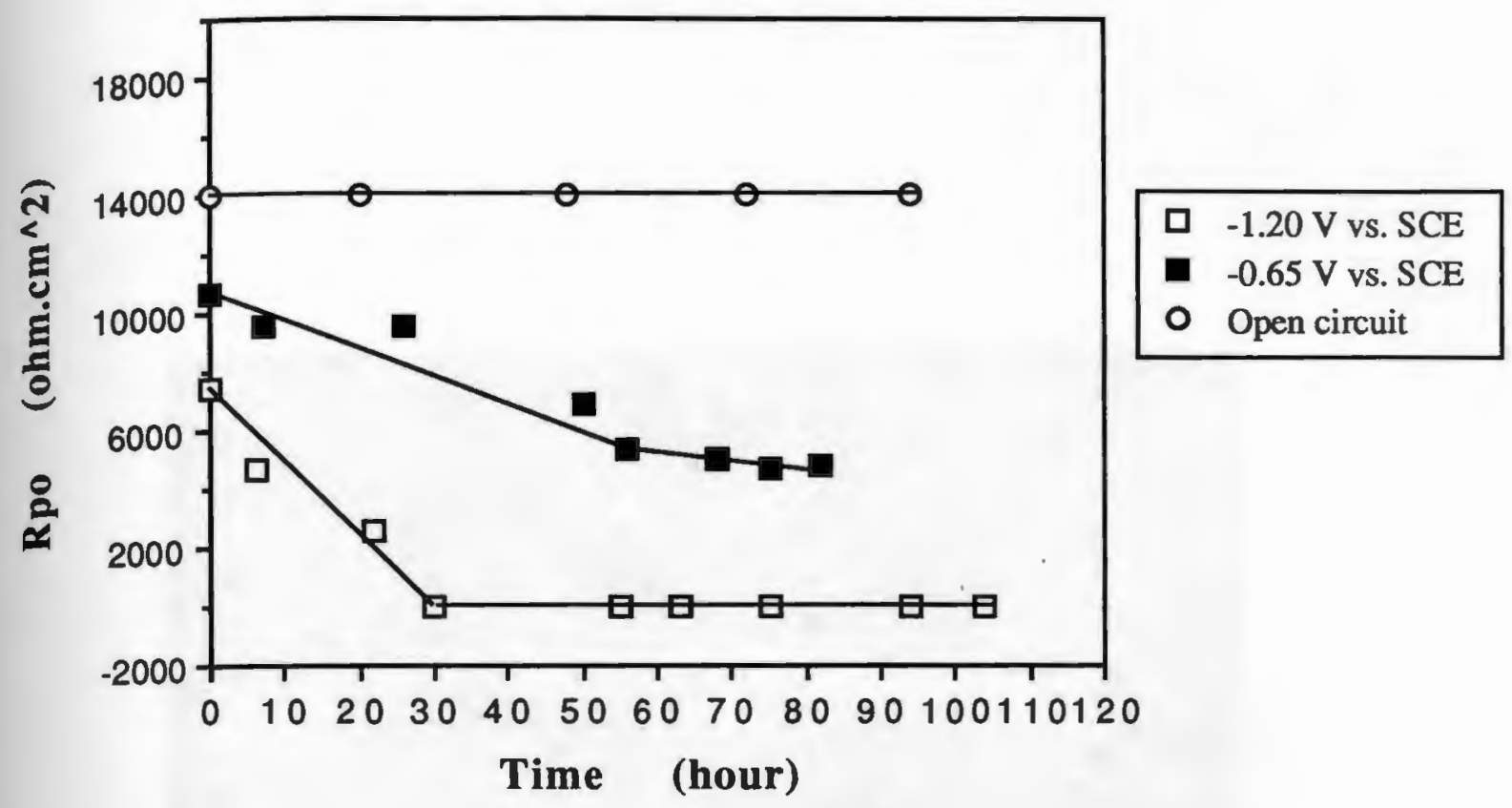

Figure 2. Pore resistance values modelled from EIS data at open circuit, -0.65 , and $-1.20 \mathrm{~V}$ vs. SCE applied potentials, from reference 2. 


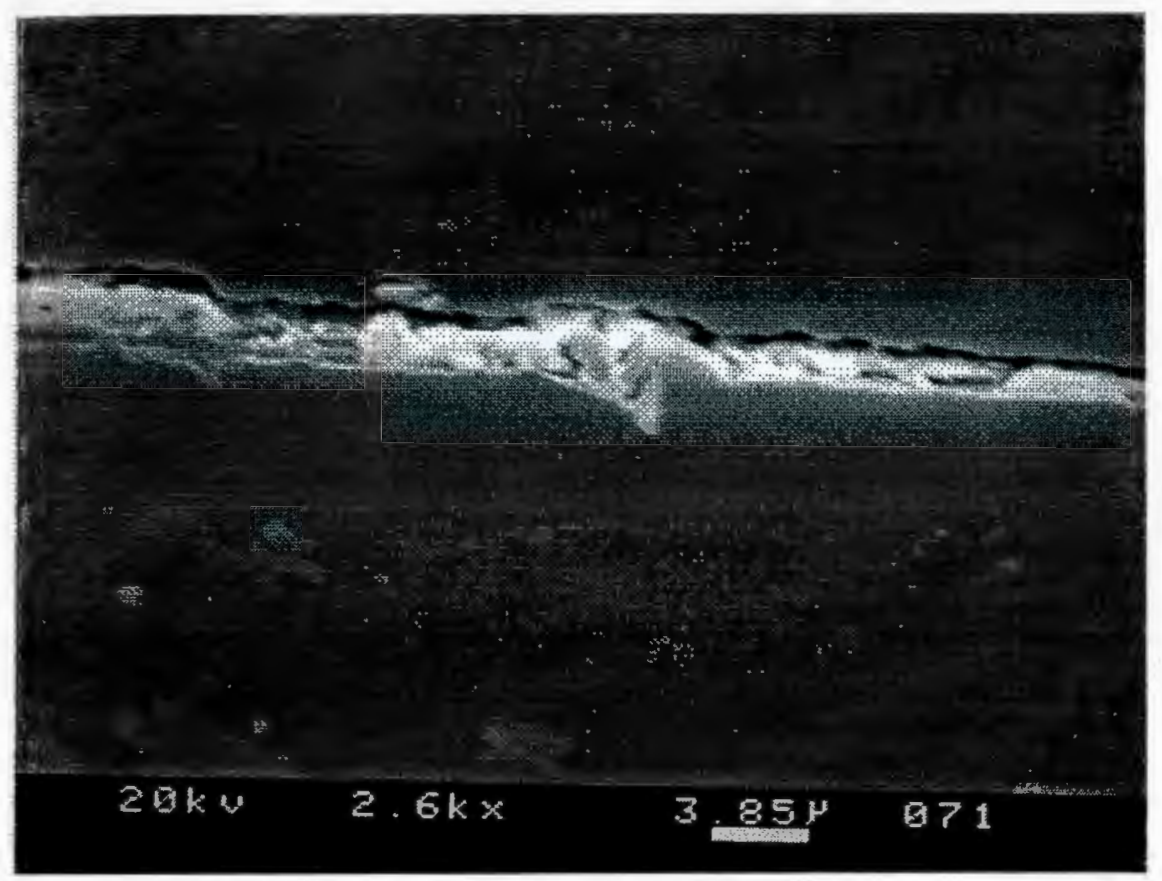

Figure 3. Scanning electron micrograph of surface damage to the vinyl ester matrix after exposure to $3.5 \% \mathrm{NaCl}$ at potential of $-0.65 \mathrm{~V}$ vs. SCE for 90 hours. Some dissolution and separation was found. 


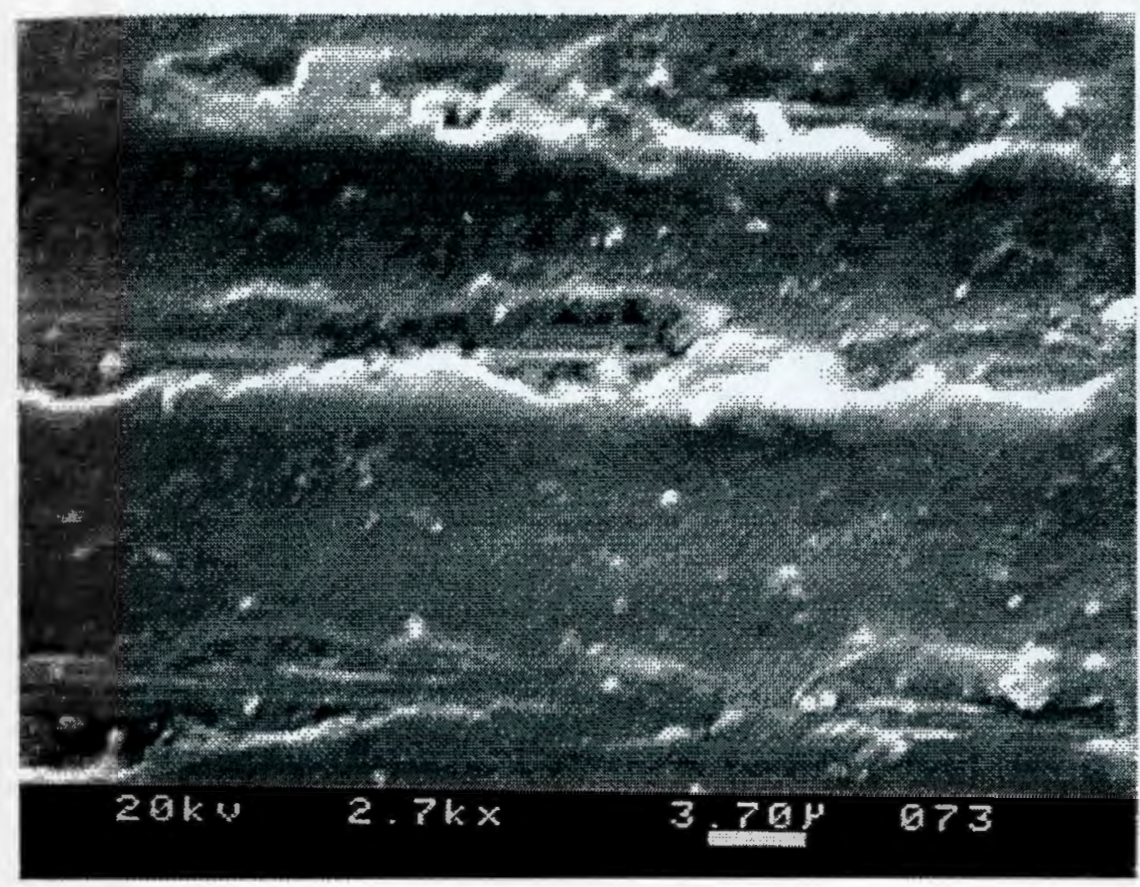

Figure 4. Surface damage to the vinyl ester matrix after galvanic coupling to steel for three months and immersion in natural seawater. 


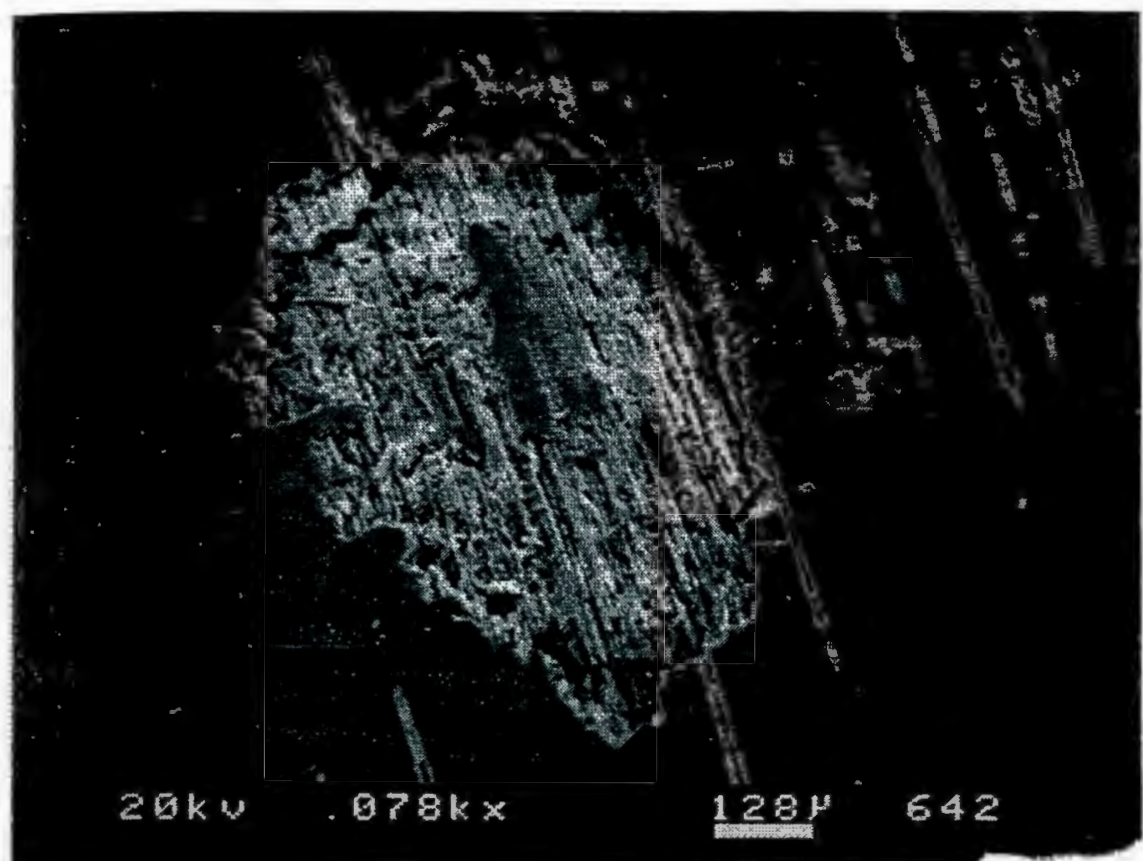

Figure 5. Scanning electron micrograph of polymer removal from regions directly over carbon fibers. The sample was maintained at a potential of $-1.2 \mathrm{~V}$ vs. SCE for 90 hours. 


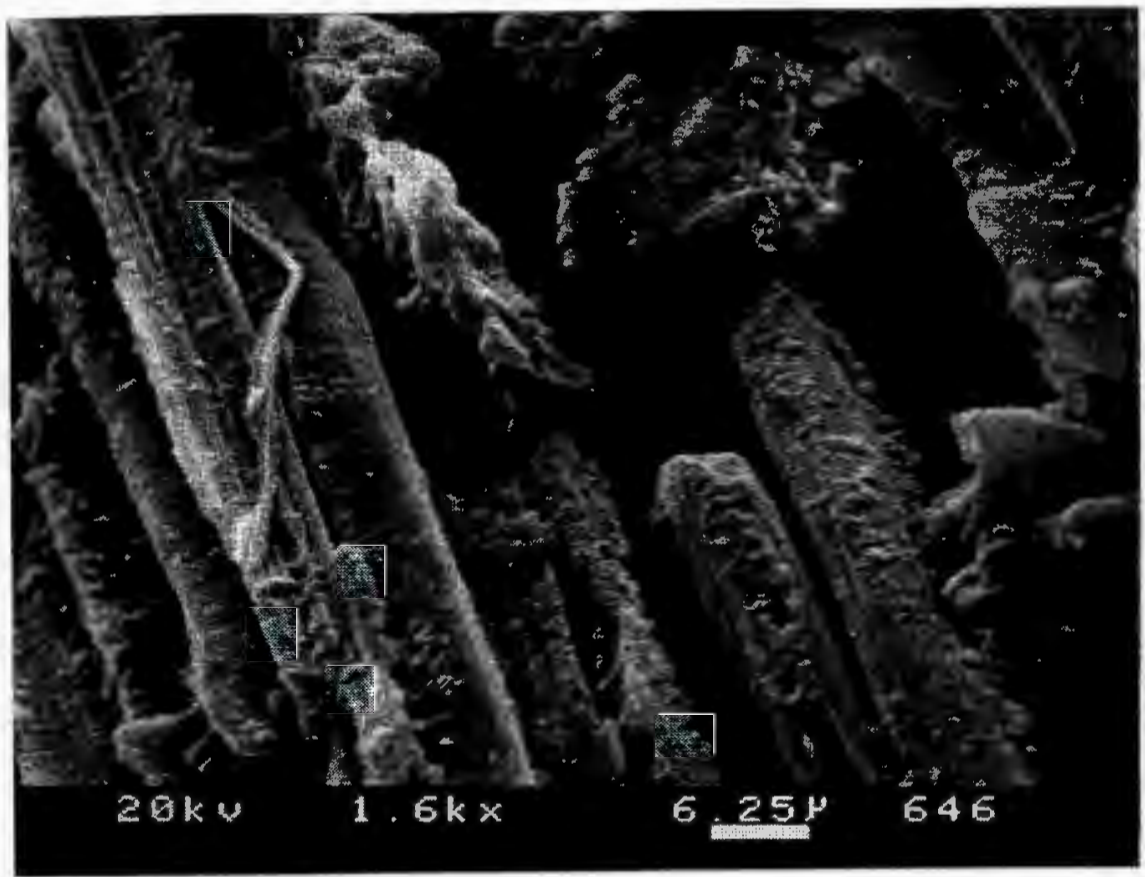

Figure 6. Carbon fibers exposed by electrochemical action. Little of the original vinyl ester matrix separating fibers from the external surface remained. 
CORROSION BEHAVIOR OF ION PLATED AND IMPLANTED FILMS 


\section{ABSTRACT}

The corrosion behavior of cathodic ion plated coatings on a 52100 and a 304 stainless steel in $0.5 \mathrm{~N} \mathrm{NaCl}$ solutions was investigated. Both TiN and $\mathrm{ZrN}$ coatings were applied. The TiN coatings were also ion implanted with $\mathrm{N}, \mathrm{Ti}$ and $\mathrm{Au}$ to determine the effect of ion implantation on corrosive behavior. To quantify corrosion behavior, both potentiodynamic scans and electrochemical impedance spectroscopy was employed. It was found that ion implantation did not enhance the corrosion resistance of the TiN on either the 52100 steel or the 304 stainless. However the $\mathrm{ZrN}$ did protect the stainless steel from corrosion. It is suggested that the $\mathrm{ZrN}$ is inherently more protective by formation of a passive layer than the TiN even with excess Ti ions from implantation. 


\section{INTRODUCTION}

Titanium nitride is well established as a coating to improve wear resistance of steels(1). It can be applied by several techniques, including reactive sputtering (2), and cathodic ion plating (3). At present cathodic ion plating is the technique of choice as rapid deposition rates in comparison to sputtering are available and it is desirable to deposit thick coatings for wear resistance. In addition the coating is amenable to substitution for gold due to its color similarity. To further enhance its service applications, it would be desirable for the TiN coating to provide improved corrosion resistance for the substrate it is deposited upon. When ARMCO iron was coated with TiN by sputtering the substrates were electrochemically active in the test environment of sulfuric acid and therefore relied on the coating for all its corrosion resistance, its corrosion resistance was questioned (4). Additional protection mechanisms are required to improve the corrosion resistance of the TiN layer when placed on steel. To this goal, an assumption was made that it is the grain boundary structure of TiN that permits diffusion to the surface of the steel that is the mechanism responsible for corrosion. A schematic diagram of this mechanism is shown in Figure 1. Defects in the coating may also play a part, but the generally poor protection offered by TiN using several different coating techniques with different defect level suggested that the inherent structure of the material may highly influence the corrosion process. One technique which modifies structures is ion implantation (5). The objective of this research was to investigate the effect on corrosion behavior of ion implantation of TiN, applied as a coating on steel, with a second element in an attempt to modify its structure and enhance corrosion resistance. It is the results of this study 
that will be reported in this paper. The aim of implanting several different elements was to determine the mechanisms of protection either by compressive stress increase in the film from ion implantation or by enhancing the passive layer from the film of TiN on both a 52100 steel and on stainless steel. As an auxiliary part of the study to determine the influence of different coatings, zirconium nitride $(\mathrm{ZrN})$ was also deposited on stainless steel by cathodic ion plating to determine its inherent corrosion resistance in comparison to the TiN.

\section{EXPERIMENTAL PROCEDURE}

Sample Preparation

Substrates used in this study were AISI 304 stainless steel and 52100 steel. Their composition is shown in table 1 . Discs $1.6 \mathrm{~cm}$ diameter and $0.3 \mathrm{~cm}$ thick for 52100 steel substrates were employed while 304 steel substrates were $3.2 \mathrm{~cm}$ diameter and $0.2 \mathrm{~cm}$ thick. Precleaning was carried out by degreasing with non freon degrease (NFD), rinsing with tap water, spraying with de-ionized water, and drying. The titanium nitride coatings were applied using cathodic arc plasma deposition technique to both plain and stainless substrates while the zirconium nitride was applied only to the stainless substrate. Each coating was 5.0 $\mu \mathrm{m}$ in thickness. Nitrogen, titanium, and gold were implanted into the substrates up to a concentration of $1 \times 10^{16}$ ions.cm-2 at an accelerating voltage of $80 \mathrm{keV}$.

52100 steels were tested in the following conditions:
(1) bare surface,
(2) Ti implanted,
(3) $\mathrm{N}$ implanted,
(4) $\mathrm{Au}$

implanted, (5) TiN coated, (6) TiN coated and Ti implanted, 
(7) TiN coated and $\mathrm{N}$ implanted, (8) TiN coated and Au implanted. Stainless steels were tested in the following conditions:

(1) bare surface, (2) TiN coated, (3) TiN coated and Au implanted, (4) TiN coated and Ti implanted, (5) $\mathrm{ZrN}$ coated.

Corrosion Test Procedure

a. Cyclic Polarization.

Cyclic polarization tests were performed on 52100 samples. Surface cleaning prior to testing included rinsing with acetone followed by methanol, and finally distilled water. Samples were then placed in a plastic holder with the prepared or coated surface area of $1 \mathrm{~cm}^{2}$ exposed to the solution. A carbon counter electrode and a saturated calomel electrode as a reference electrode were connected to a computer controlled potentiostat. The electrolyte used was de-aerated $0.5 \mathrm{~N} \mathrm{NaCl}$ solution. The solution was purged with nitrogen for an hour prior to the test, without the sample. A scan rate of $0.1 \mathrm{mV}$ per second in the positive, noble direction, was applied to the samples from a potential $100 \mathrm{mV}$ more cathodic than the open circuit potential. The scan direction was automatically reversed back to open circuit value when the anodic density was $500 \mu \mathrm{A} . \mathrm{cm}^{-2}$ or if the potential increased $+200 \mathrm{mV}$ than the Ecorr value.

\section{b. Electrochemical Impedance Spectroscopy.}


Electrochemical impedance spectroscopy was performed on the 52100 steel and the AISI 304 stainless steel samples. The experimental setup for the impedance measurement is represented in Figure 2. The electrolyte solution was $0.5 \mathrm{~N} \mathrm{NaCl}$ solution and exposure time varied from 30 to 60 days for stainless steels, and from 8 to 10 days for 52100 steels. The exposed area to the electrolyte for stainless steel was 3.25 $\mathrm{cm}^{2}$, and for 52100 steel was $0.95 \mathrm{~cm}^{2}$. Impedance measurements were conducted at open circuit potential and over a frequency range between $0.01 \mathrm{~Hz}$ and $100 \mathrm{kHz}$. A data density of seven frequency points per decade was used. Impedance spectra were represented in both complex impedance diagram ( or Nyquist plot), and Bode-phase angle plots. Data analyses were performed using a non-linear least squares fit method to obtain the equivalent electrical model for different substrate/electrolyte interfaces. Optimized parameters of the passive elements in the electrical circuit were plotted versus time.

\section{Surface Examination}

Scanning electron microscopy was employed to examine the initial surface condition of samples to detail surface characteristics prior to corrosion. A post corrosion testing examination was also conducted to identify the specific mechanism of corrosion for all the differing surface treatments. 


\section{EXPERIMENTAL RESULTS}

\section{Surface Characterization}

The initial surface conditions for the $\mathrm{TiN}$ and $\mathrm{ZrN}$ are shown in fig 3 and 4 respectively. Although small approximately circular defects were found in the coating, they did not expose the substrate surface as $\mathrm{X}$-ray energy dispersive analysis indicated elements from the coating were present in the center of defects. Both surfaces contained approximately the same level of microdefects in the coating. These defects are typical of those found in similar coatings by other researchers.

\section{Corrosion Data}

\section{(1). 52100 Steel Substrates}

\section{(a). Potentiodynamic Data}

The potentiodynamic data is shown in Figures 5 and 6 . In Figure 5 the effect of ion implantation on corrosion potential and corrosion behavior is indicated for 52100 steel implanted with $\mathrm{N}$, Ti and Au. The nitrogen and titanium implantation increased the open circuit potential from that of the steel while the gold implantation decreased the open circuit potential. None of the implantation species induced any passivation behavior in the steel at the concentration levels of $10^{16}$ ions.cm-2 implanted. The effect of ion implantation of the corrosion behavior of TiN coated steel is shown in Figure 6. Again, changes in the open circuit potential were evident and in general the open circuit potentials of the coated steel were increased to more positive values by 
the implantation of $\mathrm{N}$ while the Au decreased the corrosion potential, similar to the uncoated steel. No passive region was found for the steel with only active corrosion for all surface treatments. However, a change in corrosion behavior did occur associated with ion implantation. The plain steel in $0.5 \mathrm{~N} \mathrm{NaCl}$ solution corroded uniformly, producing oxide over the complete exposed surface. The implanted steel surface did not exhibit uniform corrosion but initiated localized pits on the surface during the potentiodynamic tests. The nature of corrosion was therefore changed by implantation in potentiodynamic tests from uniform to localized corrosion by implantation. For TiN coated and implanted steels, post test examination again indicated local pits were present, fig 7 . These penetrated through the coating and exposed the substrates to solution. Localized corrosion was again the mechanism of for all TiN coated 52100 steel treatments.

\section{(b). Impedance Data}

Electrochemical impedance tests were also conducted on the 52100 samples after implantation and coating with TiN and implantation. Typical data are shown in Figure 8 and 9 as a Bode plot of logarithm of the impedance magnitude $|Z|$ as a function of frequency, and phase angle as a function of frequency. In all cases only one fairly narrow peak in the phase angle data was found indicating one time constant for the corrosion process at the substrate/electrolyte interface. For plain 52100 steel the magnitude of the impedance (|ZI) at low frequencies of $0.01 \mathrm{~Hz}$ increased during the initial 48 hours of exposure as extensive rust formation occurred to cover the surface and then stabilized. A slight increase in phase angle also occurred with the increase in low frequency 
impedance. The Bode plot for the TiN with Ti implantation is shown in fig 9. In this case the impedance at low frequency decreased during the initial period of 48 hours and again stabilized. In all the other 52100 steel implanted and TiN coated samples an approximately constant impedance with time was found. Generally the impedance magnitude was greater for TiN coated samples than for the uncoated samples, seen by comparing figs 8 and 9.

For every sample rust formation was visually observed very early on, during the first 12 hours. However as in the case of potentiodynamic scans, the TiN coated and implanted 52100 samples corroded by a localized mechanism resulting in small pits. The plain steel samples uniformly corroded. 
(2). AISI 304 Stainless Steel Substrates

(a). Stainless Steel, and ZrN and TiN Coated Stainless Steels.

Impedance plots for the bare and coated stainless steels are

presented in Figures 10 to 12 . Only one maxima of time constant for the ionic relaxations at the substrate/electrolyte interface was observed in the impedance behavior for all three samples.

The initial impedance value at the lowest frequency $(0.01 \mathrm{~Hz})$ for all three samples shows a higher value for stainless steel coated with zirconium nitride, followed by plain stainless steel and finally stainless steel coated with titanium nitride, see Bode plots in Figure 10 to 12.

Impedance of stainless steel decreased below $10^{5} \mathrm{ohm}$ after 15 days of exposure. Pits were visually observed on the surface corresponding with the decrease in impedance. The impedance values remained in this vicinity even after 60 days of exposure. Correspondingly, the lower phase angle in that frequency region after 15 days could very well be an indication of breakdown of the oxide film.

After pit formation, the impedance at the lowest frequency remained constant. The same shapes of the peak of time constant, and same values of phase angle at the peak were observed even after 45 days after the formation of pits. Scanning electron microscopy of the pitted steel surface shown that the pits formed are in a circular shape, fig 13.

No sign of failure was observed on stainless steel coated with zirconium nitride over 60 days of exposure time. Impedance value at the lowest frequency $(0.01 \mathrm{~Hz})$ increased to $3 \times 10^{5} \mathrm{ohm}$ after 5 days and remained high until the end of the 60 days period. Phase angle at the 
lower frequency region increased and retained its shape even after 60 days.

On the other hand, titanium nitride coating did not show high resistivity in chloride environment. After one day of exposure to the chloride, the phase angle at the lower frequency region increased to 70 degree with no change in the impedance value at the lowest frequency, fig 11. The phase angle then dropped back to 60 degree, and the impedance decreased a little after 8 days. No significant sign of pits or any corrosion products were observed after that time of exposure. After 20 days, corrosion products were observed on the sample. The phase angle at the lower frequency region dropped correspondingly with no significant change in the impedance value.

\section{(b). Au Implanted on TiN Coated Stainless Steels}

Bode plots of $\mathrm{Au}$ implanted on TiN coated stainless steels were represented in Figure 14. Implantation of gold into titanium nitride coated stainless steel did not improve the resistance to the pitting attack. The initial impedance value at $0.01 \mathrm{~Hz}$ is lower than that for the bare stainless steel. Pits were observed on the surface after 2 days of exposure to the chloride solution. Correspondingly, the phase angle at the lower frequency region and the impedance at the lowest frequency decreased over that time of exposure. The phase angle and impedance increased again after 24 hours, and dropped again to a relatively lower values three days later. This shifting was observed until the 14th day of the test period (shown in Table 2), and thereafter the impedance remained at $7 \times 10^{4} \mathrm{ohm}$ and the peak of maxima at the lower frequency region show a rest with the phase angle value at 70 degree. 
TABLE 2: Impedance and phase angle at the lowest frequency $(0.01 \mathrm{~Hz})$ for TiN coated stainless steel and implanted with Au

$\begin{array}{ccc}\mathrm{t} \text { (day) } & |\mathrm{Z}| \text { at } 0.01 \mathrm{~Hz} & \theta \text { at } 0.01 \mathrm{~Hz} \\ 0 & 1 \times 10^{5} & 60 \\ 2 & 6 \times 10^{4} & 45 \\ 3 & 8 \times 10^{4} & 70 \\ 6 & 3 \times 10^{4} & 50 \\ 14 & 7 \times 10^{4} & 63 \\ 20-36 & 7 \times 10^{4} & 70\end{array}$

(c). Ti Implanted on TiN Coated Stainless Steels

For the titanium nitride coated sample with titanium implantation, pits were observed after 8 days of time of exposure. Correspondingly, the phase angle at $0.01 \mathrm{~Hz}$ dropped from 70 degrees (after 4 days) to 60 degrees (after 8 days). But, no significant decrease in the impedance value was observed during that period. From there on until the end of the test period which was 28 days, the phase angle was observed to be at 80 degrees and the impedance retained its initial value. 


\section{DISCUSSION}

\section{Modelling of Impedance Data}

It was found that a perfect dielectric model similar to that proposed for a quasi-homogeneous coating(6) could simulate the impedance behavior of the bare 52100 steel and AISI 304 stainless steel, as well as the coated and implanted samples, and those coated and further implanted. As clearly indicated on the Bode plots, only one maxima of time constant at the lower frequency region for all samples studied, which corresponded to the behavior at the substrate/electrolyte interface. In general, this behavior could be modelled as a parallel combination of a charge transfer resistance, $\mathrm{Rt}$, and a double layer capacitance of the Helmholtz model as shown in figure 15 (7). In the present study the iron component in each material is corroding. It is proposed that only the amount of surface area exposed that varies either by a passive film which suffers local breakdown or a TiN surface which permits corrosion of the substrate or from incomplete protection by implantation.

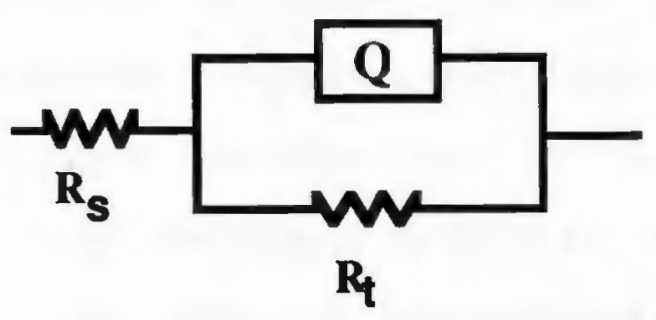

Figure 15. Model for bare steel substrates and samples coated and/or ion implanted. 
In figs 8 through 12 the experimental data is plotted along with the simulated data for the Bode representation of the circuit described above and employing appropriate values for the circuit elements. The double layer capacitance was represented by a general diffusion related element, $Q$, which is defined as a constant phase element. This element is mathematically written in its admittance form as

$$
Y^{*}(\omega)=Y_{0}(j \omega)^{n}
$$

where Yo is the adjustable parameter used in the non-linear least squares fitting, and $\mathrm{n}$ is defined as the phenomenological coefficient which could be obtained from the slope of $|\mathrm{Z}|$ on the Bode plot (8). A pure capacitance behavior is represented by $\mathrm{n}$ equals 1.0 (and the capacitance could be obtained by interpolated the impedance line of slope -1 to the $|\mathrm{Z}|$ axis), however throughout this study $\mathbf{n}$ was found to be 0.90 . This is understood as a deviation from an ideal dielectric behavior, or a leaky capacitor. This deviation is suggested due to the heterogeneity of the surface both laterally and within the depth of the oxide film which reflects the properties of the double layer (9). Therefore, the constant phase element should be a better representation of the double layer at the substrate/electrolyte interface.

The simple model was found to give the best fitting of the experimental data, for both bare and modified surface of 52100 steel and 304 stainless steel, and in both cases where uniform corrosion of the former and pitting on the latter were observed.

The optimized charge transfer resistance values were obtained from the least squares analysis (10) of the passive electrical circuit above 
for the samples tested. The important factor from a corrosion perspective is the charge transfer resistance which controls the rate of oxidation at the anodic surfaces. It is this parameter from the model that will be further discussed.

The data for 52100 steel was modelled using a non-linear least squares fit analysis, and the results of the modeling is shown in figs. 16 and 17. The data shown is the values of charge transfer resistance modelled from this approach. As can be seen, the charge transfer resistance for plain steel increased with time of exposure during the first 48 hours and then stabilized. For $\mathrm{N}, \mathrm{Ti}$ and $\mathrm{Au}$ implanted steel and plain steel after the initial increase, the charge transfer resistance was very close at $5 \times 10^{3} \mathrm{ohm} . \mathrm{cm}^{2}$ irrespective of the surface treatment, a result not unexpected from the active corrosion behavior for all samples during the impedance spectroscopy exposure time. The Ti and $\mathrm{N}$ implanted 52100 steel showed a decrease from the initial charge transfer resistance down to the stable value noted. The Au implanted steel slightly increased charge transfer resistance during the test .

The TiN coating did increase the charge transfer resistance to approximately $10^{4} \mathrm{ohm} . \mathrm{cm}^{2}$, fig 17 , but not a large enough increase to avoid corrosion. Implantation of the TiN coating resulted in a stable charge transfer resistance during exposure. Again localized corrosion was the mechanism of corrosion for all implanted and coated samples. Rust was observed on all samples during the EIS exposure time. It initiated in all cases very rapidly after the start of the test.

The charge transfer resistance for bare stainless steel follows a step function in which the step occurs between day 10 and 15 , fig 18 . This is due to the formation of pits on the surface. Rt remained constant after 
the formation of pit, and this is believed due to a very small ratio of the active pitted area to the rest of the passive area on the steel surface. Increasing metal dissolution in the pit interior attracted more chloride ions into the interior to maintain electroneutrality. Cathodic reaction protected the rest of the passive areas on the surface from further attack. Examination of the pitted surface by scanning electron microscopy shown a circular shape pits.

The increase in the charge transfer resistance of the $\mathrm{ZrN}$ coated stainless steel, fig 18, after exposure to the electrolyte could be due to the ability of the coating to induce spontaneous passivity. The plateau of the phase angle at the frequency region below $100 \mathrm{mHz}$ is believed due to the thickening of the oxide. A study on the oxide film of $\mathrm{ZrO}_{2}$ also observed variation of phase angle for thin and thick film (9), larger phase angle for thicker film. Increase in the Ecorr at the open circuit potential is related to this mechanism. Though of different alloy compositions, study on the AISI 316 stainless steel in chloride media found that the thickness of the oxide film increases linearly with the Ecorr at open circuit potential (11); this is believed the case in this study. Similar behavior was observed for the TiN coating on stainless steel, but the formation of corrosion products might explain that other characteristics of the oxide film might have contributed to the film breakdown.

It appears that film formation during exposure increased the charge transfer resistance for both the plain steel and the $\mathrm{ZrN}$ coated stainless steel. However the film on the plain steel was non protective, but the film on the $\mathrm{ZrN}$ was protective. Therefore although impedance spectroscopy will indicate film formation, it will not indicate which is 
protective unless a specific value of impedance for a protective film is

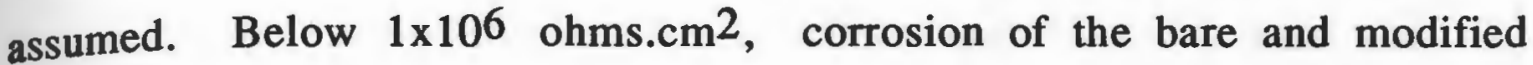
surfaces of both steels were observed; same value below which corrosion under paint occurs (12). Other samples showed a decrease in charge transfer resistance or a stable charge transfer resistance below the assumed protection value. These films were not protective. In the case of the Ti and $\mathrm{N}$ implanted into 52100, where a decrease was found, it is suggested that the passivation effects of these elements were quickly overcome by the chloride ion in solution. In other cases, the galvanic effect of gold was noted in the potentiodynamic scans and would immediately initiate local corrosion. A stable charge transfer resistance would be expected in this case.

Scanning electron examination of the samples of stainless steel coated with $\mathrm{TiN}$ and $\mathrm{ZrN}$ prior to corrosion testing showed similar surface characteristics on both samples. A four point probe test indicated that both $\mathrm{TiN}$ and $\mathrm{ZrN}$ coatings on stainless steel have similar resistivity. The TiN coating layer was broken due to the chemical attack of the chloride ions. Having no free titanium in the coating did not allow it to repair the defects on the surface film and excess titanium did not appear to help. It is suggested that these circular defects acted as the preferential sites for pit initiation on $\mathrm{TiN}$ at which the chloride ions were incorporated into the film. This prevented further formation of surface film on the stainless steel surface, and allowed the pit initiation. The $\mathrm{ZrN}$ would appear to be naturally passivating in the particular environment as no pits were found and the charge transfer resistance suggested a passive film formed. Another possible mechanism is the ability of the $\mathrm{ZrN}$ to repair the film breakdown due to a high residual compressive stress reported 
for this coating(13). However it is thought unlikely compressive stress was a factor. Ion implantation would be expected to increase the compressive stress in the both types of coated layers but little variation in charge transfer resistance indicating increased corrosion resistance was associated with implantation of individual elements. There is possibility that compressive stresses due to $\mathrm{TiN}$ and ion implantations exceed the critical breakdown stress of the passive film, in which will produce breakdown of the film (14). The inherently better $\mathrm{ZrN}$ corrosion resistance over TiN would appear to dominate coating behavior.

Implanting a more noble metal on TiN coating decreased the Ecorr potential, and did not provide a higher resistance to the chloride attack. The TiN coated stainless steel, and that further implanted with Au have equal charge transfer resistance to that of a bare stainless steel. Gold does not have the ability to induce passivation in the $\mathrm{pH} 6$ and potential regions employed in this study (15). It could not repair the defects on the oxide film which allowed the chloride attack to take place. The implanted $\mathrm{Ti}$ on the TiN coated stainless steel did not protect the substrate from chloride attack.

Increased in the charge transfer resistance after the formation of pits could be due to the inhibiting effect of the corrosion products. This was found to be indicated by the increased phase angle at the lower frequency region (below $100 \mathrm{mHz}$ ), ie. the rest of the phase angle on the Bode plot after 14 days for the TiN coated stainless steel further implanted with $\mathrm{Ti}$. 


\section{CONCLUSIONS}

1. Nitrogen gold and titanium implanted into 52100 steel, and into ion plated 304 stainless steel did not enhance protection from corrosion in $0.5 \mathrm{~N} \mathrm{NaCl}$.

2. The corrosion mechanism was changed by implantation from uniform corrosion for plain steel to localized pitting by the ion implantation.

3 TiN coatings before and after ion implantation of nitrogen, gold and titanium did not provide corrosion protection for 52100 steel or 304 stainless steel. The corrosion mechanism was local pit formation which exposed the steel substrate.

4. $\mathrm{ZrN}$ did provide protection for 304 stainless steel in $0.5 \mathrm{~N} \mathrm{NaCl}$ by formation of a passive film.

5. Over the frequency range employed, the equivalent circuit model provide best fitting of experimental data. Charge transfer resistance values obtained from this provide a quantitative basis for corrosion of substrates cover by passive film to occur; below $1 \times 106 \mathrm{ohms.cm} 2$ corrosion were observed. 


\section{ACKNOWLEDGEMENTS}

The authors would like to thank the Center for Thin Film and Interface Research associated with the University of Rhode Island and Brown University for partial funding along with the Malaysian Government (M. N. Alias). The contribution of Multi Arc Scientific Coatings in providing coatings and Dr I. G. Brown of Lawrence Berkeley Laboratories for ion implantation is gratefully acknowledged. 


\section{REFERENCES}

1. E.I. Meletis, A. Erdemir, and R. F. Hochman, J. of Materials Engineering, 7,1985, p.173

2. J. Danroc, A. Aubert, and R. Gillet, Thin Solid Films, 153, 1987, p. 281

3. O. A. Johansen, J. H. Dontje, and R. L. D. Zenner, Thin Solid Films, 153, 1987, p.75.

4. Y. Massiani, J. Crousier, L. Fedrizzi, A. Cavalleri, and P. L. Bonora, Surface Coatings and Technology, 33, 1987, p.309

5. S. M. Myers, in Treatise in Materials Science and Technology, vol 18, ed. J. K. Hirvonen, Academic Press, New York, 1980, p.57

6. J. Titz, G. H. Wagner, H. Spahn, M. Ebert, K. Juttner, and W.J. Lorentz, Corrosion, 46, 1990, p.221

7. E. C. Potter, Electrochemistry, MacMillan, New York, 1961, p.155

8. B. A. Boukamp, Solid State Ionics, 18, 1986, p.136

9. J. A. Bardwell and M. C. H. McKubre, Electrochimica Acta, 36, 1991, p.647 
10. B.A. Boukamp, in Equivalent Circuit Users Manual, University of Twente, Netherlands, 1988.

11. M. G. S. Ferreira, and J. L. Dawson, J. of Electrochemical Society, $132, \quad 1985$, p.760

12. H. Leidheiser, Jr., Corrosion, 38, 1982, p.374

13. P. C. Johnson, and H. Randhawa, Surface Coatings Technology, 33, 1987 , p.53

14. N. Sato, Electrochimica Acta, 16, 1971, p.1683

15. M. J. N. Pourbaix, Atlas of Electrochemical Equilibria in Aqueous Solutions, Pergamon Press, New York, 1966, p.169 


\section{FIGURE CAPTIONS}

Fig 1. Schematic diagram of proposed corrosion model for coated materials.

Fig 2. Experimental cell for electrochemical impedance spectroscopy.

Fig 3. TiN coated sample with circular local thin areas contained in the coating.

Fig 4. ZrN coated sample with circular local thin areas distributed in the coating.

Fig 5. Potentiodynamic scan for 52100 steel implanted with $\mathrm{N}, \quad \mathrm{Ti}$ and $\mathrm{Au}$

Fig 6. Potentiodynamic scan for TiN coated 52100 steel after implantation with $\mathrm{N}$ and $\mathrm{Au}$.

Fig 7. Micrograph of TiN coated 52100 steel after potentiodynamic testing showing the local pit mechanism of corrosion.

Fig 8. Bode plot for 52100 steel after 1 and 10 days.

Fig 9. Bode plot for 52100 steel implanted with Ti after 1 and 10 days.

Fig 10. Bode plot of stainless steel after 1 and 20 days. 
Fig 11. Bode plot of 304 stainless steel coated with TiN after 1 and 30 days.

Fig 12. Bode plot of 304 stainless steel coated with $\mathrm{ZrN}$ after 1 and 60 days.

Fig 13. Micrograph of impedance samples showing hemispherical pit on surface initiated during exposure to $0.5 \mathrm{~N} \mathrm{NaCl}$.

Fig 14. Bode plot for Au implanted into TiN on 304 steel.

Fig 15. Model for electrochemical interface for 304 and 52100 steel.

Fig 16. Charge transfer resistance for 52100 steel from modelling procedure.

Fig 17. Charge transfer resistance for 52100 steel with TiN coating and Ti implantation.

Fig 18. Charge transfer resistance of 304 stainless steel also with TiN and $\mathrm{ZrN}$. 
2 CATHODIC REACTION ON TIN

$\mathrm{O}_{2}+\mathrm{H}_{2} \mathrm{O}+4 e^{-} \rightarrow 4(\mathrm{OH})^{-}$

1 PERMEATIONOF WATER + CHLORIDE ION DOWN GRAIN BOUNDARY

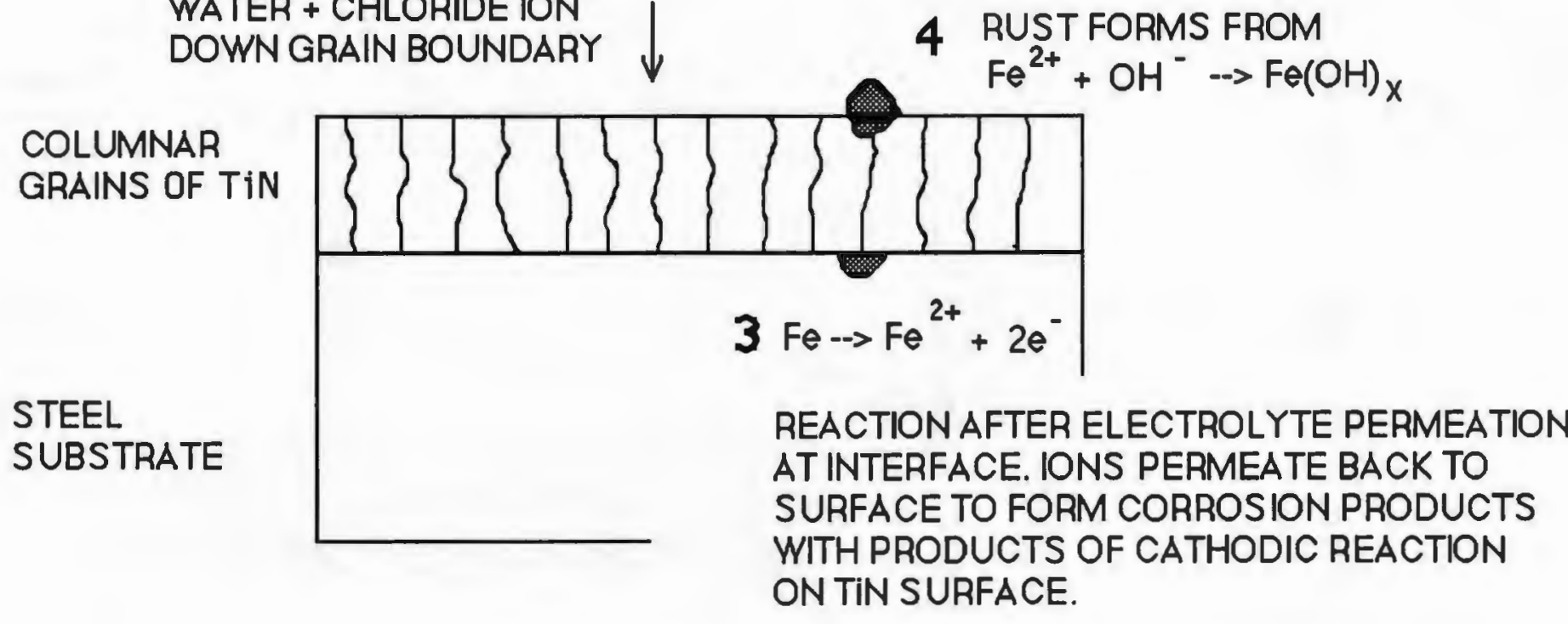

5 RUST HAS LARGER YOLUME THEN IRON USED FOR FORMATION SO LARGE TENSILE STRESSES ON FILMMAY OCCUR AS RUST PENETRATES INTO FILM TO SUBSTRATE. 


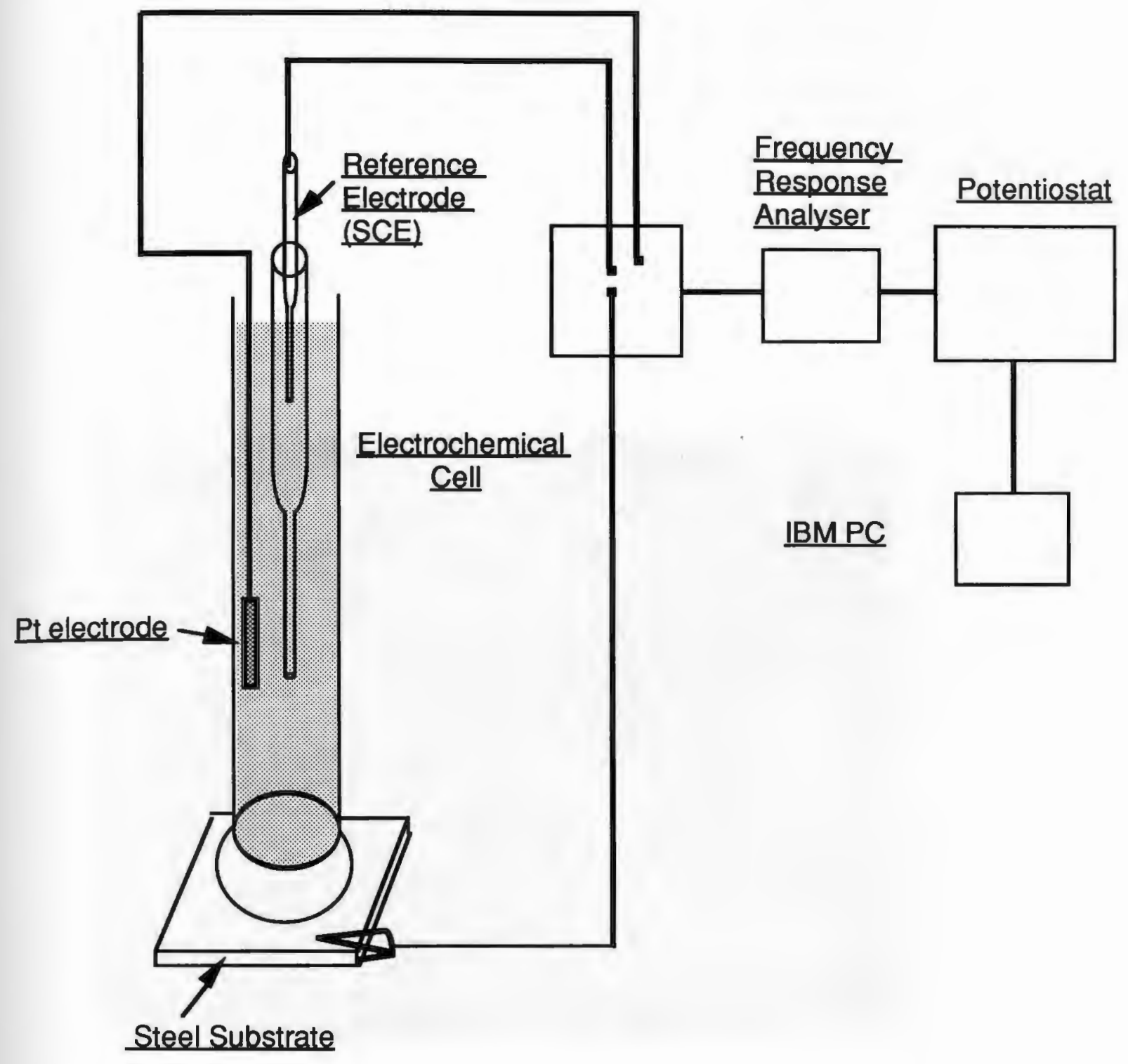

Figure 2. Experimental setup to perform electrochemical impedance spectroscopy. 


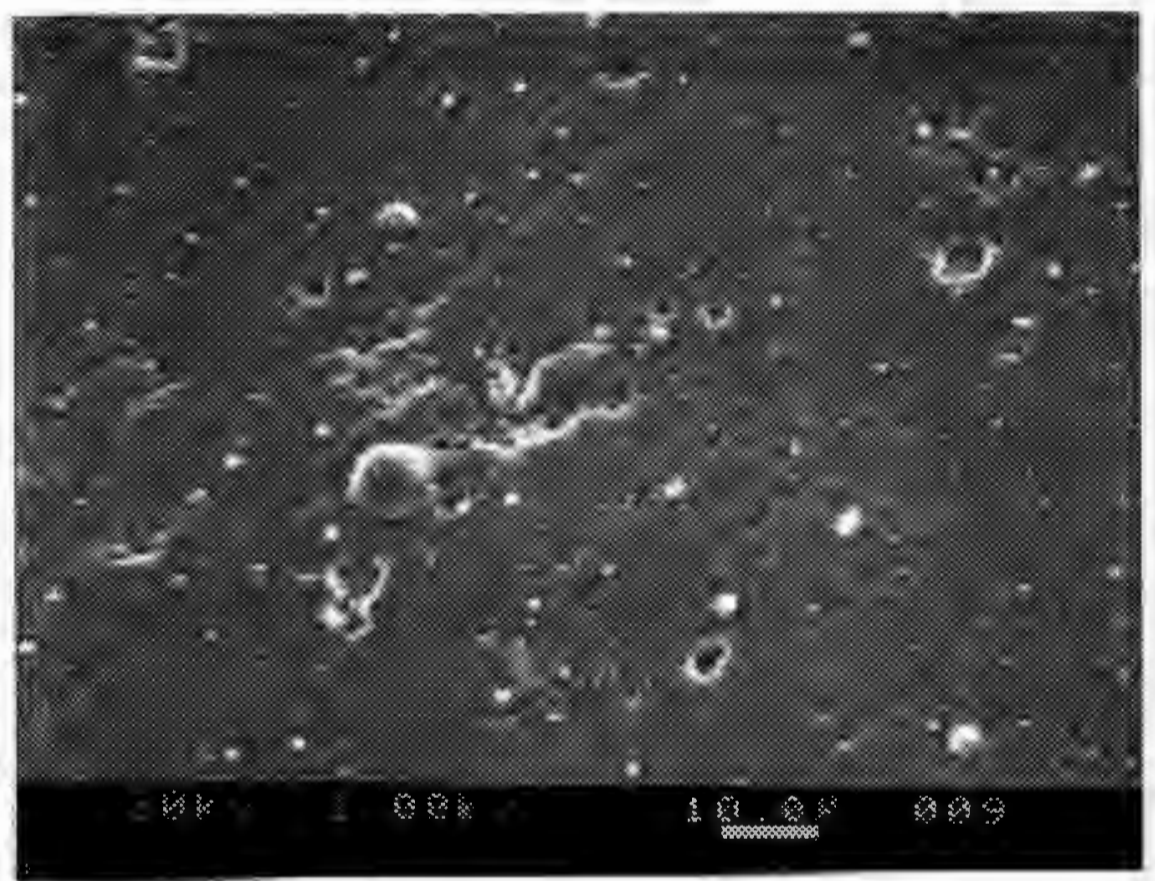

Figure 3. TiN coated sample with circular local thin areas contained in the coatings. 


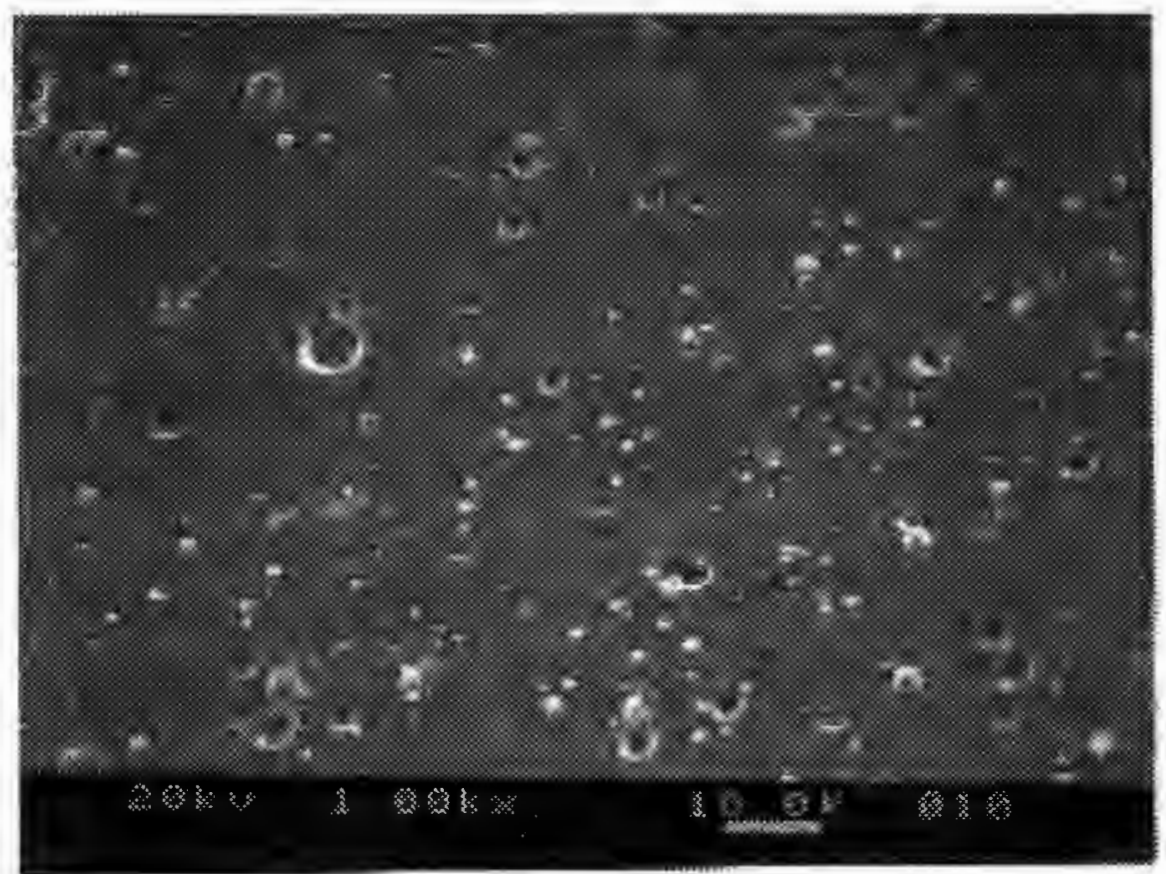

Figure 4. $\mathrm{ZrN}$ coated sample with circular local thin areas distributed in the coatings. 


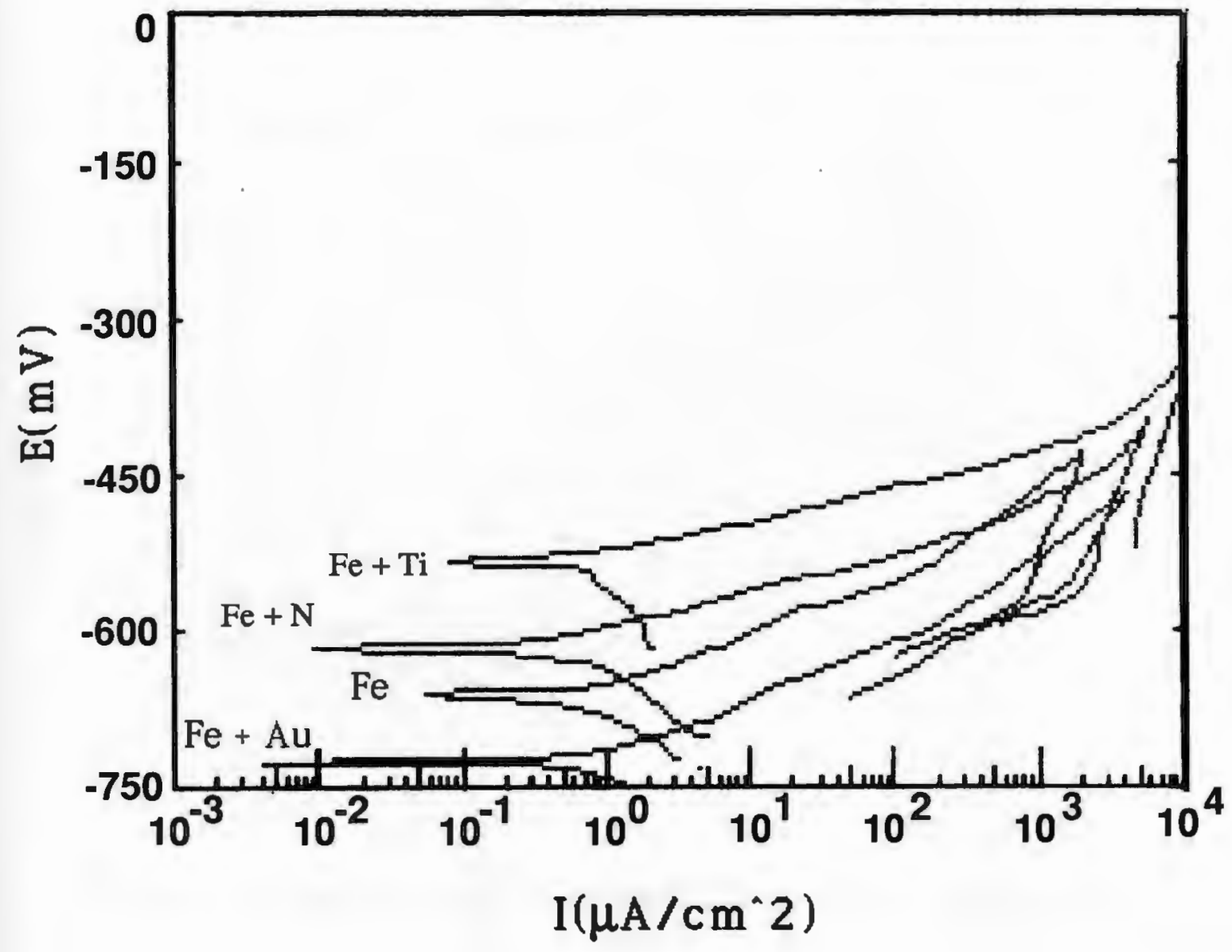

Figure 5. Potentiodynamic scan for 52100 steel implanted with $\mathrm{N}$, Ti, and $\mathrm{Au}$. 


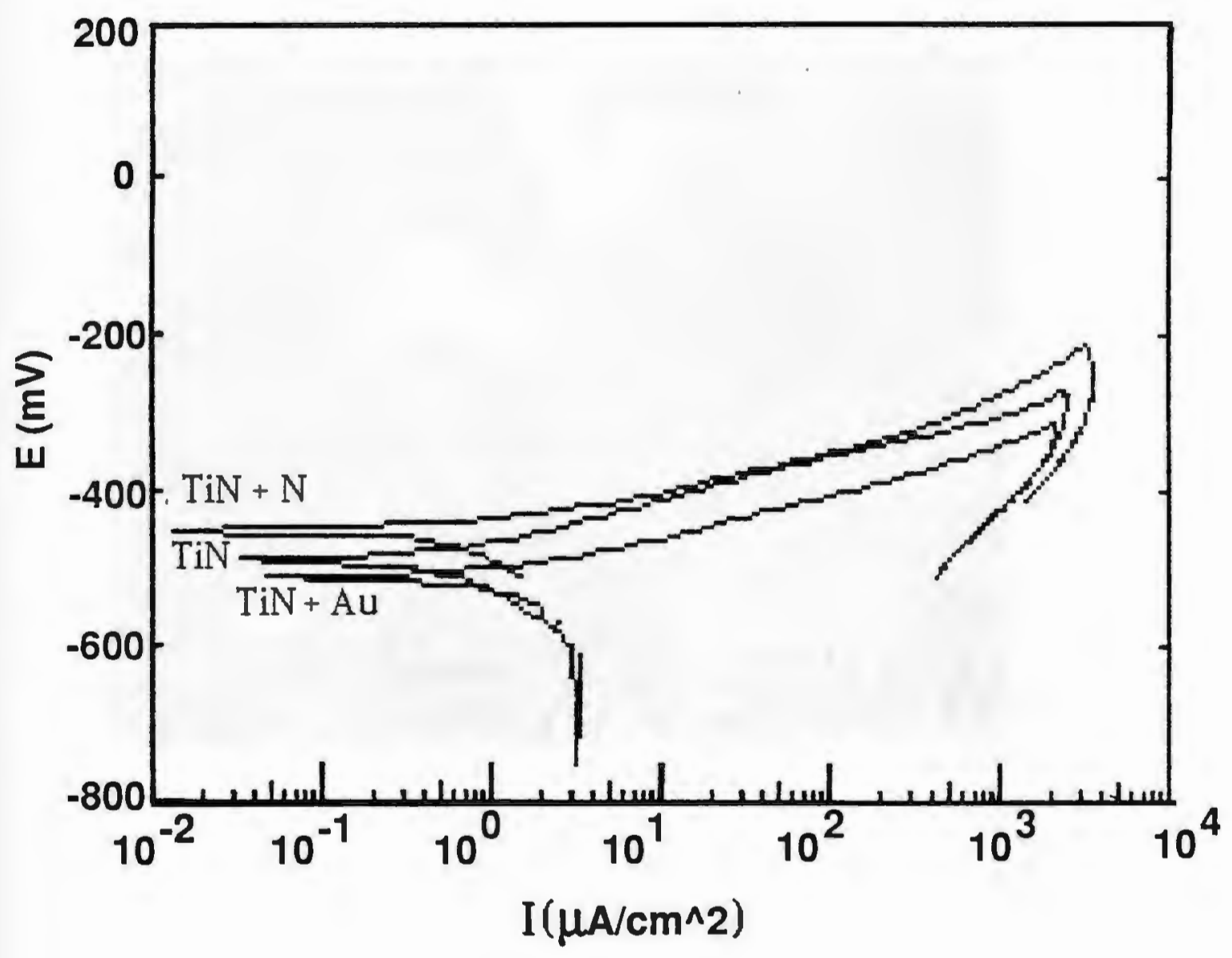

Figure 6. Potentiodynamic scan for TiN coated 52100 steel after implantation with $\mathrm{N}$, and $\mathrm{Au}$. 


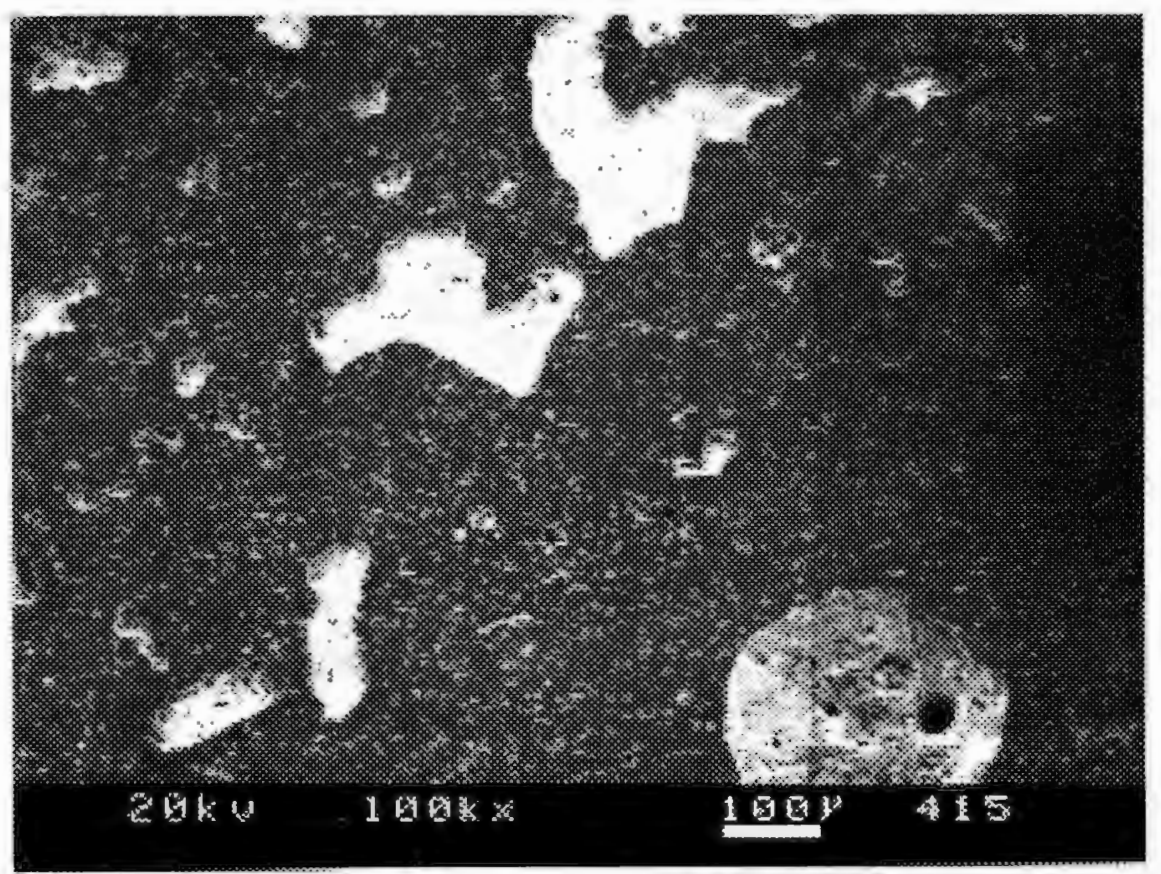

Figure 7. Micrograph of TiN coated 52100 after potentiodynamic testing showing the local pit mechanism of corrosion. 


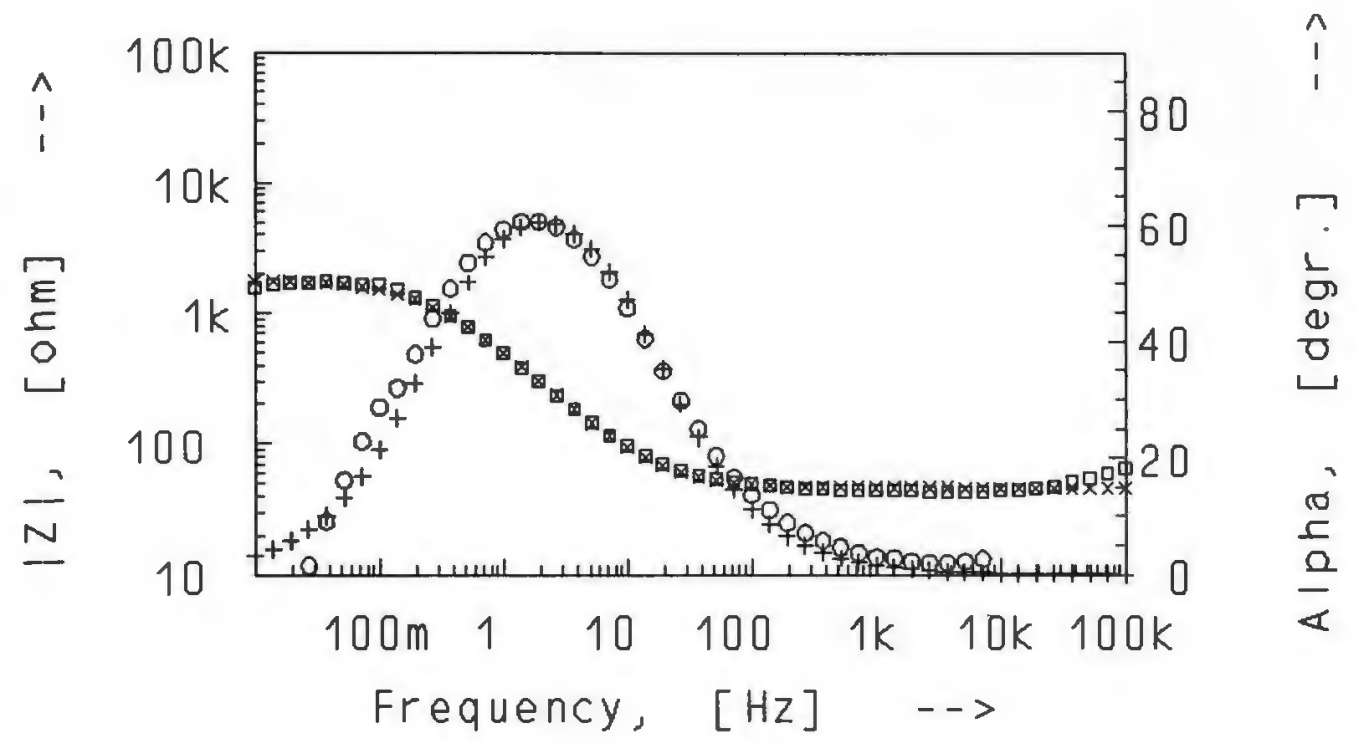

(a) Bode Plot for Day 1

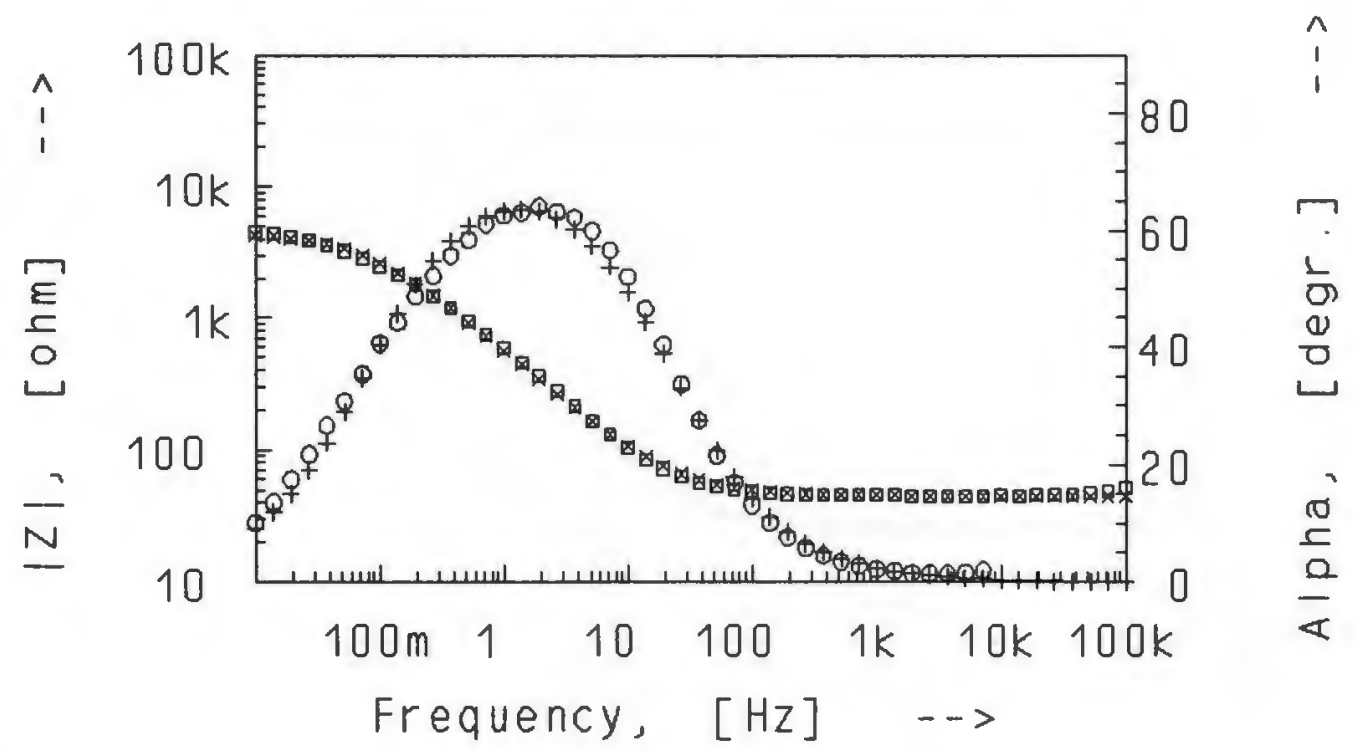

(b) Bode Plot for Day 10

Figure 8. Bode plots for 52100 after 1 and 10 days of exposure to $0.5 \mathrm{~N}$ $\mathrm{NaCl}$. The circle and squares are the experimental data for Z-modulus and phase angle, respectively. The cross and and plus are the corresponding simulated data from the non-linear least squares analysis. 


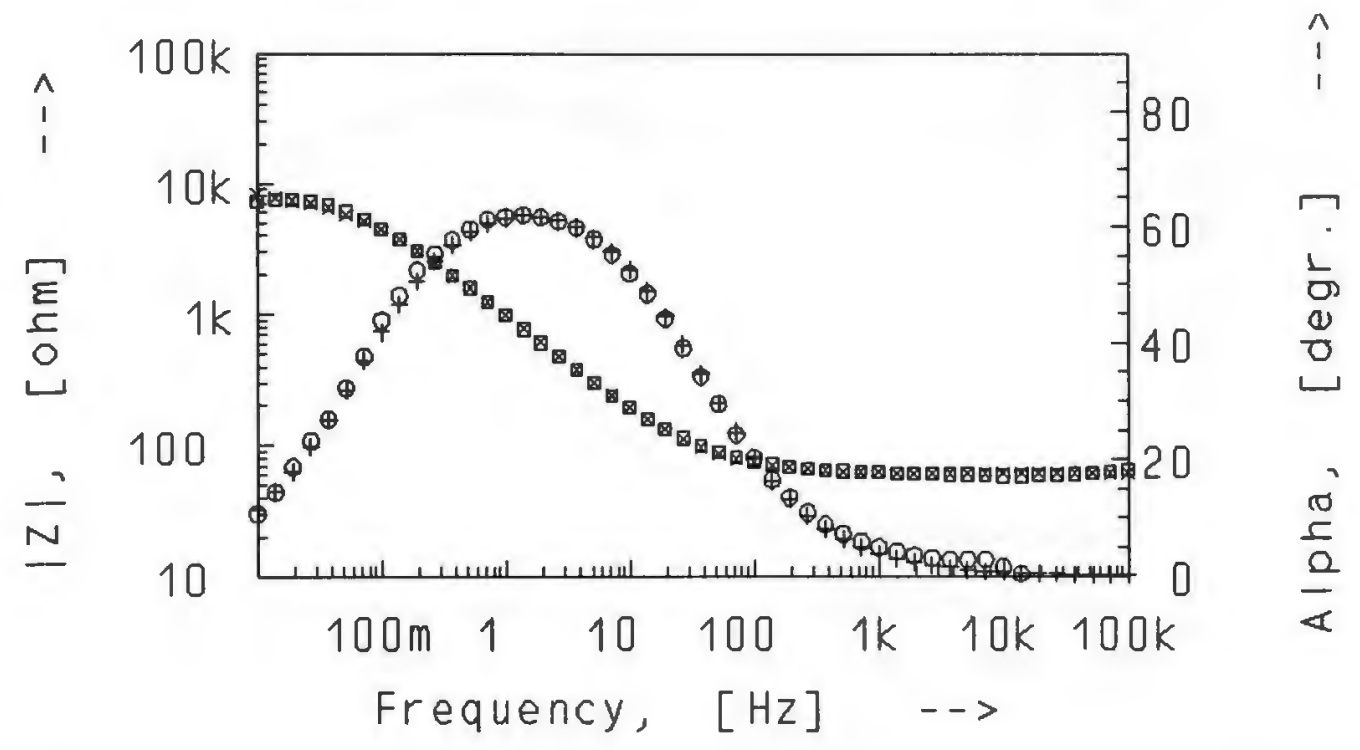

(a). Bode Plot for Day 1

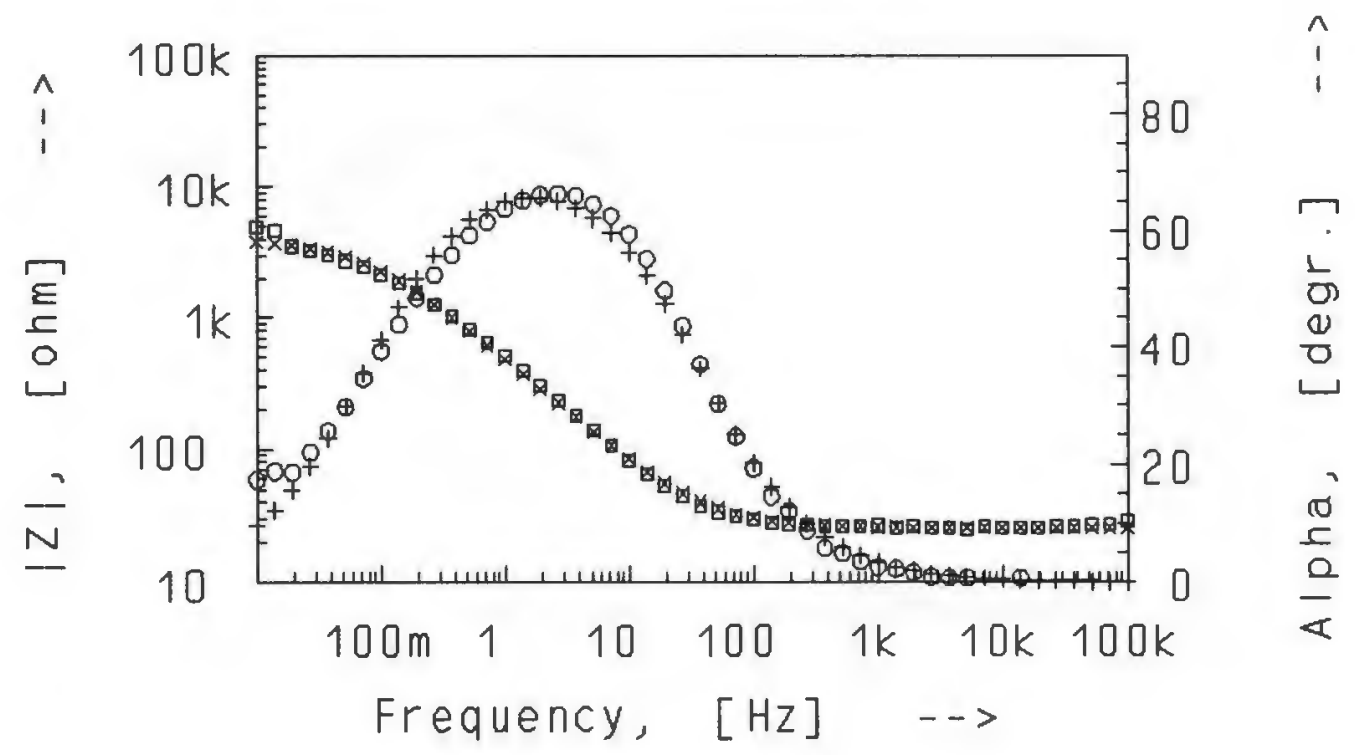

(b). Bode Plot for Day 10

Figure 9. Bode plots for 52100 steel implanted with Ti after 1 and 10 days. 


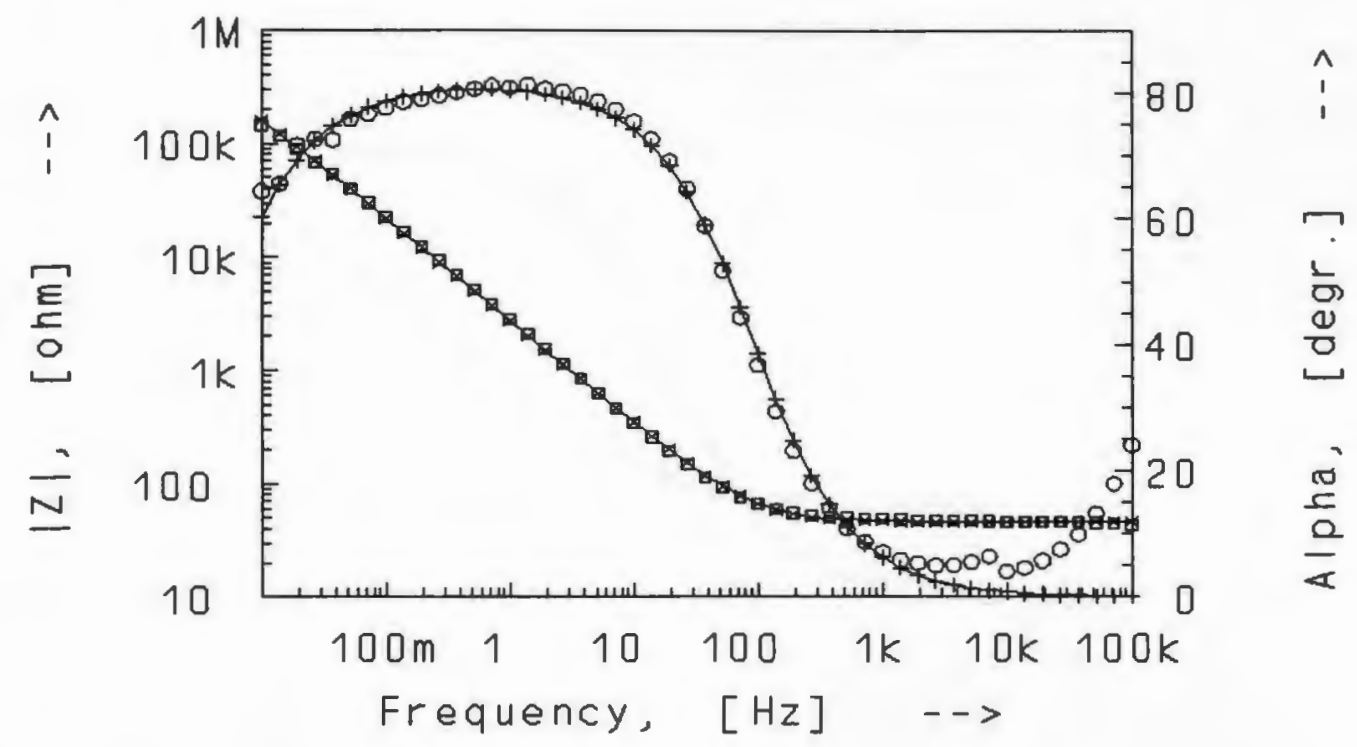

(a). Bode Plot for Day 1

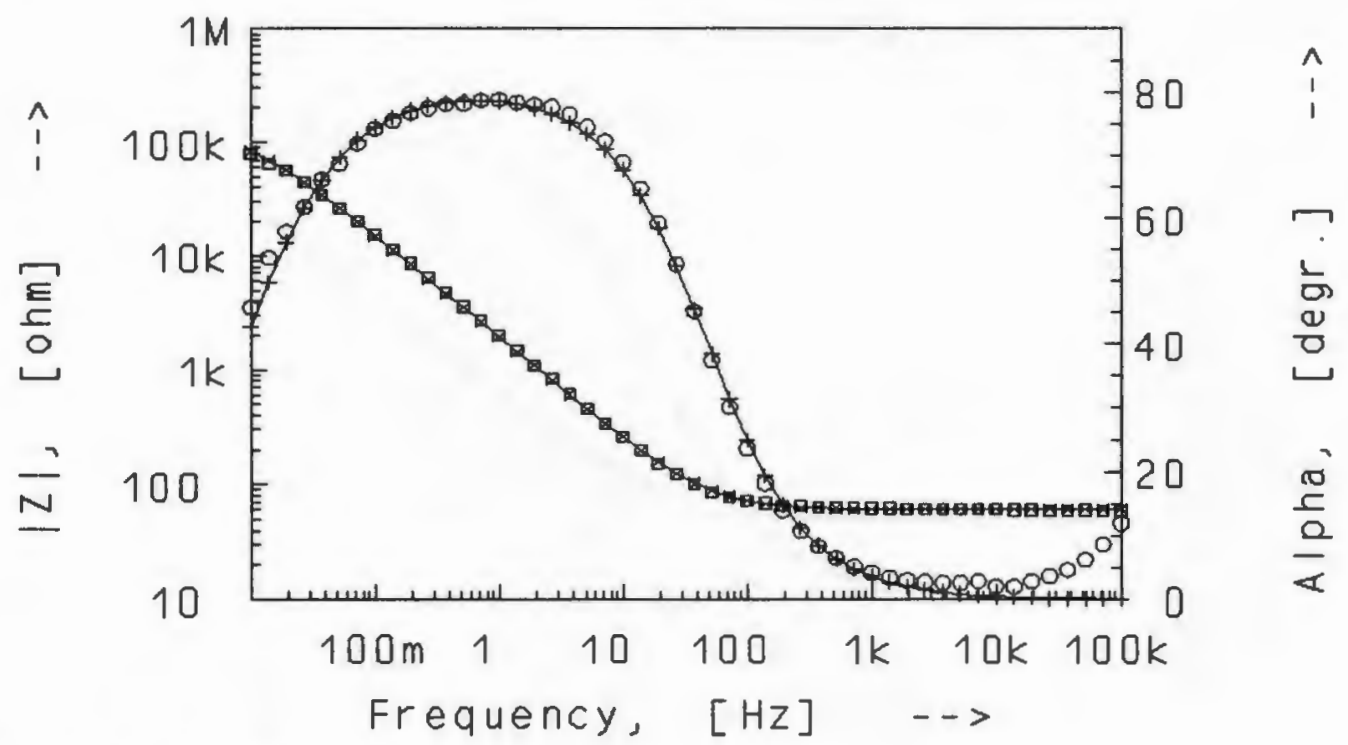

(b). Bode Plot for Day 20

Figure 10. Bode plot of stainless steel after 1 and 20 days. 


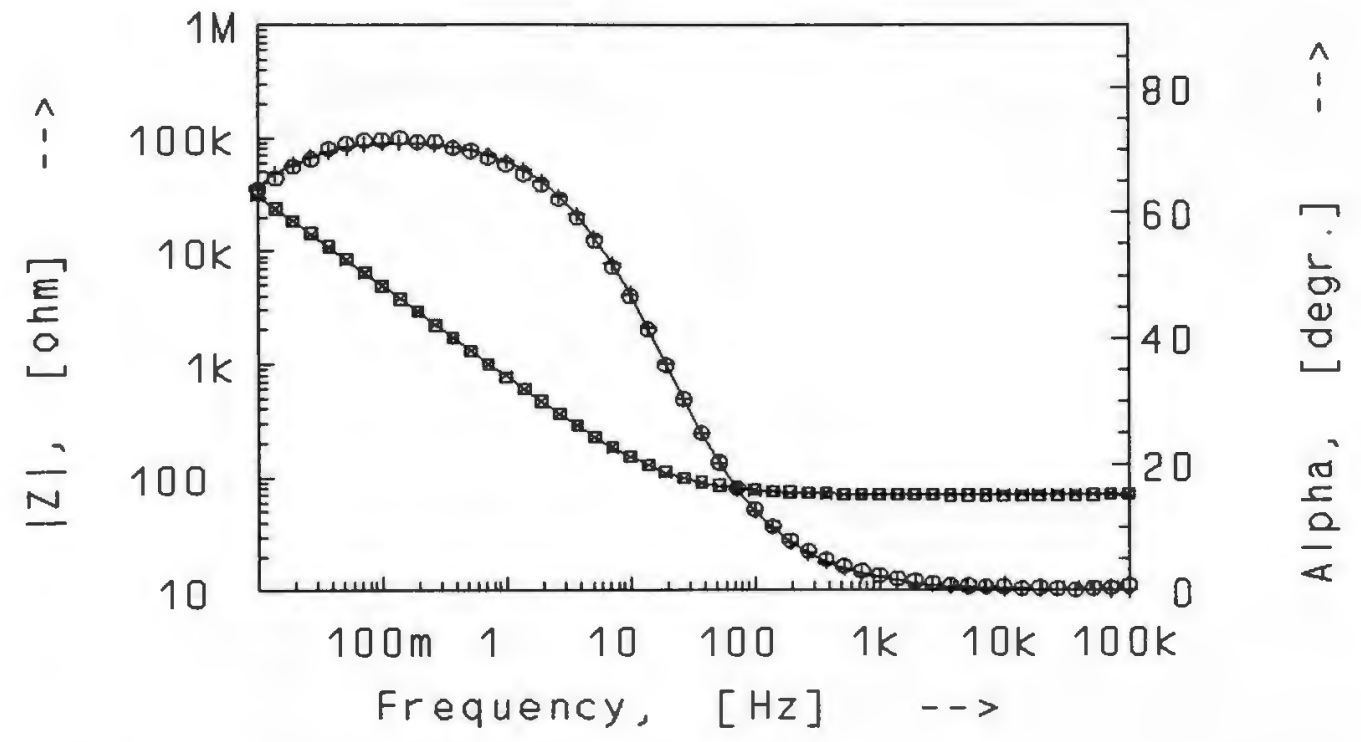

(a). Bode Plot for Day 1

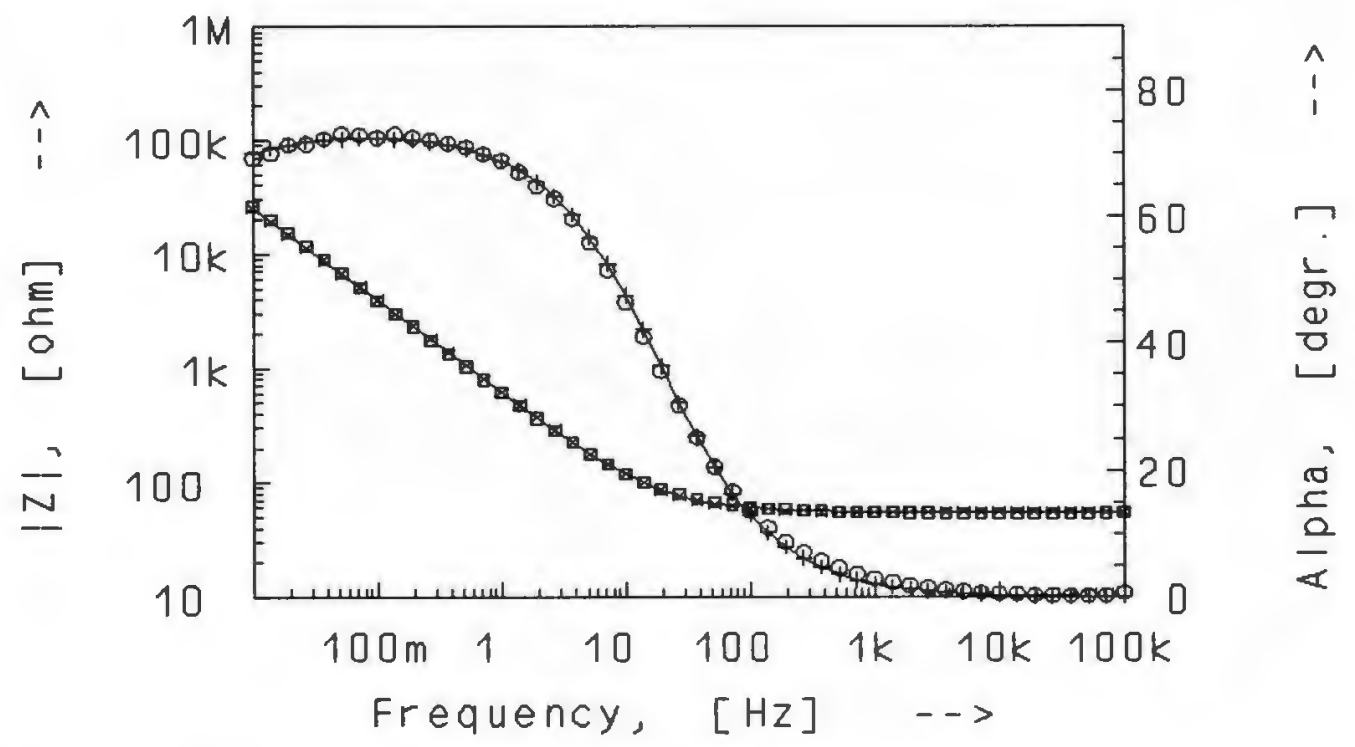

(b). Bode Plot for Day 30

Figure 11. Bode plot of 304 stainless steel coated with TiN after 1 and 30 days. 


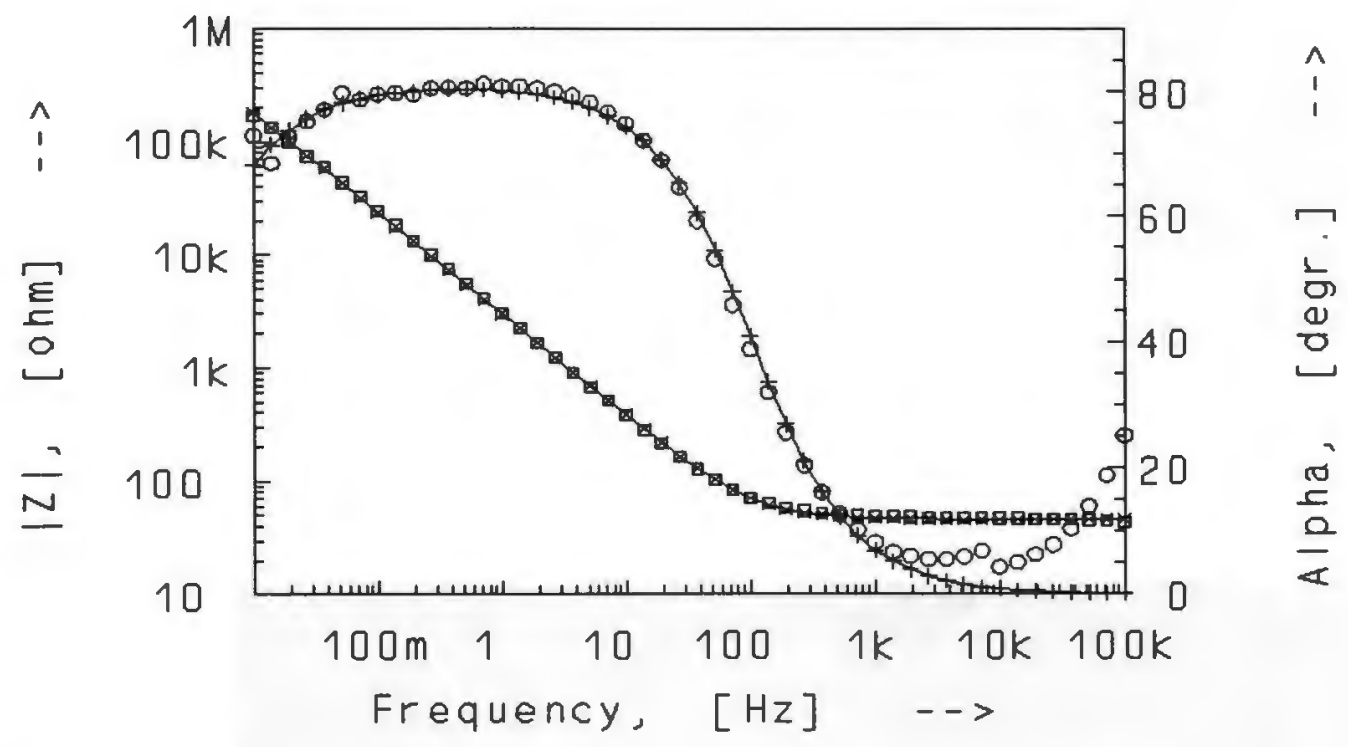

(a). Bode Plot for Day 1

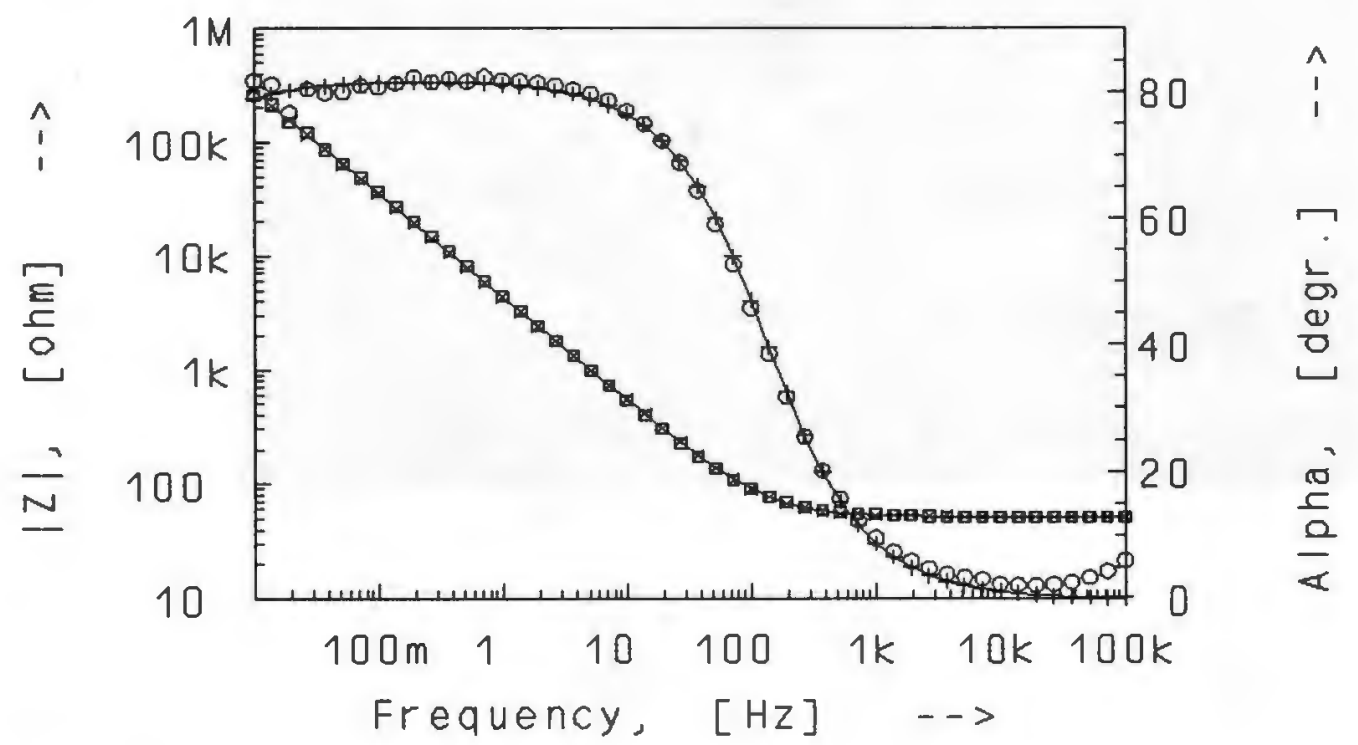

(b). Bode Plot for Day 60

Figure 12. Bode plot of 304 stainless steel coated with $\mathrm{ZrN}$ after 1 and 60 days. 


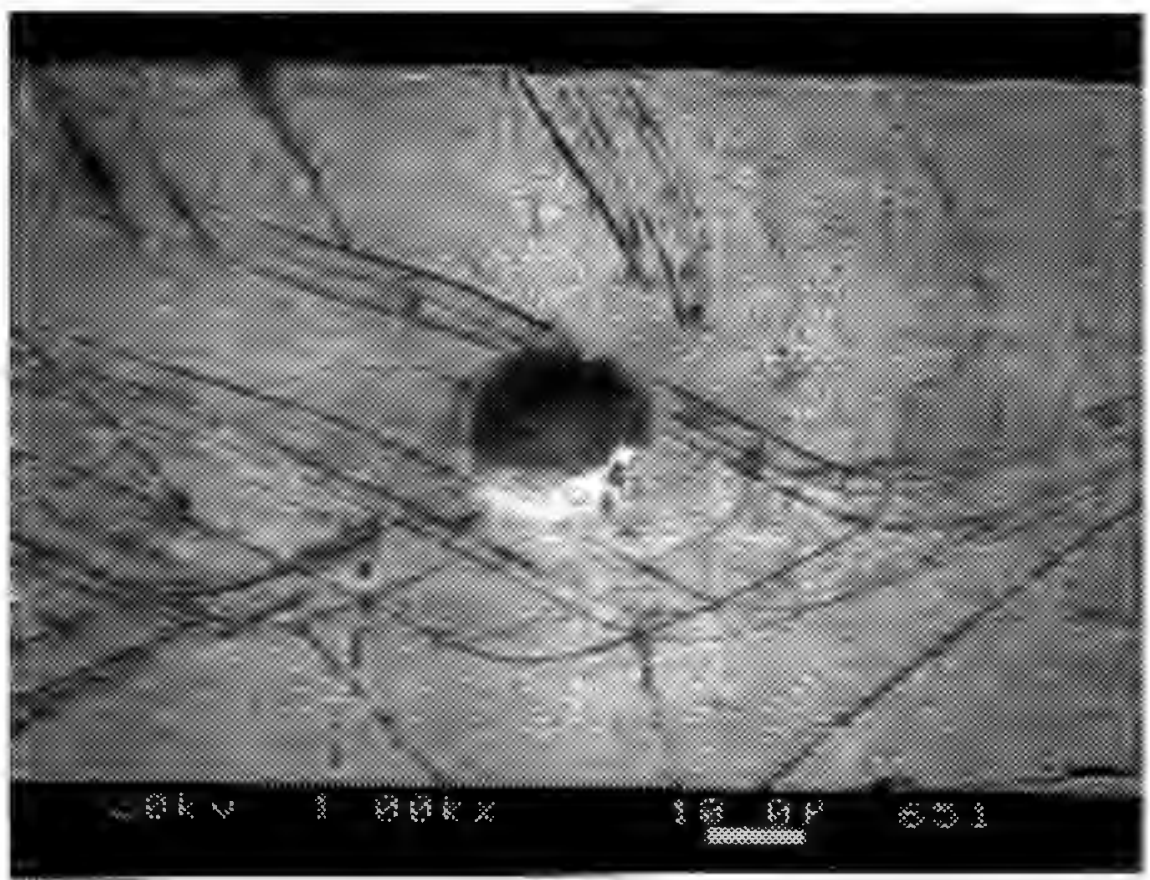

Figure 13. Micrograph of impedance samples showing hemispherical pit on surface initiated during exposure to $0.5 \mathrm{~N} \mathrm{NaCl}$. 


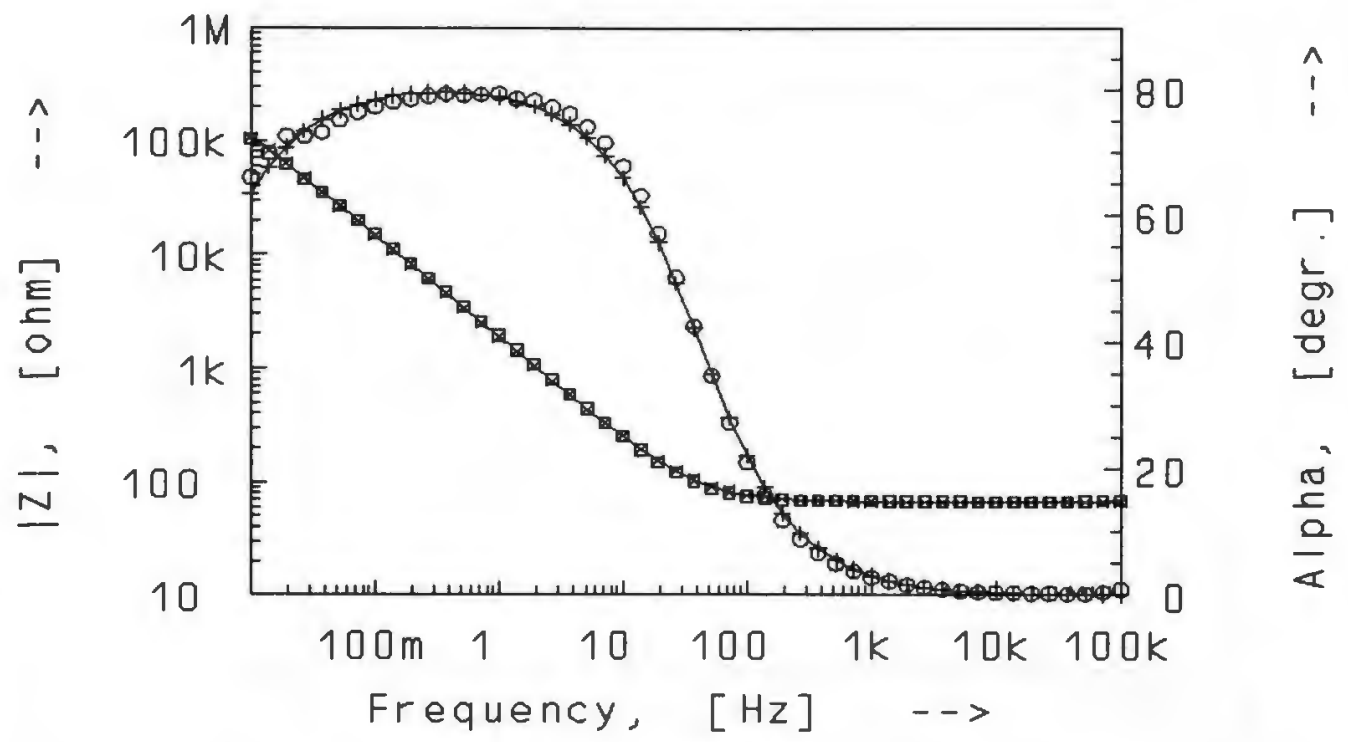

(a). Bode Plot for Day 1

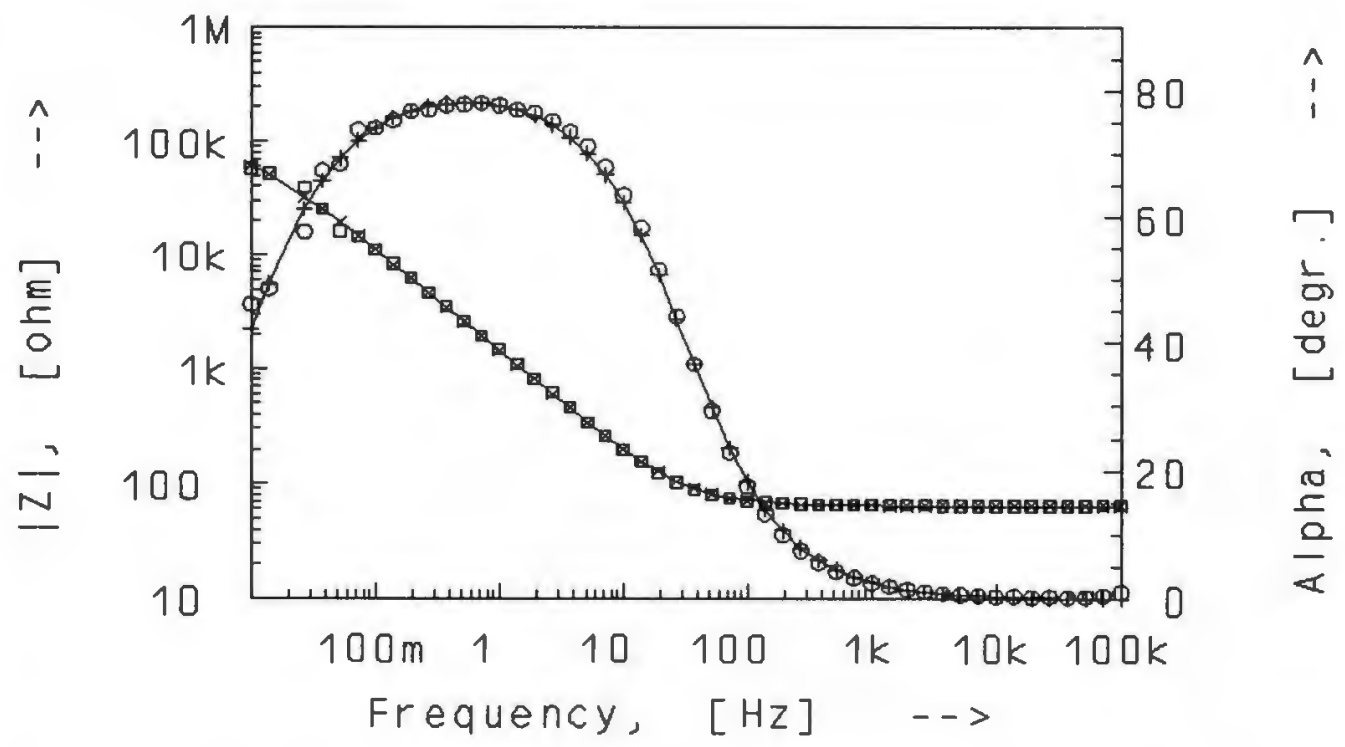

(b). Bode Plot for Day 3

Figure 14. Bode plot for Au implanted into TiN on 304 steel. 


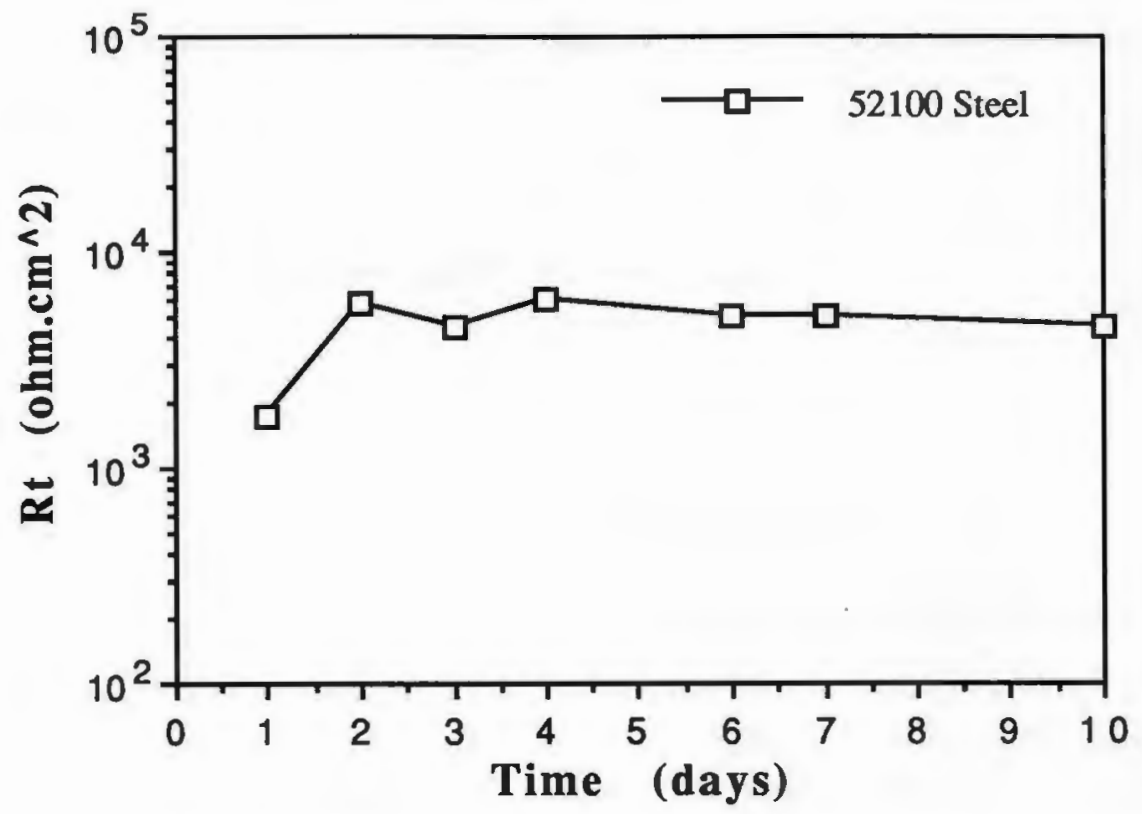

Figure 16. Charge transfer resistance for 52100 steel from modelling procedure. 


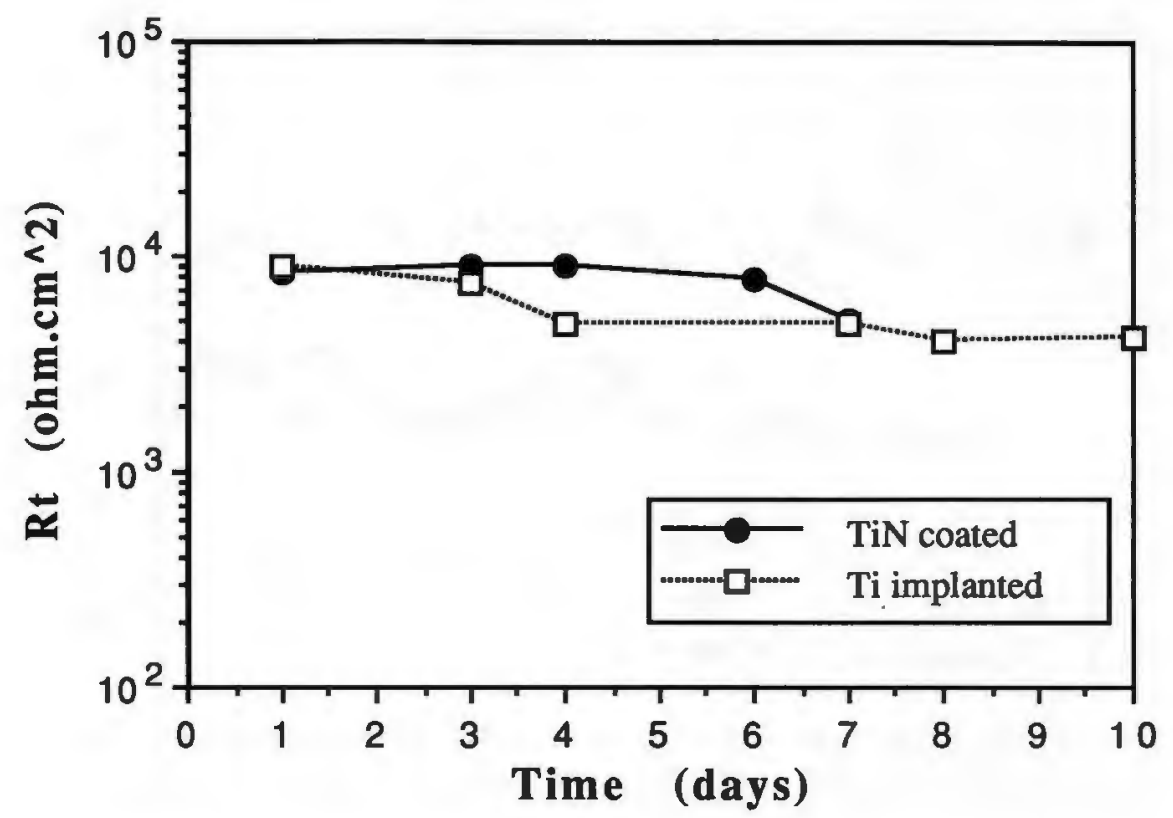

Figure 17. Charge transfer resistance for TiN coated and Ti implanted 52100 steel. 


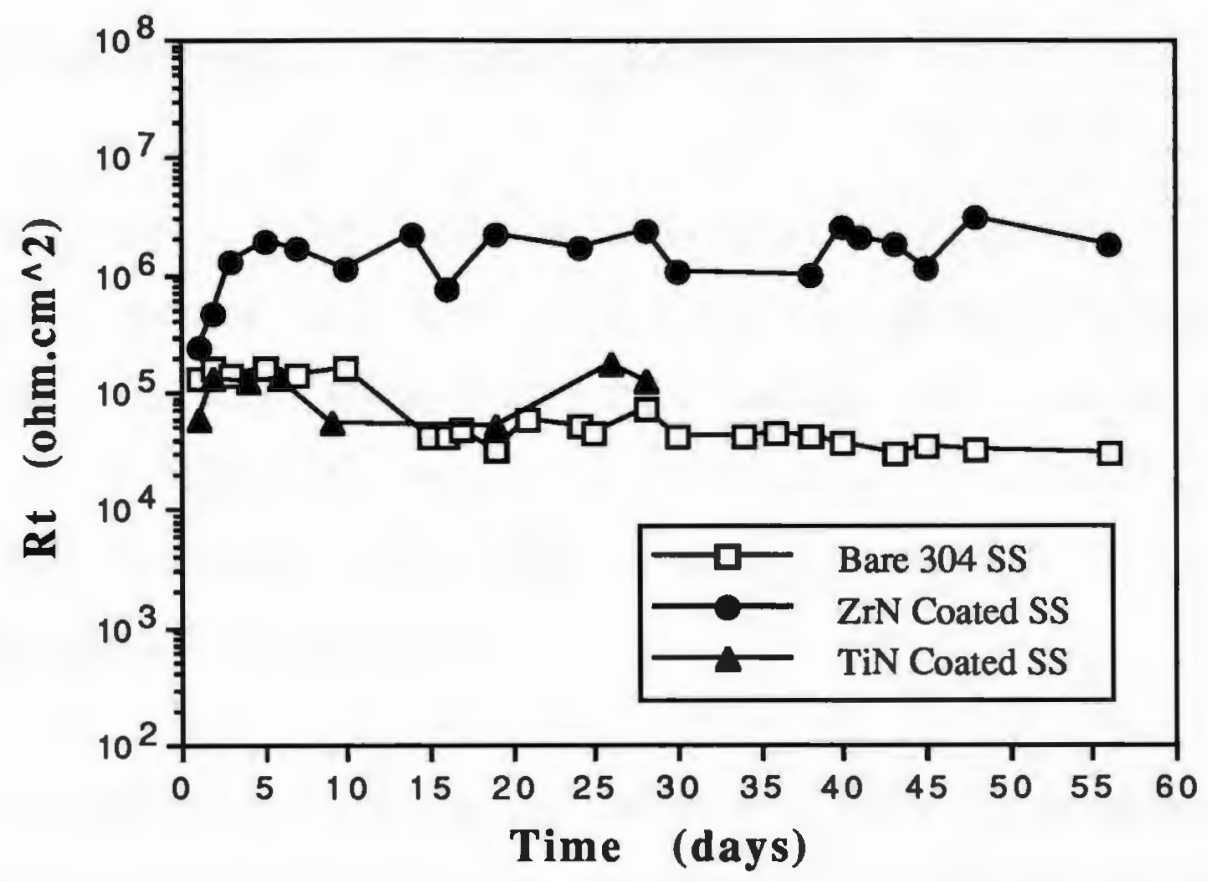

Figure 18. Charge transfer resistance of stainless steel, and those coated with TiN and $\mathrm{ZrN}$. 


\section{RECOMMENDATIONS FOR FUTURE STUDIES}

1. Multilayer Coating Study by Impedance Spectroscopy

It is important to investigate the effect of different coating thicknesses of a single layer $\mathrm{TiN}$ or $\mathrm{ZrN}$ coating, and compare with multilayers of $\mathrm{TiN} / \mathrm{Ti} / \mathrm{TiN}$ and $\mathrm{ZrN} / \mathrm{Zr} / \mathrm{ZrN}$ on their corrosion behavior when applied to steels. The effect of thickness can then be separated from the effect of multilayers.

2. Auger Electron Spectroscopy Study for Surface Conditions

This is to investigate the composition of the film before exposure to a corrosive chloride environment, and after exposure to characterize variation in the composition of these film. Possible mechanism on the corrosion of $\mathrm{TiN}$ and $\mathrm{ZrN}$ coated steels and formation of protecting surface films and their properties could be identified by this process. 


\section{BIBLIOGRAPHY}

Alias, M. N., and R. Brown, "Damage to a Vinyl Ester Based Composite from Electrochemical Processes", submitted to Corrosion, 1991

Bard, A. J., and L. R. Faulkner, Electrochemical Methods: Fundamentals and Applications, Wiley, New York, 1980

Bardwell, J. A., and M. C. H. McKubre, "AC Impedance Spectroscopy of the Anodic Film on Zirconium in Neutral Solution", Electrochimica Acta, v36 (1991), p.647

Bohe, A. E., J. R. Vilche, K. Juttner, W. J. Lorenz, W. Kautek, and W. Pattsch, "An Electrochemical Impedance Spectroscopy Study of Passive Zinc and Low Alloyed Zinc Electrodes in Alkaline and Neutral Aqueous Solutions", Corrosion Science, v32 (1991), p.621

Boukamp, B. A., "A Package for Impedance/Admittance Data Analysis", Solid State Ionics, v18 (1986), p.136

Boukamp, B. A., Equivalent Circuit (EQUIVCRT.PAS) Users Manual, 2nd ed., University of Twente, Netherlands, 1989

Bruggeman, W.H., "Blistering of Gel Coat Laminates", 33rd Annual Conference Reinforced Plastics Composites Institute, The Society of Plastics Industries, 1978. 
Chechirlian, S., P. Eincher, M. Keddam, H. Takenouti, and H. Mazille, "A Specific Aspect of Impedance Measurements in Low Conductivity Media. Artefacts and Their Interpretations", Electrochimica Acta, v35 (1990), p.1125

Chen, C-T., and B. S. Skerry, "Assessing the Corrosion Resistance of Painted Steel by AC Impedance and Electrochemical Noise Techniques", Corrosion, v47 (1991), p.598

Comprehensive Treatise of Electrochemistry, Volume 1: The Double Layer, J. O'M. Bockris, E. Conway, and E. Yeager, eds., Plenum Press, New York, 1980

Danroc, J., A. Aubert, and R. Gillet, "Hard Molybdenum Coating Prepared by Cathodic Magnetron Sputtering", Thin Solid Films, v153 (1987), p.281

Davis, R., J. S. Ghota, T. R. Mahli, and G. Pritchard, "Blister Formation in R.P. The Origin of the Osmotic Pressure", 38th Annual Conference Reinforced Plastics Composites Institute, The Society of Plastics Industries, 1983.

Dearnaley, G., "Thermal Oxidation", in Treatise on Materials Science and Technology, vol. 18, ed. J. K. Hirvonen, Academic Press, New York, 1980 
EG\&G Princeton Applied Research Technical Notes AC-1, "Basics of Electrochemical Impedance Spectroscopy (EIS)", 1989

EG\&G Princeton Applied Research Technical Notes AC-2, "Evaluation of Organic Coatings by Electrochemical Impedance Measurements", 1989

Epelboin, I., and M. Keddam, "Faradaic Impedances: Diffusion Impedance and Reaction Impedance", Journal of the Electrochemical Society, v117 (1970), p.1052

Ferreira, M. G. S., and J. L. Dawson, "Electrochemical Studies of the Passive Film on 316 Stainless Steel in Chloride Media", Journal of the Electrochemical Society, v132 (1985), p.760

Gabrielli, C., Identification of Electrochemical Proceses by Frequency Response Analysis, Solartron Instrumentation Group, 1980

Haruyama, S., M. Asari, and T. Tsuru, "Impedance Characteristics During Degradation of Coated Steel", in Corrosion Protection by Organic Coatings, ed. M.W. Kendig and H. Leidheiser, The Electrochemical Society, Proceedings vol 87-2

Hitzig, J., K. Juttner, W. J. Lorenz, and W. Paatsch, "ACImpedance Measurements on Corroded Porous Aluminum Oxide Films", Journal of the Electrochemical Society, v133 (1986), p.887 
Hladky, K., L. M. Calloway, and J. L. Dawson, "Corrosion Rates from Impedance Measurements: An Introduction", British Corrosion Journal, v15 (1980), p.20

Ives, M. B., Y. C. Lu, and J. L. Luo, "Cathodic Reactions Involved in Metallic Corrosion in Chlorinated Saline Environments", Corrosion Science, v32 (1991), p.91

Johansen, O. A., J. H. Dontje, and R. L. D. Zenner, "Reactive Arc Vapor Deposition of TiN, ZrN and HfN", Thin Solid Films, v153 (1987), p.75.

Johnson, P. C., and H. Randhawa, "Zirconium Nitride Films Prepared by Cathodic Arc Plasma Deposition Process", Surface and Coatings Technology, v33 (1987), p.53

Juttner, K., W. J. Lorenz, and W. Paatsch, "The Role of Surface Inhomogeneities in Corrosion Processes-Electrochemical Impedance Spectroscopy (EIS) on Different Aluminum Oxide Films", Corrosion Science, v29 (1989), p.279

Juttner, K., W. J. Lorenz, M. W. Kendig, and F. Mansfeld, "Electrochemical Impedance Spectroscopy on 3-D Inhomogeneous Surfaces", Journal of the Electrochemical Society, v135 (1988), p.332

Kaushik, D., M. N. Alias, and R. Brown, "An Impedance Study of a Carbon Fiber Vinyl Ester Composite", Corrosion, v47 (1991), p.859 
Kendig, M. W., E. M. Meyer, G. Linberg, and F. Mansfeld, "A Computer Analysis of Electrochemical Impedance Data", Corrosion Science, v23 (1983), p.

Kendig, M. W., F. Mansfeld, and S. Tsai, "Determination of the Long Term Corrosion Behavior of Coated Steel with A.C. Impedance Measurements", Corrosion Science, v23 (1983), p.317

Kleitz, M., and J. H. Kennedy, "Resolution of Multicomponent Impedance Diagrams" in Fast Ion Transport in Solids, P. Vashista, J. N. Mundy, and G. K. Shenoy eds., p185-188, Elsevier-North Holland, New York, 1979

Leidheiser, Jr., H., "Corrosion of Painted Metals - A Review", Corrosion, v38 (1982), p.374

Lenhart, S. J., D. D. Macdonald, and B. G. Pound, "An AC Impedance Study of the Degradation of Porous Nickel Battery Electrodes", Journal of the Electrochemical Society, v135 (1988), p. 1063

Ma, Chen-Chi, and J. Y. Tsai, "Corrosion Behavior of Sheet Molding Compound in Water (1) Crosslinked Unsaturated Polyester Resins", 43rd Annual Conference Reinforced Plastics Composites Institute, The Society of Plastics Industries, 1988. 
Macdonald, D. D., and M. C. McKubre, "Impedance Measurements in Electrochemical Systems" in Modern Aspects of Electrochemistry, J. O'M. Bockris, B. E. Conway, and R. E. White, Eds., v14, Plenum Press, New York, 1982

Macdonald, D. D., "Some Advantages and Pitfalls of Electrochemical Impedance Spectroscopy", Corrosion, v46 (1990), p. 229

Macdonald, J. R., and J. A. Garber, "Analysis of Impedance and Admittance for Solids and Liquids", Journal of the Electrochemical Society, v124 (1977), p.1022

Macdonald, J. R., CNLS Complex Non-Linear Least Squares Immittance Fitting Program (LEVM) Manual, 1990

Macdonald, J. R., Impedance Spectroscopy: Emphasizing Solid Materials and Systems, Wiley, New York, 1987

Mansfeld, F., M. W. Kendig, and S. Tsai, "Evaluation of Corrosion Behavior of Coated Metals with AC Impedance Measurements", Corrosion, v38 (1982), p.498

Massiani, Y., J. Crousier, L. Fedrizzi, A. Cavalleri, and P. L. Bonora, "Study of the Behavior in Acidic Solution of Titanium and TiN Coatings Obtained by Cathodic Sputtering", Surface Coatings and Technology, v33 (1987), p.309 
McIntyre, J. F., and H. Leidheiser,Jr., "Resistance Measurements on Thin Film Substrates as a Technique Studying the Deterioration of Coated Metals", Industrial and Engineering Chemical Property Research and Development, v24 (Sept 1985), p.348

Myers, S. M., "Implantation Metallurgy-Equilibrium Alloys ", in Treatise in Materials Science and Technology, vol 18, ed. J. K. Hirvonen, Academic Press, New York, 1980

Newman, J. S., Electrochemical Systems, Prentice Hall, New Jersey, 1973

Oltra, R., and M. Keddam, "Application of Impedance Technique to Localized Corrosion", Corrosion Science, v28 (1988), p.1

Potter, E. C., Electrochemistry: Principles and Applications, Macmillan, New York, 1961

Pourbaix, M. J. N., Atlas of Electrochemical Equilibria in Aqueous Solutions, Pergamon Press, New York, 1966

Rockett, T. J., and V. Rose, "The Causes of Boat Hull Blisters", Report for US Coast Guard, Project 1502, 1987

Sato, N., "A Theory for Breakdown of Anodic Oxide Films on Metals", Electrochimica Acta, v16 (1971), p.1683 
Scully, J. R., "Electrochemical Impedance of Organic-Coated Steel: Correlation of Impedance Parameters with Long-Term Coating Deterioration", Journal of the Electrochemical Society, v136 (1989), p. 979

Shih, H., and F. Mansfeld, "A Fitting Procedure for Impedance Spectra Obtained for Cases of Localized Corrosion", Corrosion, v45 (1989), p.610

Sloan, F. E., The Effects of Long Term Seawater Exposure on Graphite Epoxy Composite Materials, Ph. D. Thesis, University of California, San Diego, 1991

Stern, M., and A. L. Geary, "Electrochemical Polarization. I. Shape of Polarization Curves", Journal of the Electrochemical Society, v104 (1957), p.56

Streinz, C. C., "Electrochemical Impedance Spectroscopy of Surface-Modified Metals", Journal of the Electrochemical Society, v136 (1989), p.293C

Titz, J., G. H. Wagner, H. Spahn, M. Elbert, K. Juttner, and W. J. Lorenz, "Characterization of Organic Coatings on Metal Substrates by Electrochemical Impedance Spectroscopy", Corrosion, v46 (1990), p. 221 
Tucker, W. C., and R. Brown, " Blister Formation on Graphite/Polymer Composites Galvanically Coupled with Steel in Seawater ", Journal of Composites, v23 (1989), p.389

Tucker, W. C., Graphite Composites in the Marine Environment, $\mathrm{Ph}$. D. Thesis, University of Rhode Island, 1987.

Tucker, W. C., L. Russell, and R. Brown, " Corrosion Between a Graphite/Polymer Composite and Metals ", Journal of Composites, v24 (1990), p.92

Tyler, P. S., M. Levy, and L. Raymond, "Investigation of the Conditions for Crack Propagation and Arrest Under Cathodic Polarization by Rising Step Load Bend Testing", Corrosion, v47 (1991), p.82

Walter, G. W., "A Review of Impedance Plot Methods Used for Corrosion Performance Analysis of Painted Metals", Corrosion Science, v26 (1986), p.681

Walter, G. W., "Application of Impedance Measurements to Study Performance of Painted Metals in Aggressive Solutions", Journal of Electroanalytical Chemistry, v118 (1981), p.259

Walter, G. W., D. N. Nguyen, and M. A. D. Madurasinghe, "Impedance Analysis Method for Painted and Unpainted Metals", Electrochimica Acta, v37 (1992), p.245 
Walter, G. W., "The Application of Impedance Spectroscopy to Study the Uptake of Sodium Chloride Solution in Painted Metals", Corrosion Science, v32 (1991), p.1041 